\title{
INTERAÇÃO GENÓTIPOS X LOCAIS E CORRELAÇÕES ENTRE CARACTERES COM ÊNFASE NA PRODUTIVIDADE DE ÓLEO EM SOJA
}

\section{DIEGO OMAR SOLDINI}

Licenciado em Genética

Orientador: Prof.Dr. NATAL ANTONIO VELLO

Dissertação apresentada à Escola Superior de Agricultura "Luiz de Queiroz", da Universidade de São Paulo, para obtenção do título de Mestre em Agronomia. Área de concentração: Genét ica e Melhoramento de Plantas.

$\begin{array}{llllllllll}P & I & R & A & C & I & C & A & B & A\end{array}$

Estado de São Paulo - Brasil

MARÇO - 1993 
Ficha catalografica preparada pela Seçăo de Livros da Divisào de Biblioteca e Documentaçào - FCLQ/USF

\footnotetext{
Soldini. Diego Oma

Sos4i Interaço genotifos $\therefore$ locais e correiches entre caracteres com enfase ne produtivioade de bleo em

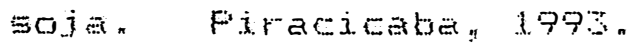

$136 \mathrm{p}$.

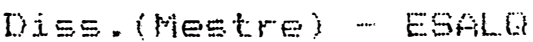

Ej.bli.jogratian

1. "Oleo de Soja -. Produtividade z. Goja - Correla Gó entre caracteres S. Soja - Interaca oenotipo-lo[a]. 4. Soja - Melhoramento I. Escola Superior de Agri cultura Luiz de Quedroz, Firacicabe
} 


\title{
INTERAÇĀO GENÓTIPOS X LOCAIS E CORRELAÇÕES ENTRE CARACTERES COM ÊNFASE NA PRODUTIVIDADE DE ÓLEO EM SOJA
}

\author{
DIEGO OMAR SOLDINI
}

Aprovada em: 09.03.93

Comissão Julgadora :

Prof. Dr. Natal Antonio Vello

ESALQ/USP

Prof. Dr. Isaias Olivio Geraldi

ESALQ/USP

Prof. Dr. Gil Miguel de Sousa Câmara

ESALQ/USP

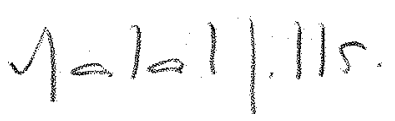

Prof.Dr. Natal Antonio Vello Orientador 
A Minha Família

A meus Amigos

Ofereço

A memória de meus Avós

Albino, Luis e Palmira 


\section{AGRADECIMENTOS}

A Coordenação de Aperfeiçoamento de Pessoal de Nível Superior (CAPES) e ao Conselho Nacional de Desenvolvimento Científico e Tecnológico (CNPq), pela bolsa de estudos.

A Escola Superior de Agricultura "Luiz de Queiroz" e especialmente ao Departamento e Instituto de Genética, pelas oportunidades e ensinamentos. Ao Professor Dr. Natal Antonio Vello, pela orientação e conselhos.

Ao Professor Dr. Roland Vencovsky, pelas sugestões.

Ao Prof. Dr. Geraldo Antonio Tosello pelas facilidades concedidas como Chefe do Departamento de Genética e pelo interesse e cooperação às pesquisas envolvendo o uso do NMR para análises do teor de óleo em sementes.

A Licenciada Maria Del Pilar Diaz pelas consultorias oferecidas sobre análises estatísticas. Ao colega do curso Milton Krieger pelas sugestões.

A secretária do Departamento de Genética, Carmen M.S.F. Pilot to.

As Bibliotecárias Silvana Marchizelli Gregório e Aparecida Elizabeth do Santos da Silva. 
Aplicada às Espécies Autógamas: Antonio Roberto Cogo, Claudinei Antonio Dodoné, José Roberto Alonso e Osmair José da Silva.

A EMBRAPA e à FINEP pelos apoios proporcionados às pesquisas, parte das quais incluem-se nesta dissertação.

A Caterpillar Brasil S.A. pelo comodato da área experimental correspondente ao local Sertãozinho.

A todos os que desinteressadamente colaboraram para que este trabalho seja uma realidade. 


\section{NDI CE}

Página

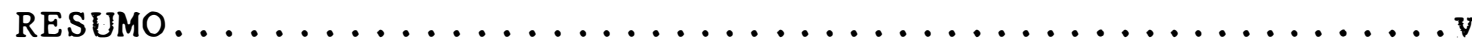

SUMMARY. vi i i

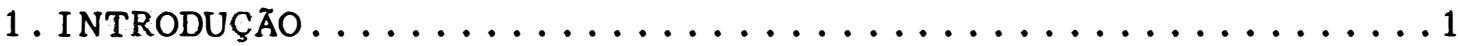

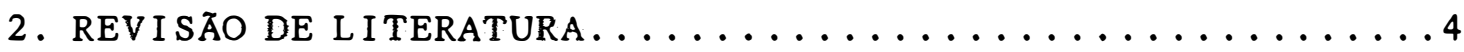

2.1. Aspectos da Interação Genótipos x Ambientes......4

2.2. Seleção de Ambientes para o Teste...............11

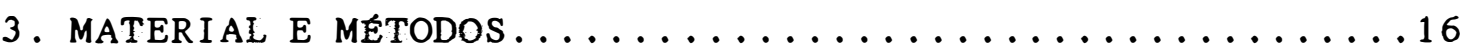

3.1. Análise da Variância e Estimativas de seus

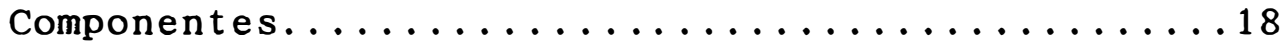

3.2. Estimativas de Parâmetros Genéticos e Fenotípicos. 24

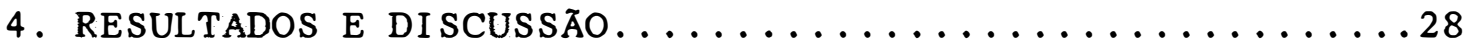

4.1 . Condições Gera is dos Experimentos . . . . . . . . 28

4.2. Análise da Variância com as Testemunhas..........30

4.3. Análises Individuais da Variância.............32

4.4. Análises Conjuntas da Variância..............36

4.5 . Valores Médios......................47

4.6. Componentes das Médias.................. 53

4.7 . Coeficientes de Correlação................54

4.8. Coeficientes de Determinação Genotípica........58

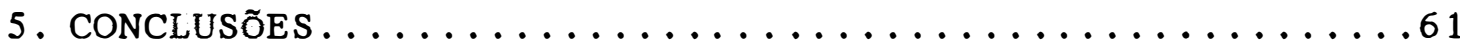

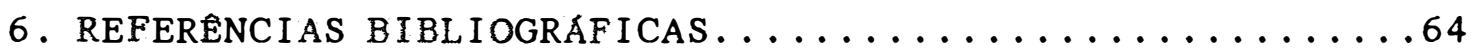

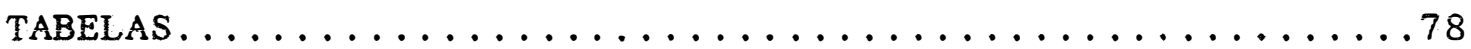




\title{
INTERAÇÃO GENÓTIPOS X LOCAIS E \\ CORRELAÇÕES ENTRE CARACTERES COM ÊNFASE NA PRODUTIVIDADE DE ÓLEO EM SOJA
}

\author{
Autor: Diego Omar Soldini \\ Orientador: Prof. Dr. Natal Antonio Vello
}

RESUMO

Foram avaliados 141 genotipos de soja (Glycine $\max (\mathrm{L}$.$) Merrill) incluindo cultivares e linhagens$ experimentais correspondentes aos grupos de maturidade (GM): precoce (GMP), intermediário (GMI) e tardio (GMT), da coleção de germoplasma do Setor de Genética Aplicada às Espécies Autógamas, pertencente ao Instituto de Genética da Escola Superior de Agricultura "Luiz de Queiroz", da Universidade de São Paulo, Brasil.

A avaliação dos genótipos foi feita em três locais: Anhembi $\left(L_{A}\right)$, ESALQ $\left(L_{E}\right)$ e Sertãozinho $\left(L_{S}\right)$, todos situados na região central do Estado de São Paulo. Em termos de fertilidade do solo, os três locais são classifica dos em $L_{A}$ : baixa fertilidade, representativo dos ambientes de cerrado; $L_{S}$ : fertilidade intermediária; $L_{B}$ : alta fertilidade. Foram conduzidos nove experimentos, sendo um experimen to para cada grupo de maturidade e cada local. Cada experimento foi delineado em blocos casualizados, com duas repe- 
tições. Cada bloco foi estratificado em conjuntos experimentais de 12 tratamentos (em média) e três testemunhas comuns. As análises individuais e conjuntas da variância mostraram a existência de significativa variabilidade genética para todos os caracteres estudados nos três GM e contribuições significativas dos efeitos de interações $G \times$ L na expressão fenotípica dos caracteres. Sendo o componente complexo das interações a principal causa destes efeitos, a seleção deve ser feita no próprio local onde os futuros cultivares serão recomendados.

O GMI mostrou estar melhor adaptado às condições da região; entretanto, o GMT foi o mais produtivo, em grãos e óleo devido à menor sobreposição das fases vegetativa e reprodutiva e do maior ciclo biologico.

Locais com condições agroecológicas extremas $\left(L_{A}\right.$ e $\left.L_{B}\right)$ evidenciam menores efeitos de interações $G \times$ L, entretanto, os efeitos de locais influenciaram a magnitude das correlações genéticas e fenotípicas. Correlações genéticas positivas entre os caracteres: produtividade de grãos (PG), porcentagem de oleo (\%OL) e produtividade de oleo (PO) favorecem novos avanços no melhoramento genético simultâneo destes caracteres. Alguns genótipos destacaram-se com valores superiores destes três caracteres em dois e três locais: Cobb, Planalto, FT-2, SOC 81-76, BR-1 (S.401) no GMP; UFV-4, SOC 81-216, SOC 81-266, Paranagoiana, FT-8 (Araucaria), BR-9 (Savana) no GMI; Cristalina-2 (S), IAC-9, UFV-2, UFV-Araguaia, EMGOPA 301 no GMT. 


\title{
GENOTYPE X LOCATION INTERACTION AND \\ CORRELATIONS AMONG CHARACTERS EMPHASIZING \\ OIL YIELD IN SOYBEANS
}

\author{
Author: Diego Omar Soldini \\ Adviser: Prof. Dr. Natal Antonio Vello
}

SUMMARY

A total of 141 soybean (Glycine $\max$ (L.) MERRILL) cultivars and experimental lines belonging to three maturity groups (GMP: early; GMI: intermediate; GMT: late) were evaluated in three locations: $\operatorname{ANHEMBI}\left(\mathrm{L}_{A}\right), \operatorname{ESALQ}\left(\mathrm{L}_{E}\right)$, SERTÃOZINHO $\left(\mathrm{L}_{\mathrm{s}}\right)$. All three locations are placed in the Central Region of São Paulo State, Brazil, at $22^{\circ} 42^{\prime}$, south latitude, $48^{\circ} 38^{\prime}$, west longitude, and $540 \mathrm{~m}$ altitude, in average. In terms of soil fertility, the locations are classified in: low $\left(L_{A}\right)$, intermediate $\left(L_{s}\right)$, and high level $\left(L_{E}\right)$.

This research was coordinated by Genetics Department, Faculty of Agriculture "Luiz de Queiroz" (ESALQ), University of São Paulo (USP). Nine experiments were carried, out that is, one experiment per maturity group and location each experiment was designed in randomized complete blocks with two replication. Each block was 
stratified in experimental sets of 12 treatments in average. Three common checks were included in each set.

Individual and joint analysis of variance showed significative genetic variability and genotype $x$ location interactions of all characters and maturity groups. Because the interactions were determined mainly by their complex component, selection must be done in the same location where the future cultivars will be recommended.

The GMI was the best adapted to the environmental conditions of the region represented by the three locations. However, the GMT showed the highest level of seed and oil yield; this fact is probably caused by the smaller overlapping of vegetative and reproductive stages of plant development, and the longest biologic cycle of the majority genotypes in GMT.

Location effects have influenced so much the magnitude of the genetic and phenotypic correlations between characters. The tendency of positive genetic correlations between seed yield, oil content, and oil yield, indicated the possibility to obtain new genetic progress by selecting for these characters, simultaneously. Actually, some genotypes exceeded by showing superior values for these three characters across the two and three locations: Cobb, Planalto, FT-2, SOC $81-76, \mathrm{BR}-1(\mathrm{~S} .401)$ in GMP; UFV-4, SOC 81-216, SOC 81-266, Paranagoiana, FT-8 (Araucaria), BR-9 (Savana) in GMI; Cristalina-2 (S), IAC-9, UFV-2, UFVAraguaia, EMGOPA 301 in GMT. 


\section{INTRODUÇÃO}

O interesse econômico da soja (Glycine max (L.) Merrill) como espécie cultivada, deve-se à qualidade nutricional de seus grãos, dada pelos conteúdos elevados de proteína e 6 leo, associada com a alta produtividade de grãos. Sendo estes caracteres quantitativos, as suas expressões fenotípicas resultam não só dos efeitos genotípicos, mas também dos efeitos ambientais e das interações genótipos $x$ ambientes.

Os efeitos genotípicos são inferidos das observações fenotípicas $e$ as interações genótipos $X$ ambientes contribuem às espressões fenotípicas reduzindo as correlações entre fenótipos e genótipos, complicando as inferências sobre os mecanismos de herança e sobre os procedimentos de melhoramento (COMSTOCK \& MOLL, 1963).

Em geral a produtividade de grãos em soja apresenta baixa herdabilidade, comparada com o conteúdo de oleo e proteína (SMITH \& WEBER, 1968).

De acordo com MINGXIANG (1990), o conteúdo de óleo e proteína nas sementes de soja não foi só condicionado por sua herança, mas também pelas condições ambientais onde cresceram os cultivares. As mesmas 
variedades cultivadas em vários anos e locais expressaram diferenças nos conteúdos de óleo e proteína. Conseqüentemente, o conhecimento da magnitude e natureza das interações genótipos $X$ ambiente torna-se valioso para avaliar com precisão as diferenças entre os genótipos (ALLARD \& BRADSHAW, 1964 ).

A soja é uma das mais importantes fontes de óleo e proteína vegetais comestíveis do mundo; no entanto, seus níveis de qualidade e quantidade têm permanecido inalteráveis há muito tempo (WILCOX, 1989). Conseqüentemente, torna-se hoje relevante o empenho no melhoramento genético, tanto da qualidade quanto da quantidade de óleo e proteína.

Correlaçôs negativas entre produtividade de grãos e porcentagem de proteína, entre porcentagem de proteína e porcentagem de óleo, têm impedido o aumento dos três caracteres simultaneamente. Correlações baixas e positivas têm evidenciado a possibilidade de se desenvolver novos genótipos com níveis elevados de produtividade de grão e porcentagem de oleo.

Atualmente, a soja no Brasil encontra-se cultivada numa considerável diversidade de ambientes, formando parte de uns dos principais produtos de exportação do Pais. Neste sentido, a seleção. de genótipos de alta produtividade e com capacidade de adaptação fisiológica ampla aos diferentes ambientes é uma das principais finalidades dos programas de melhoramento genético. 
O presente trabalho tem por objetivos:

- Estimar a contribuição das interações

genótipos $x$ locais na variação fenotípica;

- Determinar as causas principais das interaçoes

genótipos x locais;

- Estimar correlações genéticas e fenotípicas

entre caractéres. 


\section{REVISÃO DE LITERATURA}

\subsection{Aspectos da Interação Genótipos x Ambientes}

O conhecimento das influências genéticas e ambientais sobre as variações fenotípicas observadas, têm importância em manter uma alta e constante produtividade agrícola. No entanto, nos programas de melhoramento a falta de recursos torna difícil a avaliação de um grande número de linhagens experimentais através de ensaios multilocais para o teste dos efeitos das interações genótipos $x$ ambientes. Por esta razão, os melhoristas têm informações escassas sobre a variação atribuível às diferentes respostas dos genótipos quando cultivados em condições ambientais diferentes.

As mudanças no desempenho relativo dos genótipos através de ambientes diferentes têm sido referidas como interações genótipos $x$ ambientes (FEHR, 1987).

As interações genótipos $x$ ambientes podem surgir por duas razões; (a) por diferentes respostas de igual conjunto de genes em diferentes ambientes; (b) pela expressão de diferentes conjuntos de genes em diferentes ambientes (COCKERHAM, 1963). Quando um mesmo conjunto de 
genes se expressa em diferentes ambientes, as diferenças nas respostas podem ser explicadas pela heterogeneidade das variâncias genéticas, variâncias experimentais ou por ambas; e, quando diferentes conjuntos de genes se expressam, as diferenças nas respostas se explicam por uma inconsistência das correlações genéticas entre os valores de um mesmo caráter em dois ambientes diferentes (FALCONER, 1981).

Em relação ao impacto das interações genotipos $x$ ambientes no melhoramento genético (GREGORIUS \& NAMKOONG, 1986; BAKER, 1988a,b) consideram que as interações genotipos $x$ ambientes são importantes no processo de seleção, só quando provocam uma mudança no desempenho relativo dos genotipos de um ambiente para outro.

De acordo com BAKER (1988a) é importante diferenciar dois tipos de interações genotipos $x$ ambientes. A interação qualitativa que envolve mudanças no desempenho genotípico de um ambiente para outro reflete a falta de uma perfeita correlação entre os ambientes; já a interação quantitativa reflete a heterogeneidade das variancias genéticas entre locais.

$\mathrm{Na}$ presença de interação qualitativa o melhorista deve selecionar um genotipo para um conjunto de ambientes, e outro genotipo para outro conjunto de ambientes. Por esta razão, BAKER (1988b) sugere testes estatísticos apropriados para a presença de interação genotipos $x$ ambientes de tipo qualitativa.

De acordo com YANG \& BAKER (1991) as 
interações genótipos $x$ ambientes em trigo (Triticum aestivum) foram principalmente devidas às heterogeneidades das variâncias. Ao contrário das interações qualitativas, estas interações quantitativas terão um efeito mínimo sobre a seleção, no entanto, podem limitar as estimativas de ligação gênica e das variâncias de efeitos epistáticos.

De acordo com, ALLIPRANDINI (1992), as estimativas das interações genótipos $x$ ambientes para produtividade de grãos entre três grupos de maturidade de soja, for am altamente significativas, sendo as interações anos $x$ locais responsáveis por $78 \%$ a $100 \%$ da variância ambiente total; isto reforça a importância da realização de testes para recomendação de cultivares em diversos ambientes, no tempo e no espaço. Ainda o mesmo autor comenta a significância dos efeitos de locais dentro de anos, revelando a importância de se considerar os efeitos de locais quando testes de linhagens são feitos em um único ano agrícola.

TOLEDO et al.(1990), analizaram dados de produção de variedades de soja em três locais, no período 1981 a 1986 no Estado do Paraná, encontrando que os efeitos de locais foram os mais importantes entre os efeitos ambientais.

Os estudos sobre interação genótipos $x$ ambientes têm proporcionado informações para eliminar as tendências de superestimativas das variâncias genéticas, as quais levam a uma discrepancia entre respostas esperadas e 
obtidas com a seleção (ALLARD 1978).

A obtenção de genótipos superiores depende muito de estimativas precisas de produtividade, tornando necessário não só o aperfeiçoamento das técnicas experimentais, incluindo-se o número de locais e de repetições, mas também o uso de análises estatísticas mais adequadas para o desdobramento e interpretação das interações genótipos $x$ ambientes. A última opção oferece considerável eficiência em custos e precisão das estimativas de produtividade (GAUCH \& ZOBEL 1988, 1989).

o desdobramento e interpretação das interações genótipos $x$ ambientes é geralmente baseada na técnica de regressão linear (NTARE \& AKENOVA 1985; ARIYO 1987 ), ou na análise multivariada (KEMPTON 1984; GAUCH $1988)$.

A técnica de regressão linear tem experimentado deficiências tais como, confundir os efeitos principais e das interações (WRIGHT 1971), e respostas não lineares dos genótipos através dos diferentes ambientes; no entanto, os métodos que envolvem análise de regressão tem sido preferidos (DUARTE \& ZIMMERMANN, 1992).

ARIYO (1990) comparou diversas técnicas para determinar a relativa eficiência na identificação de genótipos estáveis, concluindo que os parâmetros de variância da estabilidade foram mais poderosos do que a técnica de regressão linear.

POWELl et al.(1986), sugeriram o uso de 
variancias fenotípicas para medir a estabilidade dos genótipos através dos ambientes.

De acordo com GAUCH (1988) e GAUCH \& ZOBEL (1988); as técnicas multivariadas tais como o estudo dos modelos aditivos de efeitos principais e interações multiplicativas têm-se mostrado as mais poderosas para estimar as interações genótipos $x$ ambientes, nas análises de multilocais.

O modelo aditivo de efeitos principais e interações multiplicativas foi mais eficiente no desdobramento da soma de quadrados das interações, do que a técnica de regressão linear, mostrando-se átil como ferramenta estatística para estimações precisas da produtividade, auxiliando o processo de seleção (NACHIT et a 1.,1992).

$\mathrm{Na}$ fase final de um programa de melhoramento, o potencial de um novo cultivar é avaliado através de um amplo espectro de locais e anos, para testar a sua adaptabilidade geral.

Correlações positivas entre as médias genotípicas e os valores de regressão (valores de b) das médias genotípicas sob as médias de locais para caracteres de qualidade em trigo (Triticum aestivun), sugerem que o melhoramento simultâneo das médias e da estabilidade pode ser uma tarefa difícil (PETERSON et al., 1992).

GRAVOIS et al. (1991), estimaram a frequência de ambientes nos quais um determinado genót ipo de 
arroz (oryza sativa) não diferia significativamente do genótipo de maior produtividade. Este parâmetrofornece uma estimativa da estabilidade do desempenho de um genótipo através dos ambientes; foi significativamente correlacionado com a média.

TORRES ( 1988 ), estudou o controle genético da estabilidade fenotípica no milho (Zea mays) verificando ausência de correlação significativa entre a estabilidade e a produtividade; sugeriu selecionar primeiro para produtividade e depois para estabilidade.

HELGADOTTIR \& KRISTJANSDOTTIR (1991), estudaram a interação genótipos $x$ ambientes utilizando 0 parâmentro $\left(P_{i}\right)$ que é uma medida de superioridade geral; definida como o quadrado médio das distâncias entre as respostas dos genótipos e as resposta máxima em cada local, ponderado pelo número de locais. Baseado neste parâmetro $\left(P_{i}\right)$ foi possível classificar os genotipos e selecionar os de maior produtividade e estabilidade.

LIN \& BINNS (1988b) demostraram que o parâmentro $\left(P_{i}\right)$ pode ser considerado como o quadrado médio conjunto dos efeitos genéticos e da interação genótipos $x$ ambientes. Valores pequenos de $\left(P_{i}\right)$ indicam que os efeitos genéticos são significativos; no entanto, os valores altos indicam uma adaptabilidade específica de um genótipo particular.

A ocorrência das interações genótipos $x$ ambientes pode ser detectada estatísticamente através da 
análise conjunta de experimentos repetidos em vários ambientes. A deteç̧ão de efeito de interação significativo, não esclarece as implicações que esta possa ter sobre o melhoramento, de forma que, estudos de detalhamento deste componente de variância são em geral necessários (VENCOVSKY \& GERALDI, 1977).

Os componentes da variância de interação genótipos $x$ ambientes podem ser separados em duas partes, um associado com a correlação genética de um mesmo caráter medido em dois ambientes; e outro associado com a heterogeneidade das variâncias em cada local (YAMADA, 1962). Métodos de análise das interações genótipos $x$ ambientes têm sido revisados por CROSSA (1990). O autor comenta a importância da homogeneidade das variâncias experimentais no teste da hipótese de nulidade. Se as variâncias dos resíduos experimentais são heterogêneas, a análise da variância apresenta limitações para obter estimativas confiáveis das interações.

No melhoramento de plantas, além da procura de genotipos de alta produtividade adaptados a amplas condições ambientais, também se deseja aprimorar tais genotipos para um conjunto de caracteres de importância agronômica.

De acordo com HIORTH (1985) existem três métodos principais de seleção que podem levar ao melhoramento integral dos genótipos. Na "seleção em tandem" depois de selecionar para o caráter principal, se seleciona 
para o caráter secundário e assim sucessivamente até o último caráter de interesse. Na "eliminação independente", se exige para cada caráter um valor mínimo; e na "seleção por indice", se atribue a cada caráter um certo valor; selecionando-se os individuos com maior valor da soma.

Quando existem correlações positivas entre caracteres desejáveis, basta selecionar para o caráter principal; os efeitos indiretos da seleção levarão automaticamente a um melhoramento conjunto dos caracteres secundários.

De acordo com GORSLINE (1960), quando existem correlações fortemente negativas entre dois caracteres desejáveis, é conveniente selecionar com base na linha de regressão. Selecionando os genótipos acima da linha de regressão, toma-se em consideração ambos os carateres. No entanto, o êxito da seleção pode depender da base genética específica da correlação (HIORTH, 1985).

De acordo com MARIOTTI (1986) uma das causas mais freqüentes de correlação genética entre carateres quantitativos é o pleiotropismo dos genes; além disso, há também a interação de efeitos genéticos e/ou ambientais que condicionam a expressão dos carateres envolvidos.

\subsection{Seleção de Ambientes para o Teste}


freqüentemente observada no melhoramento de plantas, trazendo principalmente, problemas na identificação dos genotipos superiores (HILL \& BAYLOR, 1983). Paraminimizar a interação torna-se necessário o aumento do número de locais, anos e repetições, com o conseguinte incremento dos custos (COMSTOK \& MOLL, 1963).

Uma alternativa para reduzir o custo do controle da interação genótipos $x$ ambientes é a divisão da área geográfica onde o cultivar será desenvolvido, em regiões homogêneas (POLLAK \& PHAM, 1989). Outra alternativa é a seleção de ambientes apropriados para os testes; os quais facilitaram a seleção dos genótipos superiores.

Vários critérios têm sido propostos na seleção de ambientes apropriados para o teste (ALLEN et al., 1978; HAMBLIN et al., 1980; BROWN et al., 1983). Todos os critérios têm como objetivo comum detectar o número mínimo de ambientes apropriados para a avaliação dos genótipos, permitindo, assim, a avaliação de um grande número de genotipos, particularmente durante as fases iniciais do desenvolvimento dos cultivares.

o critério mais usado é o alto valor do coeficiente de regressão simples, entre o comportamento dos genotipos no ambiente a ser testado e o comportamento médio através de todos os ambientes.

O relacionamento de causa-efeito, seleção de ambientes, critério de seleção e comportamento dos genotipos levou ao estabelecimento de modelos explicativos. 
JINKS \& CONNOLLY (1973 e 1975) estudaram o relacionamento entre a seleção de ambientes e a sensibilidade ambiental (estabilidade); concluíram que, a sensibilidade ambiental foi reduzida quando a seleção e os efeitos ambientais têm direções opostas; ela foi incrementada quando a seleção e os efeitos ambientais têm as mesmas direções.

Baseando-se neste modelo, FALCONER (1990) concluiu que a exclusão das espectativas do modelo só é possível quando grandes diferenças nas variâncias genéticas aditivas entre os locais (bom e ruim) foram ligadas por uma alta correlação genética.

o efeito da seleção de ambientes sobre a sensibilidade ambiental foi generalizado por JINKS \& POONI (1982), na base de que o controle genético da sensibilidade ambiental de um caráter selecionado e do desempenho médio, foram apenas parcialmente independentes.

Variedades de milho (Zea mays) com comportamento médio em vários ambientes, não foram necessariamente mais estáveis do que as variedades selecionadas para comportamento alto em ambientes específicos (CROSSA et al., 1989).

DHILLON et al. (1991) estudou oito ambientes envolvendo dois locais, para testes preliminares de produção de milho (Zea mays). Os resultados sobre a capacidade de predição do desenvolvimento dos genótipos através dos ambientes e da capacidade de discriminação dos 
genotipos superiores, parece ser uma função do ambiente. Os ambientes mais produtivos em relação à matéria seca e a produção de grãos, permitem uma melhor diferenciação dos genotipos junto com a predição de seu desempenho; no entanto, o autor concluiu que a interpretação destes resultados deve ser cuidadosa, dadas as complexas influências de muitos fatores climáticos e edáficos.

De acordo com SALVATORE \& STEFANIA (1991) os genotipos de cevada (Hordeum vulgare) selecionados para alta produtividade sobre condições ambientais desfavoráveis, foram menos sensíveis as mudanças ambientais, do que os genotipos selecionados para alta produtividade sob condições ambientais favoráveis. A alta estabilidade dos genótipos selecionados sob condições ambientais desfavoráveis, foi evidenciada pela análise de regressão linear e pela comparação dos coeficientes de variação. Os autores concluíram que o desenvolvimento de cultivares para áreas onde uma grande proporção da espécie é cultivada, terá que ser baseado na seleção sob condições ambientais desfavoráveis.

o efeito da seleção de ambientes sobre o desenvolvimento dos genotipos, nos programas de melhoramento, tem sido freqüentemente tema de controvérsia. TROYER \& ROSENBROOK (1983) expressaram que o incremento da densidade de plantas, reduz o número de testes necessários para diferenciar híbridos de milho (Zea mays). 
significância da interação genótipos $x$ densidades de plantas, indicando que a seleção poderia ser feita em qualquer densidade.

No método de seleção recorrente recíproca, MORENO-GONZALEZ (1986) comparou o uso de um ambiente diferente de avaliação para cada população, com o uso de um único ambiente de avaliação para as duas populações. o ganho genético no primeiro caso foi muito maior, sendo explicado pelas grandes diferenças nos efeitos de dominância quando diferentes conjuntos de genes se expressam em cada ambiente. BARLOW (1981) mostrou evidências de interação entre heterose e ambientes, concluindo que esta interação é comum particularmente em ambientes estressantes. 


\section{MATERIAL E METODOS}

No ano agrícola 1984/85 foram avaliados 141 genótipos de soja incluindo cultivares e linhagens experimentais correspondentes a três grupos de maturidade (GM): precoce (GMP), intermediário (GMI) e tardio (GMT); estes GM contém 68,51 e 22 genótipos respectivamente, da coleção de germoplasma do Setor de Genética Aplicada às Espécies Autógamas do Instituto de Genética da Escola Superior de Agricultura "Luiz de Queiroz", da Universidade de São Paulo. Todos os 141 genótipos estão identificados nas Tabelas $1,2,3$.

A avaliação dos genótipos foi feita em nove experimentos distribuídos em três locais: Anhembi ( $\left.L_{A}\right)$, caracterizado por solo arenoso de baixa fertilidade, semelhante aos solos encontrados nos cerrados; o uso de calcário neutralizou parcialmente a acidez do solo em anos anteriores; ESALQ $\left(L_{B}\right)$, com solo tipo Terra Roxa Estruturada série "Luiz de Queiroz" de alta fertilidade; Sertãozinho $\left(L_{s}\right)$ com solo tipo Latossol Vermelho-Amarelo, de fertilidade intermediária. Os três locais situam-se no Estado de são Paulo, município de Piracicaba.

o local LA está situado na Estação 
Experimental de Anhembi, pertencente ao Departamento de Genética/ESALQ/USP e distante cerca de $60 \mathrm{Km}$ de $\mathrm{L}_{\mathrm{E}}$. O local Ls situa-se em uma área da Caterpillar Brasil S.A., distante cerca de $5 \mathrm{Km}$ de $\mathrm{L}_{\mathrm{E}}$

Em cada local foram avaliados os três GM em delineamento de blocos ao acaso com tratamentos estratificados em conjuntos experimentais; três testemunhas comuns participaram de todos os conjuntos do mesmo GM. Em cada local foram utilizadas duas repetições (Tabela 4).

A parcela experimental foi representada por quatro fileiras de 5,0 metros de comprimento; o espaçamento entre fileiras foi de 0,6 metros. Para a avaliação dos caracteres: altura da planta no florescimento e na maturidade, e altura de inserção da primeira vagem, utilizaram-se oito plantas competitivas dentro da área útil da parcela, as quais foram identificadas antes do florescimento.

Os seguintes caracteres foram avaliados em cada experimento (Tabela 5 ):

- NDF: número de dias para florescimento; compreendeu o período vegetativo entre a data de semeadura e a data em que haviam flores abertas em $50 \%$ das plantas da parcela;

- APF: altura da planta no florescimento; compreendeu a distância na haste principal entre o colo e a inserção da inflorescência mais distal, expressa em cm;

- NDM: número de dias para maturidade; 
compreendeu o período entre a data de semeadura e a data em que $95 \%$ das vagens da parcela alcançaram a maturidade fisiologica;

- APM: altura da planta na maturidade; compreendeu a distância na haste principal entre o colo e a inserção da vagem mais distal, expressa em $\mathrm{cm}$;

- Ac: acamamento; avaliado através de uma escala de notas visuais, variando de 1 (todas as plantas eretas) a 5 (todas as plantas prostradas); os dados foram transformados em $\sqrt{x}+1$, antes da realização das análises estatístico-genét icas;

- AIV: altura de inserção da primeira vagem; compreendeu a distância na haste principal entre o colo e a inserção da primeira vagem, expressa em cm;

- VA: valor agronômico; avaliado através de uma escala de notas visuais, variando de 1 (plantas ruins) a 5 (plantas 6timas); os dados foram transformados em $\sqrt{x}+1$ antes da realização das análises estatísticasgenéticas;

- PG: produtividade de grãos; compreendeu o peso das sementes de todas as plantas localizadas na área útil de 4,8 metros quadrados de cada parcela, transformada em $\mathrm{kg} / \mathrm{ha}$;

- \%ol: porcentagem de 6́leo; avaliada a partir de uma amostra de 20 sementes (umidade interna de $6 \%$ ) no espectrômetro de ressonância nuclear magnética (NMR), no Laboratório de Física da UNICAMP (Convênio 
F INEP/UN I CAMP /USP / I AC ) ;

- PO: produtividade de óleo; obtida multiplicando-se a produtividade de grãos pela porcentagem de oleo, transformada em $\mathrm{kg} / \mathrm{ha}$

\subsection{Análises da Variância e Estimativas de seus Componentes}

Com a finalidade de verificar a existência de efeitos ambientais entre os conjuntos experimentais, inicialmente realizaram-se análises da variância conjuntas dos três locais, com as testemunhas comuns. Para cada grupo de maturidade utilizou-se o esquema de análise da variância da Tabela 6. A seguir procedeu-se às análises da variância dos genotipos. (cultivares e linhagens experimentais).

Ignorando-se o efeito de conjuntos experimentais, empregaram-se os esquemas de análise da variância das Tabelas 7 e 8 , respectivamente para análises individuais e conjuntas dos três locais.

As estimativas dos componentes da variância foram calculadas com base nas esperanças dos quadrados médios ( $Q M)$ desenvolvidas através da aplicação da regra de BENNETT \& FRANKLIN (1963); e as análises da variância foram realizadas com o auxilio do programa "SAS" (1983) para computadores.

Os modelos matemáticos usados para as análises da variância foram: 
- Para as testemunhas:

$$
\begin{aligned}
& Y_{1 f B p}=m+T_{1}+C_{s}+L_{p}+B / L_{f i p}+(T C)_{18}+(B C) / L_{f B: p}+ \\
& +(T B) / L_{1 f: p}+(T L)_{1 p}+(C L)_{s p}+(T C L)_{18 p}+(T B C) / L_{1 f B: p}
\end{aligned}
$$

- Para as análises individuais dos genót i pos :

$$
Y_{1 f}=m+G_{1}+B_{j}+e_{1 j}
$$

- Para as análises conjuntas nos três

locais:

$$
Y_{1 j p}=m+G_{1}+L_{p}+(G L)_{1 p}+B / L_{f, p}+\bar{e}_{1 f i p}
$$

onde:

$Y_{\text {ijsp: }}$ Observação da testemunha $i$, no bloco $j$, no conjunto s, no local p;

m: Média geral do caráter;

$\mathrm{T}_{\mathbf{i}}$ : Efeito fixo da testemunha $i ; i=1, \ldots, 3$;

$\mathrm{C}_{\mathbf{s}}$ : Efeito aleatório do conjunto experimental s; $s=$ $1, \ldots, 4$;

$L_{p}$ : Efeito fixo do local p; $p=1, \ldots, 3$;

B/L $L_{j:}$ : Efeito aleatório do bloco j dentro do local p; $\mathrm{j}=1,2$;

(TC) $)_{\text {is: }}$ Efeito aleatório da interação entre a testemunha i e o conjunto s;

(BC)/L je:p: Efeito aleatório da interação entre o bloco je o conjunto s, dentro do local p; 
(TB) $/ L_{\text {ij:p: }}$ Efeito aleatório da interação entre a testemunha $i$ e o bloco j, dentro do local p;

$(\text { TL })_{\text {ip }}$ : Efeito fixo da interação entre a testemunha i, e o local p;

$(C L)_{\mathbf{s p}}:$ Efeito aleatório da interação entre o conjunto s e o local p;

$(\text { TCL })_{\text {isp: }}$ Efeito aleatório da interação tripla entre a testemunha $i, o$ conjunto $s$ e o local p. (resíduo experimenta $1_{2}$ );

$(T B C) / L_{i j s: p}$ Efeito aleatório da interação tripla entre a testemunha i, o bloco j, e o conjunto s, dentro do local p (resíduo experimental médio 1 )

$\mathbf{Y}_{\mathbf{i j}}$ : Observação do genótipo i, no bloco j;

$\mathbf{G}_{\mathbf{i}}$ : Efeito fixo do genótipo $i=1,2, \ldots, 68$ (GMP); $\mathrm{i}=1,2, \ldots, 51(\mathrm{GMI}) ; \mathrm{i}=1,2, \ldots 22(\mathrm{GMT})$;

$\mathbf{B}_{\mathbf{j}}$ : Efeito aleatório do bloco $\mathrm{j} ; \mathrm{j}=1,2$;

$\bar{e}_{i j}$ : Efeito aleatório da interação entre o genótipo i e o bloco j. (resíduo experimental);

$Y_{i j p}$ : Observação do genótipo i, no bloco j, no local p;

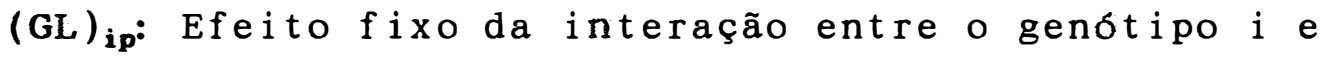
o local p;

$\bar{e}_{i j: p}:$ Efeito aleatório da interação entre o genótipo $i$ e o bloco j, dentro do local p (resíduo experimental ( médio ).

A variância das interações genótipos $x$ locais pode ser atribuida às seguintes fontes principais: a) variância dos efeitos principais; b) diferenças entre 
variância genética nos ambientes; c) correlação menor do que um (1) entre locais (COCKERHAM, 1963). De acordo com COCHRAN $\& \operatorname{cox}(1957)$, a heterogeneidade das variâncias experimentais também pode induzir interações. Em vista do conhecimento da importância destas causas de interações para os principais caracteres quantitativos, foram feitos os teste de heterogeneidade dos quadrados médios correspondentes aos efeitos genotípicos e ao resíduo experimental, e os cálculos das estimativas de correlação genética de um mesmo caráter medido em dois locais.

A decomposição dos efeitos de interação genótipos $x$ locais para os caracteres PG, \%OL e PO foi feita de acordo com COCKERHAM (1963), conforme segue:

$$
\sigma_{G B}^{2}=1 / 2\left(\sigma_{G_{1}}-\sigma_{G_{3}}\right)^{2}+\sigma_{G_{1}} \sigma_{G_{2}}\left(1-\Gamma_{G 1,2}\right)
$$

onde :

$\sigma_{Q B}^{2}$ : Variância da interação genótipos $x$ locais;

$\sigma_{G 1} ; \sigma_{G 2}:$ Desvio padrão genotípico nos locais 1 e 2 , respectivamente;

$\Gamma_{G 1,2:}$ Coeficiente de correlação genética de um mesmo caráter entre os locais 1 e 2 .

A heterogeneidade dos quadrados médios foi estimada de acordo com YANG \& BAKER (1991):

$$
\begin{aligned}
& H O_{(A E)}=\left(Q M_{G_{A}}-Q M_{Q_{A}}\right) /\left(Q M_{G_{z}}-O M_{Q_{g}}\right) \\
& H O_{(A S)}=\left(Q M_{G_{A}}-Q M_{Q_{A}}\right) /\left(O M_{G_{g}}-Q M_{Q_{g}}\right)
\end{aligned}
$$




$$
\begin{aligned}
& H O_{(B G)}=\left(Q M_{G_{I}}-Q M_{\theta_{g}}\right) /\left(Q M_{G_{g}}-Q M_{\theta_{g}}\right) \\
& H 1_{(A B)}=Q M_{\Theta_{2}} / Q M_{\theta_{3}} \\
& H 1_{(A S)}=O M_{\theta_{A}}-Q M_{\theta_{s}} \\
& H 1_{(B S)}=O M_{\theta_{B}} / O M_{\theta_{s}}
\end{aligned}
$$

onde:

- Ho e H1: Heterogeneidade dos quadrados médios genotípicos e do resíduo experimental, respectivamente, nos locais: Anhembi - ESALQ (AE); Anhembi - Sertãozinho (AS); ESALQ - Sertãozinho (ES);

- QM $\mathbf{G}$ Q QMe: Quadrados médios genotípicos e do resíduo experimental, respectivamente;

- a: Anhembi;

- e: ESALQ;

- s: Sertãozinho.

A significância da heterogeneidade dos quadrados médios genotípicos (HO) foi testada pelo teste "F" com graus de liberdade aproximados (SATTERTHWAITE, 1946); para os quadrados médios correspondentes ao resíduo experimental (H1), o teste "F" ("F" máximo) foi calculado utilizando-se como dividendo o quadrado médio do resíduo experimental maior de um local e como divisor o quadrado médio menor do outro local.

A significância das diferenças dos coeficientes de correlação genética $\left(\Gamma_{G 1,2}\right)$ foi testada contra os valores zero (0) e um (1) através do teste "t" com $n-2$ 
graus de liberdade (VENCOVSKY \& BARRIGA, 1992):

Para as comparações com o valor zero fez-

se :

$$
t=\frac{\Gamma_{G 1,2}}{\sqrt{V_{a x}\left(\Gamma_{G 1,2}\right)}}
$$

Para as comparações com o valor um ( adaptada), fez-se :

$$
t=\frac{1-\Gamma_{G 1,2}}{\sqrt{V_{a x}}\left(\Gamma_{G 1,2}\right)}
$$

onde:

$\Gamma_{\text {G1,2: }}$ Coeficiente de correlação genética de um mesmo caráter medido nos locais 1 e 2 ;

$V_{a r}\left(\Gamma_{G 1,2}\right)$ : Estimativa de variância do coeficiente de correlação genética de um mesmo caráter medido nos locais 1 e 2 .

3.2. Estimativas de Parâmetros Genéticos e Fenotípicos

$$
\text { As estimativas das médias para cada }
$$
caráter foram calculadas para os três grupos de maturidade (GM) individualmente em cada local e em conjunto nos três locais. Uma média para cada local foi estimada em base às médias de cada caráter nos três grupos de maturidade.

No cálculo do desvio padrão das médias dos GM utilizou-se das fórmulas: 


$$
\begin{gathered}
S_{\bar{x}}= \pm \sqrt{\frac{\sigma_{\theta}^{2}}{j}} \\
S_{\bar{x}}= \pm \sqrt{\frac{V_{1 p}}{P}+\frac{\sigma_{\theta}^{2}}{j p}}
\end{gathered}
$$

onde :

$$
\begin{aligned}
& \sigma_{e}^{2}: \text { Resíduo experimental; } \\
& v_{i p}: \text { Componente quadrático da interação genótipos } x
\end{aligned}
$$
loca is;

P: Número de locais;

j: Número de blocos

Com a finalidade de estimar os componentes das diferenças entre as médias de cada caráter avaliado nos três GM e locais (Tabela 37), foram calculados os efeitos de grupos de maturidade, efeitos médios de locais e de interação grupos de maturidade $x$ locais. Os cálculos dos efeitos que compõem as médias for am feitos segundo o esquema da Tabela 9 para todas as combinações de dois GM em dois locais; visando detectar locais com maior capacidade preditiva do desempenho genotipico, utilizando-se as fórmulas:

$$
\begin{gathered}
G_{i}=\frac{1}{2}\left(\bar{X}_{1 .}-\bar{X}_{2 .}\right) \\
L_{P}=\frac{1}{2}\left(\bar{X}_{.1}-\bar{X}_{.2}\right) \\
(G L)_{i p}=\frac{1}{4}\left[\left(\bar{X}_{1: 1}-\bar{X}_{1: 2}\right)-\left(\bar{X}_{2: 1}-\bar{X}_{2: 2}\right)\right]
\end{gathered}
$$


onde:

$G_{i}$ : Efeito de grupo de maturidade;

$L_{p}$ : Efeito médio de local;

$\left(\right.$ (GL $_{\text {ip: }}$ Efeito de interação grupos de maturidade $x$ locais;

$\overline{\mathrm{X}}_{1 .}$ : Média do grupo de maturidade 1 em dois locais;

$\bar{X}_{2 .}$ : Média do grupo de maturidade 2 em dois locais;

$\overline{\mathrm{X}}_{.1}$ : Média do local 1 com dois grupos de maturidade;

$\overline{\mathrm{X}}_{.2}$ : Média do local 2 com dois grupos de maturidade;

$\overline{\mathrm{X}}_{1: 1}$ : Média do grupo de maturidade 1 no local 1 ;

$\overline{\mathrm{X}}_{1: 2}$ : Média do grupo de maturidade 1 no local 2 ;

$\overline{\mathrm{X}}_{2: 1}$ : Média do grupo de maturidade 2 no local 1 ;

$\overline{\mathrm{X}}_{\text {2:2: }}$ Média do grupo de maturidade 2 no local 2 .

Foram estimados os coeficientes de

correlação genética e fenotípica entre todos os possíveis pares de caracteres, para os três GM nos três locais individualmente e em conjunto.

Os componentes necessários para o cálculo dos coeficientes de correlação foram estimados a partir das análises da variância (Tabelas 7 e 8 ). Os cálculos das covariâncias foram feitos segundo KEMPTHORNE (1966).

Para as estimativas dos coeficientes de correlação genética de um mesmo caráter medido em dois locais foi empregada a mesma metodologia, ou seja:

$$
\operatorname{Cov}_{(x, y)}=\frac{1}{2}\left[\sigma_{(x+y)}^{2}-\sigma_{(x)}^{2}-\sigma_{(y)}^{2}\right]
$$




$$
\Gamma_{(x, y)}=\frac{\operatorname{cov}_{(x, y)}}{\sqrt{\sigma_{x}^{2} \cdot \sigma_{y}^{2}}}
$$

onde :

$$
\begin{aligned}
& \operatorname{cov}_{(x, y)} \text { Covariância entre os caracteres } x \text { e } y ; \\
& \sigma_{(x+y) ;}^{2} \text { Variância da soma dos caracteres } x \text { e } y ; \\
& \sigma_{(x) ;}^{2} \sigma_{(y):}^{2} \text { Variância dos caracteres } x \text { e } y, \\
& \quad \text { respectivamente; } \\
& \Gamma_{(x, y): \text { Coeficiente de correlação entre os caracteres } x}
\end{aligned}
$$

e $\mathrm{y}$.

Também foram estimados os coeficientes de herdabilidade no sentido amplo (b) para todos os caracteres dos três GM, em cada local individualmente e em conjunto, utilizando-se das formulas:

$$
\begin{aligned}
& b=\frac{\hat{V}_{1}}{\hat{V}_{1}+\sigma^{2}} \\
& b=\frac{p \hat{V}_{1}^{\prime}}{p \hat{V}_{1}^{\prime}+\sigma^{2}}
\end{aligned}
$$

onde :

b: Coeficiente de herdabilidade no sentido amplo;

$V_{i}^{\prime} ; V_{i}^{\prime}:$ Componentes quadráticos da variação genética ao nível de locais individuais e conjuntos, respectivamente $\sigma_{e}^{2}$ : Resíduo experimental;

P: Número de locais 


\section{RESULTADOS E DISCUSSÃo}

\subsection{Condições Gerais dos Experimentos}

As condições experimentais dos três locais podem ser consideradas normais, conforme indicam as médias gerais (Tabela 37 e 38 ) e os coeficientes de variação experimental (Tabela 32 ).

Os experimentos foram conduzidos em três locais considerados como efeitos principais fixos, já que não representam uma amostra de todos os possíveis tipos de solos e condições climáticas da região ecológica que compreende o município de Piracicaba. No entanto, FEHR (1987) salienta que os locais de testes deveriam ser considerados como efeitos aleatórios, dado que não existe um controle sobre as condições climáticas dos locais.

ALLARD (1978) considera que as medições dos valores genotípicos devem ser feitas num certo número de locais dentro de uma área geográfica relativamente homogênica, obtendo-se assim, uma amostra de ambientes para os testes dos genótipos.

LIN \& BINNS (1988a) sugerem um método de análise das interações genótipos $x$ ambientes, baseado na 
separação das variações ambientais previsíveis (solo) e imprevisíveis (precipitações); desde que as variações previsiveis podem ser controladas por seleção de cultivares com adaptabilidade específica a uma região. As variações imprevisíveis não podem ser controladas, sendo necessários diferentes critérios de seleção.

FINLAY \& WILKINSON (1963), usaram os quadrados médios de anos dentro de locais (A/L) para avaliar a estabilidade dos cultivares (estabilidade tipo 4 ).

Os genotipos incluídos nos testes das interações $G \times L$ também foram considerados como efeitos principais fixos; desde que são linhagens experimentais e cultivares homozigóticas que não representam o "pool" gênico de uma população de referência em equilíbrio. No entanto, considerando-se o número relativamente grande de genótipos avaliados nos GMP e GMI de 68 e 51 genótipos, respectivamente, até seria aceitável o fato destes genótipos representarem uma amostra das populações de genótipos correspondentes a seus respectivos GM; em tal caso, seus efeitos seriam do tipo aleatório.

Embora, não tenha sido considerado neste trabalho um modelo matemático misto com efeitos genotípicos aleatorios, os resultados experimentais referentes aos efeitos genotípicos e de interação $G \times$ L obtidos a partir de um modelo fixo, poderiam ser tratados como parâmetros nos GMP e GMI.

De acordo com FEHR (1987), estimativas de 
interações genótipos $x$ ambientes obtidas com genótipos selecionados, podem ser altas ou baixas comparativamente com aquelas obtidas de uma amostra aleatoria de genótipos individuais.

\subsection{Análise da Variância com as Testemunhas}

Os resultados obtidos das análises da variância realizadas com as testemunhas comuns, são apresentados nas Tabelas 10 a 15 . Os efeitos de conjuntos foram não significativos, pelo teste $F$ a $5 \%$ de probabilidade, nos três GM para todos os caracteres. No entanto, no GMP foram detectados alguns efeitos significativos das interações simples: blocos $x$ conjuntos dentro de locais ( $B$ C )/L para o caráter AIV; conjuntos $x$ locais ( $\mathrm{C}$ L) para os caracteres NDF, VA e \%OL; e das interações triplas: testemunhas $x$ conjuntos $x$ locais $(T \times C$ $x$ L) para o caráter VA. Portanto, pode-se considerar que a estratificação dos tratamentos em conjuntos experimentais dentro dos blocos, mostrou a não existência de efeitos ambientais pronunciados entre os conjuntos.

Uma análise de variância mantendo a estratificação dos tratamentos em conjuntos experimentais para os caracteres que apresentaram interações significativas envolvendo efeitos de conjuntos teria a desvantagem de reduzir o número de graus de liberdade, tanto no resíduo quanto nos efeitos das interações genót ipos $x$ 
locais dentro de conjuntos (GL)/C, diminuindo, assim, a probabilidade de detectar significância das interações.

De acordo com FARIAS NETO (1987) há

eficiência em se manter a estratificação dos tratamentos em conjuntos experimentais quando, efeitos significativos das interações envolvendo conjuntos, estiverem presentes.

Por outro lado, as análises da variância ignorando os conjuntos experimentais provavelmente superestimam os efeitos das interações $G \times L$, devido a que estes efeitos podem estar incluindo os efeitos das interações conjuntos $x$ locais $(C \times L)$. No entanto, o modelo matemático ignorando os conjuntos experimentais mostrou-se altamente significativo.

Conforme pode ser observado nas Tabelas 10 a 15 , os coeficientes de variação experimental considerando como resíduo as interações triplas (testemunhas $x$ blocos $x$ conjuntos experimentais dentro de locais, $\mathrm{CV}_{1} \%$ ), situaram-se dentro dos 1 imites de $1,28 \%$ a $24,69 \%$, para os caracteres NDM e AIV, ambos pertencentes ao GMI. Entretanto, os CV\% baseados nas interações triplas (testemunhas $x$ conjuntos $x$ locais, $\left.C V_{2 \%}\right)$ situaram-se dentro dos limites de $0,62 \%$ a $25,49 \%$, para os caracteres NDM no GMI, e AIV no GMP, respectivamente.

Para os caracteres PG, \%OL e PO as testemunhas do GMI apresentaram os menores $\mathrm{CV}_{1} \%$, mostrando maior estabilidade frente aos efeitos de variação microambiental (dentro dos locais). As testemunhas do GMT 
apresentaram os menores $\mathrm{CV}_{2} \%$ experimentais para os caracteres PG e PO; isto mostra a maior estabilidade frente aos efeitos de variação macroambiental (entre locais).

Uma comparação das médias das testemunhas mostra que o GMT foi o mais produtivo em grãos e óleo com médias de $2694 \mathrm{Kg} / \mathrm{ha}$ e $589,70 \mathrm{Kg} / \mathrm{ha}$ para PG e PO, respectivamente; os GMP e GMI apresentaram os maiores valores de \%OL, com $22,83 \%$ e $22,81 \%$, respectivamente.

\subsection{Análises Individuais da Variância}

Nas Tabelas 16 a 25 são apresentados os quadrados médios correspondentes às análises individuais da variância dos GMP, GMI e GMT, nos locais Anhembi $\left(\mathrm{L}_{\mathbf{A}}\right)$, ESALQ $\left(L_{E}\right)$ e Sertãozinho $\left(L_{S}\right)$. Observam-se significâncias dos efeitos genotípicos para todos os caracteres a $1 \%$ de probabilidade pelo teste F; exceções ocorreram no $\mathrm{L}_{\mathrm{E}}$, onde os caracteres APF no GMT e PO no GMP apresentaram significância a 5\% de probabilidade e o caráter PG no GMP não apresentou efeitos significativos de genotipos. Os caracteres Ac no GMT e PG no GMI também foram significativos a $5 \%$ de probabilidade para os efeitos genotípicos nos $L_{A} e L_{S}$, respectivamente.

As significâncias dos efeitos genotípicos para todos os caracteres nos três GM, mostra a disponibilidade de suficiente variabilidade genética entre genótipos homozigóticos (cultivares e linhagens 
experimentais), os quais poderão ser selecionados: por suas superioridades em desempenho médio nos três locais de avaliação (Tabelas 42, 43 e 44); ou, por seus desempenhos superiores em relação à melhor testemunha em um ou mais locais; isto permitiria resgatar aqueles genótipos de maior estabilidade fenotípica (Tabelas 45,46 e 47 ).

$\mathrm{Na}$ medida em que a variabilidade genética seja devida não só a diferentes concentrações de genes dominantes favoráveis, correspondentes a um conjunto genético comum, mas, também seja devida às diferenças no número de loci favoráveis e nas freqüências alélicas dentro de um "pool" gênico não comum a todos os genótipos; maiores serão as perspectivas de se obter genótipos superiores a partir do uso destes materiais como parentais em diferentes delineamentos genéticos a serem empregados futuramente.

Diversos métodos têm sido propostos para identificar germoplasma com a lélos dominantes favoráveis, não presentes nos parentais superiores selecionados (DUDLEY, 1982; GERLOFF \& SMITH, 1988a,b; BERNARDO, 1990).

Com base em três métodos de seleção de características para análise de distância genética, HE (1991) agrupou linhagens de trigo e estabeleceu correlações entre a distância genética e a potência estandardizada, que é uma medida dos efeitos genéticos não aditivos na expressão dos caracteres. O autor sugere a seleção de parentais de grupos diferentes para se obter cruzamentos promissores. Tecnologias de eletroforese, técnicas 
imunoquímicas, cromatografia gasosa e raios infra-vermelhos, permitem uma rápida e simples avaliação química das sementes de soja, além de facilitar a seleção de genotipos com atributos desejáveis na composição de ácidos graxos, ausência de lipoxigenases específicas e inibidores de tripsina, conteúdo de óleo e proteína. De acordo com WilcoX (1989), estas novas tecnologias levaram a uma maior competitividade e expansão no uso dos produtos da soja na economia mundial.

Além da análise multivariada existem outros métodos para avaliação do potencial dos parentais, com base nos seus próprios desempenhos: coeficiente de parentesco (VELLO \& PIRES, 1992), marcadores bioquímicos (STUBER, 1992), marcadores moleculares (PATERSON, et al., $1991)$.

Metodologias baseadas na seleção precoce de cruzamentos superiores, também podem aumentar significativamente a eficiência dos programas de melhoramento, via avaliação da produtividade dos materiais mais promissores (TOLEDO, 1989). Assim como a caracterização dos processos fisiológicos da produtividade e das causas que a limitam (BRIM, 1973).

A não significância dos efeitos genotípicos no caráter $P G$ no GMP avaliado no $L_{E}$ pode ser explicada pelo forte efeito das interaçoses genótipos $x$ blocos (resíduo experimental), o qual mostrou-se superior e significativamente heterogêneo quando comparado com os 
resíduos experimentais do mesmo GM avaliado nos outros dois locais (Tabela 33). Este fato, junto com os efeitos genotípicos altamente significativos para o mesmo caráter nas análises individuais correspondentes aos $L_{A}$ e $L_{S}$ e na análise conjunta da variância, evidencia que uns dos principais problemas no progresso do melhoramento genético está na falta de controle de numerosos fatores que participam na diminuição da precisão das técnicas e delineamentos experimentais empregados para detectar a variabilidade genética disponível.

GAUCH \& ZOBEL $(1988,1989)$ sugerem não só o uso de análises estatísticas mais adequadas, mas também o aperfeiçoamento das técnicas experimentais na procura de estimativas precisas.

No Apêndice 1 encontram-se os valores e significâncias dos quadrados médios obtidos das análises da variância, após a eliminação de alguns genótipos com valores discordantes (entre repetições), para caracteres que inicialmente mostraram modelos matemáticos não significativos.

Os CV\% das análises individuais da variância se apresentam reunidos na (Tabela 32 ); observa-se que os CV\% variaram de $1,56 \%$ a $46,30 \%$ para os caracteres NDM no GMT e AIV no GMP ambos no $\mathrm{L}_{s}$, respectivamente. 


\title{
4.4. Análises Conjuntas da Variância
}

\begin{abstract}
Nas Tabelas 26 a 31 se apresentam os quadrados médios correspondentes às análises conjuntas da variância para os três GM. Observa-se que no GMP apenas o caráter APF mostrou efeito não significativo das interações G X L; os demais caracteres mostraramefeitos significativos a $1 \%$ de probabilidade pelo teste F; os caracteres AIV e PG apresentaram efeitos significativos a $5 \%$ de probabilidade. No GMI os efeitos das interações $G \times L$ foram significativos para os caracteres NDM, Ac, VA e OL\% a $1 \%$ de probabilidade; os caracteres NDF e APF mostraram interação $G \times$ L significativos a $5 \%$ de probabilidade; nos demais caracteres, a interação $G \times L$ não foi significativa. Finalmente, no GMT os caracteres AIV, PG e PO mostraram efeitos significativos das interações $G \quad x \quad L \quad$ a $5 \%$ de probabilidade, sendo não significativas para os restantes caracteres.
\end{abstract}

De acordo com BARIL (1992) a interação genótipos $x$ ambientes é essencialmente provocada por fatores que limitam a produtividade no estádio de enchimento dos grãos .

BONATO ( 1978 ) verificou estatisticamente a ocorrência da interação genotipos $x$ locais $x$ anos na produtividade de grãos; o que indicou diferenças específicas na reação de determinados genótipos de soja em determinados anos e locais. Para ANDERSON \& VASILAS (1985) as diferenças 
na reação dos genótipos de soja também variam com as épocas de semeadura.

De acordo com XIANGXUN et al. (1991) análises da variância de dados obtidos a partir de ensaios de quatro cultivares em cinco localidades durante dois anos indicaram efeitos altamentes significativos para cultivares, anos, localidades $e$ interações anos $x$ localidades, para porcentagem de óleo e proteína. Isto sugere que a realização de ensaios em vários anos não resolve o problema de obtenção de estimativas precisas sobre o desempenho genotípico para porcentagem de 6 leo e proteína nas sementes.

Uma comparação dos efeitos significativos das interações $G \times$ L entre os GM, mostra que os GMP, GMI e GMT apresentam nove, seis e três caracteres com efeitos significativos, respectivamente. Isto pode ser explicado, pelo menos em parte, pelo elevado número de graus de liberdade nos testes das significâncias dos efeitos de interações $G \times L$; principalmente no GMP.

Para caracteres avaliados nos três locais o número de graus de liberdade para numerador ( $G \times L$ ) e denominador (resíduo experimental médio) na análise conjunta da variância, foram respectivamente: $n_{1}=134, n_{2}=201$ no GMP; $\mathrm{n}_{1}=100, \mathrm{n}_{2}=150$ no GMI e $\mathrm{n}_{1}=42, \mathrm{n}_{2}=63$ no GMT.

Sendo o resíduo experimental médio $(\bar{e})$, uma média dos quadrados médios residuais de todos os locais, ponderados pelos respectivos graus de liberdade, o teste da hipótese de nulidade considera que as diferenças genotípicas 
são as mesmas para todos os locais. Se as variâncias residuais são heterogêneas, a análise da variância apresenta limitações para obter estimativas confiáveis de componentes genéticos e das interações $G \times$ L (CROSSA, 1990).

Para que experimentos em locais diferentes possam ser reunidos em uma análise conjunta da variância, é preciso que os quadrados médios residuais sejam relativamente homogêneos (GOMES, 1990). Embora a homogeneidade dos quadrados médios residuais, para alguns caracteres, esteja comprometida pela significância da heterogeneidade com o teste de "F máximo" (Tabelas 33, 34, 35 e 48), em geral estes caracteres não superaram o limite aceitável de sete para o quociente entre o maior e o menor quadrado médio residual (Tabela 31 de PEARSON \& HARTLEY, 1956 ) exceções significativas ocorreram para Ac no GMP e PO no GMT, mas esta heterogeneidade dos resíduos não afetou a significância dos efeitos genotípicos e das interações $\mathrm{G} \times \mathrm{L}$.

Embora seja difícil atribuir uma maior tolerância ou insensibilidade às condições ambientais críticas a um determinado GM, devido ao fato dos testes das significâncias dos efeitos de interações $G \times \quad L$ terem envolvidos diferentes graus de liberdade, observa-se que os caracteres AIV, PG e PO apresentaram efeitos significativos de interações $G \times \mathrm{L}$ no $\mathrm{GMT} \operatorname{com} \mathrm{n}_{1}=42$ e $\mathrm{n}_{2}=63$ graus de liberdade. Entretanto, os mesmos caracteres no GMI não mostraram efeitos significativos de interações $G \times L$ com 
$\mathrm{n}_{1}=100$ e $\mathrm{n}_{2}=150$ graus de $1 \mathrm{iberdade}$.

Is to sugere que para os caracteres PG e PO - GMI apresenta variação genética (variabilidade intragenotípica) entre ambientes, o que leva a uma capacidade de resposta (plasticidade fisiológica) maior que as variações ambientais associada com a qualidade agroecológica do local; ao mesmo tempo que apresenta um desempenho uniforme ou estável (estabilidade morfológica), em relação com as variações macroambientais e microambientais que escapam ao controle experimental.

Quanto maior a base genética do material testado, menor interação haverá com o ambiente (Sprague ${ }^{1}$, citado por SANTOS, et al.,1981). Segundo HIORTH (1985) a plasticidade fisiológica refere-se à variabilidade intragenotípica que leva a uma estabilidade morfológica e, conseqüentemente, à adaptação genotípica. O autor enfatiza a importância da seleção para plasticidade em relação com os problemas práticos do melhoramento. De acordo com MARIOTTI (1986) os componentes da interação $G \times$ L, resposta $e$ estabilidade, são suscetíveis de seleção independente e não há motivos para vincular estes componentes com outros da expressão fenotípica, como o desempenho médio.

VERNETTI et al. (1990), avaliaram a

${ }^{1}$ SPRAGUE, G.F. Repetitions Vs. Locations In: Annual Hybrid Industry Research Conference, 10, 1955. Proceeding. S.L., Americam Seed Trade Association, 1955. p. 10-3. 
estabilidade de 13 cultivares de soja em 35 ambientes no estado do Rio Grande do sul. Todos os cultivares responderam aproximadamente da mesma maneira aos estímulos positivos do ambiente, sendo o cultivar Hampton o de maior produtividade e estabilidade.

\section{As pesquisas de JINKS \& CONNOLLY (1975)} revelaram que a seleção com base nos melhores desempenhos em um local de alta qualidade leva também a selecionar os genótipos com um elevado valor de resposta. Entretanto, a seleção com base nos melhores desempenhos em um local de baixa qualidade, geralmente também leva à seleção de genótipos com baixa capacidade de resposta, ou seja genótipos estáveis.

Para detectar qualquer associação entre a capacidade genotípica para se adaptar às flutuações climáticas ao longo do ano agrícola dentro de uma dada região, e o comprimento do ciclo biológico da planta, sugere-se o teste de um mesmo número de genótipos em cada GM, o que permitiria avaliar os efeitos de interações com os mesmos graus de liberdade.

Outro aspecto de importância a ser considerado na avaliação da magnitude da interação $G \times$ entre GM refere-se à época de semeadura. Na época de semeadura considerada convencional adaptam-se melhor os genótipos precoces ou intermediários; a instalação de experimentos com genótipos de GM diferentes na mesma época, pode trazer dificuldades na avaliação da verdadeira resposta 
dos genótipos às condições ambientais. Sugere-se, assim, o uso de duas ou três épocas de semeadura.

De a cordo com FARIAS NETO (1987) as épocas de cultivo influenciaram a duração dos estádios de desenvolvimento dos cultivares, provocando reduções maiores no tempo para florescimento e menores no período reprodutivo dos cultivares no inverno.

SAKIYAMA et al. (1988), estudaram a eficiência da seleção de genótipos de soja, baseada em dados obtidos de 43 ensaios em 16 localidades do estado de Minas Gerais, comparada com a seleção realizada apenas em duas localidades, em três épocas de semeadura. Concluiram que a seleção de genótipos melhorados de soja pode ser feita com boa eficiência, em dois anos, três épocas de semeadura e duas localidades adequadamente escolhidas.

NOGUEIRA (1983) trabalhando com os cultivares UFV-1 e IAC-7, no estado de São Paulo, verificou que os cultivares não diferiam na produtividade de grãos na época de semeadura considerada convencional. Porém, o retardamento da semeadura fez diminuir a produtividade dos dois cultivares, nos dois anos de ensaio; por outro lado, a antecipação da semeadura alterou somente a produtividade do cultivar UFV-1. Os cultivares UFv-1 (GMT) e IAC-7 (GMI) também foram pesquisados nesta dissertação, alcançando médias de tempo para maturidade de 160 e 120 dias, respectivamente. O desempenho diferencial destes dois genótipos em épocas diferentes de semeadura (NOGUEIRA, 1983) 
poderia explicar a interação $G \times$ L no GMT em relação ao GMI, nos caracteres PG e PO.

Os efeitos de locais foram testados com o quadrado médio correspondente aos blocos dentro de locais $(B / L)$, com os mesmos graus de liberdade nos três grupos de maturidade; sendo $n_{1}=2, n_{2}=3$ e $n_{1}=1, n_{2}=2$ graus de liberdade para caracteres avaliados em três e dois locais, respectivamente. A significancia destes efeitos para a maioria dos caracteres, mostra as marcantes diferenças nas condições ambientais dos três locais de teste.

Segundo TOLEDO et al (1990) os efeitos de locais foram os mais importantes entre os efeitos ambientais na análise de dados de produção em soja, obtidos em três locais durante seis anos no estado do Paraná.

Os caracteres VA e PG mostraram efeitos significativos de locais nos três GM; já para os caracteres NDM, APM, \%OL e PO os efeitos significativos de locais corresponderam aos GMP e GMI. Para os caracteres NDF e Ac, a significância só ocorreu no GMT. Finalmente, para os caracteres APF e AIV os efeitos de locais foram significativos no GMP, e GMI, GMT, respectivamente.

Uma comparação dos efeitos significativos de locais entre os GM, mostra que os GMP e GMI apresentaram significância em sete caracteres e o GMT em cinco caracteres. O GMT foi o mais influenciado pelos efeitos de locais nos caracteres NDF e Ac. Para o caráter NDF, as diferenças de temperaturas diurnas ou noturnas, além de 
outros fatores ambientais, podem ter influenciado os genótipos tardios durante um período de tempo maior: 18,48 dias (33\%) e 13,36 dias $(25,50 \%)$ comparado com GMP e GMI, respectivamente.

BOARD \& HALL (1984) constataram que as temperaturas mais altas influenciaram o tempo para 0 florescimento mais eficazmente os cultivares dos GM VI e VII, comparado com os cultivares do GM V, sob indução de dias curtos.

Para o caráter Ac (Tabela 37), os efeitos significativos de locais no GMT se explicam por uma diferença de $18,28 \mathrm{~cm}$ entre as médias dos $\mathrm{L}_{\mathrm{A}}$ e $\mathrm{L}_{\mathrm{E}}$ no caráter APM; além disso, a APM foi $28,02 \mathrm{~cm}(44 \%)$ e $23,90 \mathrm{~cm}$ $(35,50 \%)$ superior ao mesmo caráter nos GMP e GMI, respectivamente.

Os CV\% obtidos das análises conjuntas da variância (Tabela 32), mostraram uma amplitude de variação de $1,16 \%$ a $36,91 \%$ para os caracteres NDM no GMI e AIV no GMP, respectivamente. Os valores baixos de CV\% para NDM podem ser explicados pela herança relativamente simples (número limitado de genes) e pelo controle eficiente dos fatores ambientais durante a avaliação do caráter. De maneira contrária, a herança relativamente complexa associada com o controle ineficiente dos fatores ambientais durante a avaliação do caráter, explicariam os valores altos de CV\% para AIV. De fato, a AIV foi avaliada no campo, antes da colheita; nestas condições, durante os tratos culturais 
(uso de cultivadores) a quantidade de terra acumulada na base das plantas pode variar de uma fileira para outra, tornando imprecisa a avaliação da AIV; uma possível solução seria o arranquio de uma amostra de plantas para avaliação da AIV; neste caso, a região do colo da planta seria facilmente identificada, aumentando a eficiência da avaliação da AIV.

De acordo com BILBRO \& RAY (1966) os parâmetros estimados através de análises conjuntas, embora úteis, não fornecem uma indicação adequada das respostas dos genótipos aos diferentes ambientes onde serão cultivados, sendo pois necessária uma análise complementar.

O coeficiente de correlação genética de um mesmo caráter medido em dois locais $\left(\Gamma_{\mathrm{Gl}, 2}\right)$ e a heterogeneidade das variações genéticas e variâncias experimentais resultantes da decomposição dos efeitos de interações $G \quad x$ L nos caracteres PG, \%OL e PO são apresentadas nas Tabelas 33 a 35 , juntamente com os quadrados médios das interações em dois e três locais.

Observa-se que nos caracteres PG e PO, as significâncias das interações $G \times$ L nas análises conjuntas da variância de três locais não são explicadas pelas significâncias das interações em todas as combinações de dois locais. Assim, a combinação de locais ESALQ Sertãozinho ( $\left.\mathrm{L}_{\mathrm{E}} \mathrm{L}_{\mathrm{S}}\right)$ no $\operatorname{GMP}($ Tabela 33$)$ e a combinação de locais Anhembi - ESALQ $\left(\mathrm{L}_{A} \mathrm{~L}_{\mathbf{B}}\right)$ no GMT, (Tabela 35) não contribuíram significativamente às interações $G \quad x \quad L$ nas 
análises conjuntas da variância de três locais. Entretanto, no GMI, (Tabela 34) a falta de significância das interações G $x$ L nas análises conjuntas da variância de três locais, foi acompanhada de efeitos significativos da interação na combinação de locais Anhembi - Sertãozinho $\left(L_{A} L_{S}\right)$, para os caracteres PG e PO. Isto também foi verificado no GMT (Tabela 35) para o caráter \%OL, na combinação de locais Anhembi - ESALQ $\left(L_{A} L_{B}\right)$.

Estes resultados sugerem que o local ESALQ $\left(L_{E}\right)$ teve um efeito neutralizador das interações $G \times$ L no GMI, para os caracteres PG e PO; já o local Sertãozinho ( $\mathrm{L}_{\mathrm{s}}$ ) mostrou efeito neutralizador no GMT para o caráter \%OL. Assim, locais onde a expressão fenotípica média dos genótipos está associada com valores extremos superiores ou inferiores (Tabela 37 e 38), provocariam uma redução nos efeitos das interações $G \times$ L.

A decomposição das interações $G \times$ L, conforme se pode observar nas Tabelas 33 a 35 mostra que o componente complexo devido à falta de correlação genética de um local para outro $\left[\sigma_{1} \sigma_{2}\left(1-\Gamma_{G 1,2}\right)\right]$, nos caracteres PG, \%OL e PO; explica essas interações com uma amplitude de variação de $34 \%$ a $99 \%$, mesmo com correlações não significativamente diferentes de um (1).

De acordo com VENCOVSKY \& BARRIGA (1992), a magnitude relativa dos componentes simples e complexo deve ser considerada com cautela, pois mesmo com correlações altas pode-se ter o componente complexo maior do que o 
simples.

Assim, estes resultados explicam que, apesar das correlações genéticas não significativamente diferentes de um (1), o componente complexo é o principal fator que contribui para as interações $G \times$ L; isto leva a identificação de poucos genótipos superiores em dois e três locais, principalmente para os caracteres PG e PO (Tabelas 45 e 47). Entretanto, para o caráter \%OL no GMP, oito genótipos $(11,76 \%)$ foram superiores às melhores testemunhas nos três locais (Tabela 46).

Isto sugere que o desdobramento dos efeitos da interação $G \times L$, deve ser acompanhado de estudos de repetibilidade dos genotipos através dos locais. Para confirmar o tipo de interação sugere-se também os testes de análise da variancia propostos por AZZALINI \& CoX (1984) e BAKER (1988b).

De acordo com SANTOS et al. (1981) a interação do tipo complexo em híbridos crípticos de milho confirma a impossibilidade de selecionar em um local e extrapolar para outras regioes.

A heterogeneidade das variações genéticas entre locais (Tabelas 33 a 35 ) mostra que a resposta fenotípica a cada mudança de ambiente não é a mesma para todos os genótipos. Portanto, as conseqüencias da diversidade genotípica dependem do ambiente 


\subsection{Valores Médios}

Na Tabela 37 se apresentam as médias dos caracteres para os três GM individualmente em cada local e em conjunto nos três locais. Observa-se que para o caráter PG a amplitude de variação das médias nos locais individuais foi de $1598 \mathrm{Kg} / \mathrm{ha}$ a $3025 \mathrm{Kg} / \mathrm{ha}$, no GMP $\mathrm{L}_{\mathrm{A}}$ e GMT $\mathrm{L}_{\mathrm{E}}$, respectivamente. As médias dos GM nos três locais em conjunto indicaram o GMT como o mais produtivo $(2549 \mathrm{Kg} / \mathrm{ha})$ e o GMP como o menos produtivo com $(2100 \mathrm{Kg} / \mathrm{ha})$.

A amplitude de variação mostrada pelas médias nos locais individuais, no caráter $\%$ ol foi de $20,28 \%$ a $24,22 \%$ no GMT $\mathrm{L}_{\mathrm{S}}$ e GMI $\mathrm{L}_{\mathrm{E}}$, respectivamente; o GMI apresentou a maior porcentagem de 61 eo $(22,99 \%)$.

Finalmente, o caráter Po apresentou amplitude de variação de 359 a $645 \mathrm{Kg} / \mathrm{ha}$, no GMP $\mathrm{L}_{\mathrm{A}}$ e GMT $\mathrm{L}_{\mathrm{E}}$, respectivamente; o GMT mostrou maior produtividade de óleo com (548 $\mathrm{Kg} / \mathrm{ha})$, enquanto que o GMP foi o menos produtivo $(473 \mathrm{Kg} / \mathrm{ha})$.

Destes resultados concluiu-se que o GMT foi o mais produtivo em termos de grãos e 6leo, e que o $L_{E}$ mostrou médias superiores para os caracteres PG, \%OL e PO, associado com menor média nos caracteres NDF e APF (Tabela 38). O segundo local de importância, em termos de qualidade agroecologica foi o $\mathrm{L}_{\mathrm{s}}$ para os caracteres PG, PO, Ac, AIV e VA; o pior ambiente foi o $L_{A}$ respecto aos três caracteres quantitativos principais (PG, \%OL, PO), associado com as 
menores médias para os caracteres NDM e APM. Na Tabela 38 se apresentam as médias de cada local calculadas com base na médias de cada caráter nos três GM.

Um aspecto interessante refere-se ao fato de que o GMP foi mais produtivo em grãos e óleo no $L_{s}$ e GMT expressou-se mais favoravelmente para o caráter \%OL no $L_{A}$ (Tabela 37); sendo que em média o melhor ambiente de expressão destes três caracteres quantitativos, foi o $L_{E}$, (Tabela 38). O primeiro caso, explica-se principalmente por uma maior expressão no $L_{s}$ do caráter APM, em relação aos outros locais; isto se confirma na Tabela 39 onde os coeficientes de correlações genéticas do caráter APM com os caracteres PG e PO são significativamente positivos. Entretanto, o segundo caso é explicado por uma diminuição na expressão do caráter NDM no $L_{A}$ em relação aos outros locais. Isto também se reafirma na Tabela 39 com uma correlação significativamente negativa entre os caracteres NDM e \%OL. Uma composição das médias de três locais, das testemunhas com as médias dos genótipos, nos respectivos GM, mostra a superioridade das testemunhas nos três caracteres quantitativos principais (PG, \%OL, PO); exceção ocorreu no GMI onde a média dos genótipos foi superior, para o caráter \%OL. Entretanto, baseando-se na média de seis observações (duas repetições em três locais), os dez melhores genótipos nos três GM foram superiores às médias das testemunhas para os três caracteres quantitativos principais; exceção ocorreu para o caráter \%OL no GMT, onde 
os sete melhores genótipos superaram as médias das testemunhas, (Tabelas 42,43 e 44 ).

Nas Tabelas 45,46 e 47 se apresentam os genótipos de cada GM que superam às médias das melhores testemunhas em dois e três locais, nos caracteres PG, \%OL e Po, respectivamente. Considerando estes genótipos como os mais estáveis, observa-se em geral uma tendência a serem os mais produtivos na média dos três locais (Tabelas 42,43 e 44). Apesar desta vinculação entre estabilidade e produtividade, existem genótipos estáveis cujos valores fenotípicos médios de três locais, são menos expressivos (não classificados entre os dez melhores genótipos). Conseqüentemente para uma maior eficiência na seleção para estabilidade sugere-se uma intensidade de seleção média, que permita resgatar os genótipos estáveis com níveis excelente e bom de produtividade.

De acordo com MARIOTTI (1986) é provável que os individuos mais estáveis possam ser descartados por uma seleção rigorosa em ambientes de alta qualidade, com tendência de seleção de tipos relativamente especializados que interagem favoravelmente com o ambiente, aumentando a expressão do caráter.

Com a finalidade de estabelecer uma comparação da expressão dos caracteres em termos de médias de três locais (Tabela 37), entre GM, foi organizado o apêndice 2 mostrando a variação em porcentagem das médias dos GMI e GMT em relação às médias do GMP consideradas como 
O\% (ponto de origem).

Observa-se no GMI que um incremento nos caracteres PG, $\%$ e PO de $11 \%, 2 \%$ e $13 \%$, respectivamente, foi acompanhado de um incremento de $9 \%$ no caráter NDF, e de uma diminuição do período reprodutivo $(P R=N D M-N D F)$ e do crescimento vegetativo $(\mathrm{CV}=\mathrm{APM}-\mathrm{APF})$ durante o PR de $2,94 \%$ e $-15,30 \%$, respectivamente. Entretanto, ocorreram incrementos nos caracteres PG e PO de $21 \%$ e $16 \%$, respectivamente no GMT, acompanhados de incrementos no caráter NDF e no $P R$ de $33 \%$ e $5,5 \%$, respectivamente, e de uma diminuição do CV durante o PR de $-71,81 \%$.

Isto demonstra a importância do incremento no caráter NDF e a diminuição do CV durante o PR, para a expressão da produtividade de grãos e óleo. Esta expressão é favorecida quando a diminuição do CV durante o PR é acompanhada de um incremento do PR em comparação ao GMP. Estes resultados sugerem que, quanto menor for a sobreposição dos desenvolvimentos das fases vegetativa e reprodutiva do ciclo biológico da planta, melhor será a distribuição da energia, canalizando-se na fase reprodutiva exclusivamente para o desenvolvimento de flores e grãos.

De acordo com Shibles \& Green ${ }^{2}$, citados por LIN \& NELSON (1988), haste de crescimento determinado minimiza a sobreposição das fases vegetativa e reprodutiva;

2 SHIBLES, R.M. \& GREEN, D.E. Morphological and physiological considerations in greeding for narrow. In: Soybean breeding conference, ames, 1969. Proceedings, Edited by W.R. FEHR. Ames, Iowa State University, 1969. p. 1-12. 
isto permite que uma grande proporção da fotossíntese após a anteses possa teóricamente estar disponível para os órgãos reprodutivos e, conseqüentemente, incrementar a produtividade de grãos.

Este incremento da produtividade associado a uma diminuição do CV durante o PR, torna os genótipos fortemente suscetíveis a prolongados pefíodos de escassez hídrica no solo (veranicos), característicos de determinadas zonas, já que o período de florescimento fica reduzido comparativamente ao florescimento seqüencial dos genótipos de crescimento indeterminado. Assim, períodos de seca associados com um único período de florescimento pode facilmente levar ao fracasso da safra agrícola.

Com referência aos valores médios da Tabela 37 , observa-se também que a porcentagem do período reprodutivo (\%PR) em relação ao ciclo biológico completo da planta, medido em número de dias para maturidade (NDM) foi de $52,20 \%, 49,30 \%$ e $46,50 \%$ para GMP, GMI e GMT, respectivamente. As consistentes estimativas de herdabilidade obtidas para todos os estádios reprodutivos estudados em dois cruzamentos de soja por DESTRO, et al (1987) sugerem a possibilidade de encurtamento do PR nos genotipos precoces e, conseqüentemente, o aumento do NDF, permitindo maior desenvolvimento vegetativo e alta produtividade. 
De acordo com Bays ${ }^{3}$ citado por DESTRO et al (1987), alta estimativa de herdabilidade foi verificada para a porcentagem do período reprodutivo (\%PR). Entretanto, o número de dias dos estádios $R_{2}$ a $R_{8}$ apresentam altos efeitos indiretos sobre a produtividade de grãos, através da altura da planta (ALA AL-DIN et a1., 1989).

De acordo com JOHNSON et al (1955) é possível o encurtamento do período reprodutivo através do aumento do NDF já que ambos caracteres estão correlacionados negativamente.

Finalmente, com base nas médias dos genótipos no caráter NDM e na sua amplitude de variação (111 a 126,114 a 135 e 130 a 160 dias, no GMP, GMI e GMT, respectivamente); observa-se uma sobreposição do GMI principalmente com O GMP; observa-se, também semelhança das médias gerais destes dois grupos de maturidade, com 119 dias e 122 dias, respectivamente (Tabela 37 ). Isto sugere uma reclassificação dos genótipos, formando um novo GMI a partir dos valores máximos do GMP até os valores mínimos do GMT:
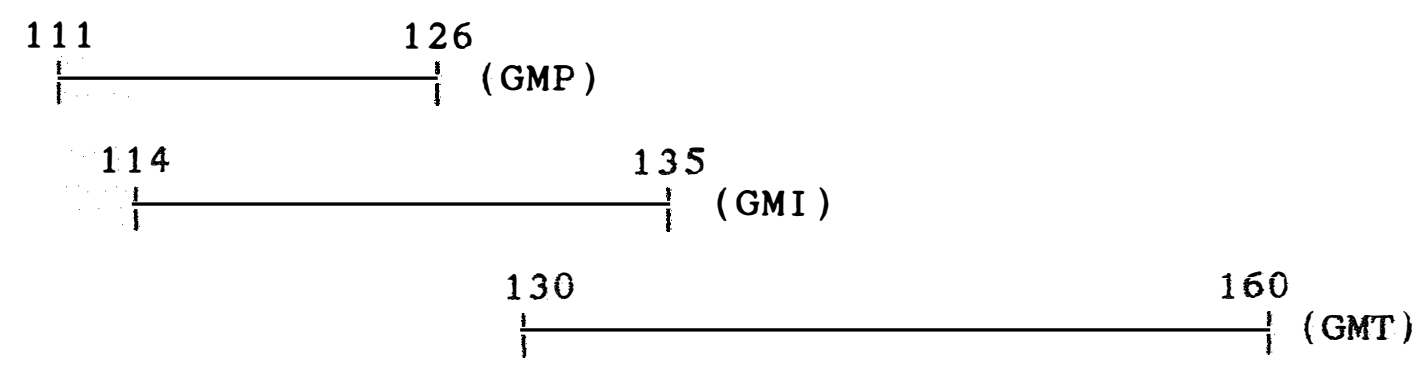

\footnotetext{
3 BAYS, I.A. Heritability and association of several quantitative characters in segregating populations of soybeans (Glycine $\max$ (L.) Merrill). Mississippi 1975. 92 p. (PHD - MIssissippi State University).
} 


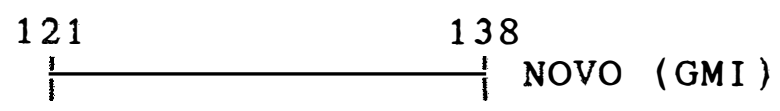

\subsection{Componentes das Médias}

A tabela 36 relaciona os efeitos de grupos de maturidade, locais e da interação grupos de maturidade $x$ locais para todas as combinações de dois GM em dois locais. Observa-se que para o carater PG, a amplitude de variação dos efeitos de grupos de maturidade que compõem as diferenças entre as médias, foi de $60,68 \mathrm{Kg} / \mathrm{ha}$ a 357,78 $\mathrm{Kg} /$ ha entre os GMI e GMT nos $\mathrm{L}_{\mathrm{B}} \mathrm{L}_{\mathrm{S}}$ e entre os GMP e GMT nos $\mathrm{L}_{\mathrm{A}} \mathrm{L}_{\mathrm{B}}$, respectivamente.

Para o caráter \%ol, estes efeitos de grupos de maturidade tiveram uma amplitude de variação de $0,13 \%$ a $1,13 \%$ entre os GMP e GMI em $\mathrm{L}_{\mathrm{A}} \mathrm{L}_{\mathrm{s}}$ e entre os GMI e GMT em $\mathrm{L}_{\mathrm{E}} \mathrm{L}_{\mathrm{s}}$, respectivamente. Finalmente, para o caráter PO, a amplitude de variação dos efeitos de grupos de maturidade foi de 6,16 a $65,18 \mathrm{Kg} / \mathrm{ha}$, entre os GMI e GMT nos $\mathrm{L}_{\mathrm{A}} \mathrm{L}_{\mathrm{S}} \mathrm{e}$ entre os GMP e GMT nos $\mathrm{L}_{A} \mathrm{~L}_{E}$, respectivamente.

Os resultados mostram que a combinação de locais Anhembi - ESALQ $\left(L_{A} L_{E}\right)$ permite uma maior expressão dos efeitos de grupos de maturidade, para os caracteres PG e PO; ao mesmo tempo, ocorrem reduções nos efeitos das interações grupos de maturidade $x$ locais, principalmente entre os GMP e GMT, e entre os GMI e GMT. Este fato pode ser explicado por serem ambos locais contrastantes, sendo o $\left(L_{A}\right)$ 
o pior e o $\left(\mathrm{L}_{E}\right)$ o melhor, tanto para a expressão do caráter PG quanto para o caráter PO (Tabela 38). Sendo válida a mesma explicação para o caráter \%ol, cuja máxima expressão para os efeitos de grupos de maturidade evidencia-se na combinação de locais ESALQ - Sertãozinho $\left(L_{E} L_{S}\right)$.

Isto sugere que o emprego simultâneo dos locais Anhembi - ESALQ $\left(L_{A} L_{E}\right)$, pode ser útil para a seleção dos caracteres PG e PO; já que suas expressões fenotípicas com maior capacidade preditiva do desempenho genotípico, oferecem vantagens do ponto de vista do melhoramento.

MARIOTTI (1980) relata uma localidade na província de Tucumán (Argentina) que resulta em alto grau preditivo do desempenho genotípico geral, além de induzir com freqüência uma maior diferenciação dos valores genotípicos individuais; sendo por tal motivo um local apto para selecionar tipos de ampla adaptabilidade agroecológica. De acordo com CHAVES et al. (1989) ambientes favoráveis em que a média do caráter é maior, propiciam melhor discriminação entre os genótipos

\subsection{Coeficientes de Correlação}

Na Tabela 39 se apresentam os coeficientes de correlações genéticas ao nível de locais individuais e conjuntos entre todos os possíveis pares formados com dez caracteres, correspondentes aos três GM. Observa-se as grandes variações na magnitude dos coeficientes de 
correlações genética entre locais, dentro de GM, para a maioria dos pares de caracteres. Isto mostra a influência dos locais sobre a magnitude da expressão genotípica afetando as variâncias e covariâncias genéticas, devido provavelmente a interações específicas de efeitos genéticos e/ou ambientais.

Apesar destas variações, existem pares de caracteres cujos coeficientes de correlações genéticas significativos a $1 \%$ de probabilidade pelo teste " $t$ ", apresentam uma amplitude de variação menor entre locais, dentro de GM. Assim, o caráter PO quando correlacionado com os caracteres PG e \%OL apresenta correlações genéticas positivas altamente significativas em todos os locais para GMP e GMI. No GMT avaliado no $L_{E}$, embora a correlação com o caráter \%OL não seja significativa, ela é positiva.

Estes resultados mostram a forte dependência do caráter PO sobre os caracteres PG e \%OL, os quais apresentam correlações genéticas positivas e significativas. Isto sugere possíveis progressos no melhoramento genético do caráter Po, via incremento da produtividade de grãos, da porcentagem de $61 e o$, ou de ambos os caracteres.

De acordo com ZIMBACK (1993) grandes correlações positivas genotípicas e fenotípicas entre os caracteres PG e PO permitem a obtenção de cultivares produtivos com alto teor de $6 l e o$.

No melhoramento da soja tem sido 
enfatisado o incremento da produtividade de grãos, embora a composição química seja importante. De acordo com BURTON (1987), este incremento da produtividade tem mantido ou incrementado também o conteúdo de óleo em detrimento do conteúdo de proteínas, devido às correlações positivas entre produtividade de grão e conteúdo de 61 eo.

De acordo com WILCOX (1984) o conteúdo de óleo em soja está controlado principalmente por efeitos genéticos aditivos, o que facilita a seleção; portanto a escases de cultivares com alto oleo reflete a falta de programas de melhoramento enfatizando a seleção para alto óleo.

Embora as correlações simples não sejam uma medida adequada das relações funcionais (causa-efeito) entre caracteres; permitem fazer certas aproximações. Assim, as correlações positivas do caráter NDF com os caracteres APF, NDM, APM e AIV; sugerem que o incremento da magnitude da expressão fenotípica destes caracteres depende do caráter NDF, cuja expressão se desenvolve primeiro. Segundo esta interpretação os caracteres que se desenvolvem primeiro seriam reguladores da expressão dos caracteres de desenvolvimento posterior, evidenciando-se uma estrutura hierárquica e seqüencial no desenvolvimento ontogenético dos caracteres na planta.

Para comprovar esta interpretação sugerese um análise de causa efeito através da correlação de caminhamento (Path Coefficients; WRIGHT, 1921) que mede as 
influências diretas de uma variável sobre outra, independentemente das demais variáveis.

$$
\text { De acordo com ALA AL-DIN et a 1. (1989) }
$$

coeficientes de correlação genética simples e da correlação de caminhamento indicam que a altura da planta e peso de cem sementes, tiveram um efeito direto sobre a produtividade de grãos; entretanto, o número de ramificações por planta teve um efeito indireto sobre a produtividade. Os mesmos autores salientam a importância de se considerar também a altura da planta e peso de cem sementes no melhoramento da produtividade.

A partir dos coeficientes de correlação genética estimados entre os caracteres quantitativos principais (PG, \%OL, PO) e os caracteres de importância agronômica secundária se destacam as correlações negativas do caráter NDM com os caracteres PG e PO, principalmente dentro do GMP. Isto sugere que os genótipos de maior precocidade devem ter crescimento indeterminado, o que pode levar a um maior crescimento vegetativo CV durante o período reprodutivo PR e, conseqüentemente, causando as correlações negativas entre os caracteres NDM e APM. Além disso, maior CV durante o PR também leva a correlações negativas do caráter NDM com os caracteres PG e PO, dentro do GM.

Por outra lado, as mesmas correlações negativas do caráter NDM com os caracteres PG e PO, no GMT; sugerem a diminuição ou detenção do incremento da produtividade, depois do caráter NDM ter alcançado certos 
limites.

De acordo com MARIOTTI (1986) correlações negativas são causadas comumente por interações de efeitos genéticos e ou ambientais que levam a forma de competição por recursos limitados.

As correlações fenotípicas (Tabela 40) mostraram-se em geral ligeiramente inferiores às correlações genéticas para a maioria dos pares de caracteres; este fato sugere ser pouco importante o componente ambiental acrescido às covariâncias fenotípicas. Esta superioridade das correlações genéticas favorece o processo de seleção para vários caracteres, levando teoricamente a um melhoramento integral dos genótipos.

De acordo com GOLDENBERG (1968) o fato das correlações genéticas e fenotípicas não necessariamente coincidirem em magnitude e em sinal torna imprescindível a estimação das correlações genéticas quando se pretende praticar seleção indireta, especialmente quando a espécie que se deseja melhorar já tenha alcançado um nível alto de aperfeiçoamento agronômico.

\subsection{Coeficientes de Determinação Genotípica}

O coeficiente de determinação genotípica expressa o grau no qual os fenótipos são determinados pelos genótipos (FALCONER, 1981). Quando os indivíduos compreendem uma amostra de uma população genética, ou seja, são 
relacionados reprodutivamente, o coeficiente de determinação genotípica corresponde ao coeficiente de herdabilidade; isto acontece por exemplo com uma geração $F_{2}$.

Em termos gerais, os valores relativamente altos destes coeficientes de determinação genotípica, indicam a importância das causas genéticas na variação fenotípica para todos os caracteres. Estes coeficientes superestimam o verdadeiro valor da contribuição genotípica, devido incluirem os efeitos das interações genótipos $x$ anos; mesmo assim, eles oferecem uma idéia relativa sobre as dificuldades e facilidades existentes para o melhoramento dos caracteres envolvidos; de fato, MARTINS \& VELLO (1981) consideram que, caracteres com valores de (b) próximos à unidade (1) são pouco influenciados pelas condições ambientais, sendo mais facilmente alterados pela seleção.

As estimativas dos coeficientes de determinação genotípica (b) para os dez caracteres avaliados, encontram-se na Tabe 1 a 41 ; tais estimativas foram obtidas a partir dos componentes da variância das Tabelas 16 a 31 .

Embora os coeficientes (b) evidenciaram variabilidade entre locais; o que sugere influência ambiental nas estimativas, principalmente para os caracteres PG e PO nos GMP e GMI. E possível classificar os caracteres em três classes de dificuldades para serem alterados por seleção nas gerações iniciais de endogamia: a) dificuldades pequenas: NDF, APF, APM, AC e VA; b) dificuldades 
intermediárias: NDM, AIV e \%OL; c) dificuldades grandes: PG e PO, principalmente no GMI.

De acordo com PACOVA (1992) os caracteres NDF e NDM foram classificados como de dificuldades pequenas; entretanto os caracteres APF, APM e VA classificaram-se como de dificuldades intermediárias; sendo o caráter PG de grande dificuldades para a seleção. 


\section{CONCLUSÕES}

Os resultados obtidos permitem as seguintes conclusões:

a. Existe significativa variabilidade genética para todos os caracteres estudados, nos três grupos de maturidade, oferecendo amplas possibilidades para a seleção de genótipos parentais.

b. Os efeitos das interações $G \times$ L contribuiram significativamente na expressão fenotípica dos caracteres estudados; no entanto, o número de caracteres influenciados pelas interações foi diferente nos três grupos de maturidade.

c. O componente complexo das interações $G$ $x$ L explica a maior parte dos efeitos nos caracteres produtividade de grãos (PG), porcentagem de 61 eo (\%OL) e produtividade de 6 leo (PO) apesar das correlações genéticas entre locais serem significativamente diferentes de zero.

d. O grupo de maturidade intermediário mostrou estar melhor adaptado às condições ambientais da região, para os caracteres PG e PO; entretanto, o grupo de maturidade tardio foi o mais produtivo em grãos e 6 leo.

e. A menor sobreposição dos


desenvolvimentos das fases vegetativa e reprodutiva, junto com o aumento do ciclo biológico da planta favorecem a maior produtividade.

f. Diferenças significativas foram detectadas nas condições ambientais dos três locais de teste, principalmente entre Anhembi e ESALQ, respectivamente com menor e maior qualidade agroecológica.

g. Os locais Anhembi - ESALQ $\left(L_{A} L_{E}\right)$ podem ser úteis para a seleção dos caracteres PG e PO; já que minimizam os efeitos das interações $G \times L$. Isto permite uma maior capacidade preditiva do desempenho genotípico e conseqüentemente vantagens para o melhoramento genético.

h. O número de dias para maturidade foi o menos influenciado por fatores experimentais não controlados e o caráter altura de inserção da primeira vagem foi o mais prejudicado por tais fatores.

i. Os locais influenciaram significativamente a magnitude dos coeficientes de correlação genética e fenotípica.

j. Correlações genéticas superiores às correlações fenotípicas para a maioria dos pares de caracteres favorecem o processo de seleção para vários caracteres, podendo levar a um melhoramento genético integral.

k. Os coeficientes de correlações genéticas positivos entre os caracteres PG, \%OL e PO são indicadores de novos avanços no melhoramento genético 
simultâneo destes caracteres.

1. Alguns genótipos destacaram-se com valores altos de PG, \%OL e PO em dois e três locais: Cobb, Planalto, FT-2. SOC 81-76, BR-1 (S.401) com ciclo precoce; UFV-4, SOC 81-216, SOC 81-266, Paranagoiana, FT-8 (Araucária), BR-9 (Savana), com ciclo intermediário; Cristalina-2 (S), IAC-9, UFV-2, UFV-Araguaia, EMGOPA 301 , com ciclo tardio. 


\section{REFERENCIAS BIBL IOGRAFICAS}

ALA AL-DIN, A.M.; FRAJ, B.H.; IBRAHEEN, S.A. Correlation and path - coefficient analysis of yield and certain characters of soybean (Glycine max (L.) Merrill) in IRAQ. In: WORLD SOYBEAN RESEARCH CONFERENCE, 4., Buenos Aires. Proceedings. Buenos Aires, Asociación Argentina de la soja, 1989. p. 974-82.

ALLARD, R.W. \& BRADSHAW, A.D. Implications of genotype environmental interactions in applied plant breeding. Crop Science, Madison, 4: 503-7, 1964.

ALLARD, R.W. Principios de la mejora genética de las plantas. 3. ed. Barcelona, Edgard Blücher, 1978, 498 p. ALLEN, F.L.; COMSTOCK, R.E.; RASMUSSON, D.C. Optional environment for yield testing. Crop Science, Madison, 18: $747-51,1978$.

ALLIPANDRINI, L.F. Estudo dos efeitos ambientais, estabilidade, adaptabilidade e ganho genético em linhagens de soja (Glycine $\max$ (L.) Merrill) no Estado do Paraná. Londrina, 1992. 122p. (Mestrado - Universidade Estadual de Londrina, Instituto Agronômico do Paraná/EMBRAPA, CNP Soja). 
ANDERSON, L.R. \& VASILAS, B.L. Effects of planting date on two soybean cultivars: seasonal dry matter accumulation and seed yield. Crop Science, Madison, 25(6): 999-1004, 1985 .

ARIYO, O.J. Stability of performance of okra as influenced by planting date. Theoretical Applied Genetics, Berlin, $74: 83-6,1987$.

ARIYO, O.J. Efectiveness and relative discriminatory abilities of techniques measuring genotype $x$ environment interaction and stability in okra (Abelmoschus esculentus (L.) Moench). Euphytica, Wageningen, 47(2):99-105, 1990. AZZALINI, A. \& COX, D.R. Two new tests associated with analysis of variance. Journal of the Royal statistical Society, B., London, 46: 335-43, 1984.

BAKER, R.J. Analysis of genotype - environmental interations in crop ISI at las science. Animal Plant Science, 1: 1-4, 1988a.

BAKER, R.J. Tests for crossover genotype - environmental interactions. Canadian Journal of Plant Science, Ot tawa, 68: $405-10,1988 b$.

BARIL, C.P. Factor regression for interpreting genotype $x$ environment interaction in bread - wheat trials. Theoretical Applied Genetics, Berlin, 83(8): 1022-6, 1992 .

BARLOW, R. Experimental evidence for interaction between heterosis and environment in animals. Animal Breeding Abstracts, Edinburgh, 49: 715-37, 1981 . 
BENNETT, C.A. \& FRANKLIN, N.L. Statistical Analysis in Chemistry and the Chemical Industry. 3 imp. New York, John Wiley and Sons. 1963. 724 p.

BERNARDO, R. Identifying populations useful for improving parents of a single cros based on net transfer of alleles. Theoretical Applied Genetics, Berlin, 80:34952,1990 .

BILBRO, J.D. \& RAY, L.L. Environmental stabibity and adaptation of several cotton cultivars. Crop science, Madison, 16: 821-4, 1966 .

BOARD, J.E. \& HALL, w. Premature flowering in soybean yield reductions at monoptimal planting dates. Agronomy Journa 1, Madison, 76:700-4, 1984 .

BONATO, E.R. Estabilidade fenotípica da produção de grãos de dez cultivares de soja (Glycine max (L.) Merrill) nas condições do Rio Grande do Sul. Piracicaba, 1978. 75 p. (Mestrado - Escola Superior de Agricultura "Luiz de Queiroz"/USP).

BRIM, C.A. Quantitative genetics and breeding. In: CALDWELL, B.E., ed. Soybeans; improvement prodution and uses. Madison, American Society of Agronomy, 1973. cap. 5. p. $155-83$.

BROWN, K.D.; SORRELLS, M.E.; COFFMAN, W.R. A method for classification of testing environments. Crop science, Madison, 23: 889-93, 1983 . 
BURTON, J.W. Quantitative genetics: Results relevant to soybean breeding. 211-247. In: WILCOX, J.R., ed. Soybeans; improvement, production and uses. 2 ed. Madison, American Society of Agronomy, 1987. p. 211-47. CHAVES. L.J.; VENCOVSKY, R.; GERALDI, I.O. Modelo nãolinear aplicado ao estudo da interação genótipos $x$ ambiente em milho. Pesquisa Agropecuária Brasileira, Brasilia, 24(2):259-68, 1989 .

COCHRAN, W.G. \& COX, G.M. Experimental Designs. 2 ed. New York, John Wiley \& Sons, 1957. 611 p.

COCKERHAM, C.C. Estimation on genetic variances. In: HANSON, W.D. \& ROBINSON, H.F., ed. Statistical Genetics and Plant Breeding. Washington, National Academy of Sciences - National Research Council, 1963. p. 53-94. (Publication, 982).

COMSTOCK, R.E. \& MOLL, R.H. Genotype - environment interactions. In: HANSON, w.O. \& ROBISON, H.F., ed. Statistical Genetics and Plant Breeding. Washington National Academy of Sciences - National Research Council, 1963. p. 164-96. (Publication, 982).

CROSS, H.Z. \& HAMMOND, J.J. Plant density effects on combining abilities of early maize synthetics. Crop Science, Madison, 22: 814-7, 1982 .

CROSSA, J. Statistical analyses of multilocation trials. Advances in Agronomy, San Diego, 44: 55-85, 1990. 
CROSSA, J.; WESTCOTT, C.; GONZALEZ, C. The yield stability of CIMMYT's maize germplasm. Euphytica, Wageningen, 40: $245-51,1989$.

DESTRO, D.; SEDIYAMA, T.; SILVA, J.C. SEDIYAMA， C.S.; TIEBAUT, J.T.L. Estimativas de herdabilidade de alguns caracteres, em dois cruzamentos de soja. Pesquisa Agropecuária Brasileira, Brasília, 22(3): 291-304, 1987. DHILLON， B.S.; UTZ, H.F.; POLLMER， W.G.; GURRATH， P.A.; KLEIN, D. Evaluation of environments for preliminary testing of maize for yield and stover digestibility. Euphytica, Wageningen, 54: 19-26, 1991 .

DUARTE, J.B. \& ZIMMERMANN, M.J.O. Comparison of tree methods used for the study of adaptation and phenotypic stability in the common bean (Phaseolus vulgaris L.). Revista Brasileira de Genética, Ribeirão Preto, 15(1): $125-36,1992$.

DUDLEY, J.W. Theory for transfer of alleles. Crop science, Madison, 22: $631-7,1982$.

FALCONER, D.S. Introducción a la genét ica cuantitativa. 2 . ed. México, Cecsa, 1981.383 p.

FALCONER, D.S. Selection in different environments: Effects on environmental sensitivity (Reaction Norm) and on mean performance. Genetical Research, London, 56: 57-70. 1990. 
FARIAS NETO, J.T. Comportamento e variabilidade de genótipos de soja (Glycine $\max (\mathrm{L}$.$) Merrill) em cultivos$ de verão e inverno. Piracicaba, 1987. 87p. (Mestrado Escola Superior de Agricultura "Luiz de Queiroz"/USP). FEHR, W.R. Principles of cultivar development; Theory and technique. New York, Macmillan, 1987. V.1. 536 p. FINLAY, K.W. \& WILKINSON, G.N. The analysis of adaptation in a plant - breeding programme. Australian Journal Agricultural Research, Melbourne, 14: 742-54, 1963.

GAUCH, H.G. Model selection and validation for yield trials with interaction. Biometrics, Washington, 88: 705-15, 1988 .

GAUCH, H.G. \& ZOBEL, R.W. Predictive and postdictive success of statistical analyses of yield trials. Theoretical Applied Genetics, Berlin, 76: 1-10, 1988 . GAUCH, H.G. \& ZOBEL, R.W. Accuracy and selection success in yield trial analyses. Theoretical Aplied Genetics, Berlin, 77: 473-81, 1989 .

GERLOFF, J.E. \& SMITH, O.S. Choice of method for identifying germplasm with superior alleles. 1. Theoretical Result. Theoretical Applied Genetics. Berlin, 76: 209-16, 1988 a.

GERLOFF, J.E. \& SMITH, O.S. Choice of method for identifying germplasm with superior alleles. 2. Computer Simulations Results. Theoretical Applied Genetics. Berlin, 76: 217-27, 1988 b. 
GOLDENBERG, J.B. El empleo de la correlacion en el mejoramiento genetico de las plantas. Fitotecnia Lat inoamericana, Castelar, 5(2): 1-9, 1968 .

GOMES, F.P. Curso de Estatística Experimental. 13. ed. Piracicaba, Nobel, 1990. 468 p.

GORSLINE, G.W. A graphical "Regression Selection" technique for maturity related characters in field crop. Agronomy Journal, Madison, 52:581-4, 1960 .

GRAVOIS, K.A.; MOLDENHAVER, K.A.K. ; ROHMAN, P.L. Genetic and genotype $x$ environment effects for rough rice and head rice yields. Crop Science, Madison, 31: 907-11, 1991.

GREGORIUS, H.R. \& NAMKOONG, G. Joint analys is of genotypic and environmental effects. Theoretical Applied Genetics, Berlin, 72: 413-22, 1986 .

HAMBLIN, J.; FISCHER, H.M.; RIDINGS, H.L. The choice of locality for plant breeding when selection for high yield and general adaptation. Euphytica, Wageningen, 29: $161-8,1980$.

HE, $Z$. An investigation of the relationship between the $F_{1}$, potential and the measures of genetic distance among wheat lines. Euphytica, Wageningen, 58(2): 165-70, 1991. HELGADÓTTIR, A. \& KRISTJANSDOOTTIR, T.A. Simple approach to the analysis of $G \times E$ interactions in a multilocational spaced trial with timothy. Euphytica, Wageningen, 54: $65-73,1991$. 
HILL, JUNIOR, R.R. \& BAYLOR, J.E. Genotype x environment interaction analysis in alfalfa. Crop Science, Madison, 23: $811-5,1983$.

HIORTH, E.H. Genética Cuantitativa II; Seleccion. Cordoba, Universidad Nacional de Córdoba, Facultad de Ciencias Agropecuárias, 1985. 249 p.

JINKS, J.L. \& CONNOLLY, V. Selection for specific and general response to environmental differences. Heredity, London, 30: 33-40, 1973 .

JINKS, J.L. \& CONNOLLY, V. Determination of the environmetal sensitivity of selection lines by the selection environment. Heredity, London, 34: 401-6, 1975 .

JINKS, J.L. \& POONI H.S. Determination of the environmental sensitivity of selection lines of Nicotiana rustica by the selection environment. Heredity, London, 49: $291-4,1982$.

JOHNSON, H.W.; ROBINSON, H.F.; COMSTOCK, R.E. Genotypic and phenotypic correlations in soybeans and their implications in selection. Agronomy Journal, Madison, $47: 477-83,1955$.

KEMPTHORNE, O. An Introduction to Genetic statistica. 3. ed. New York, John Wiley \& Sons, 1966. 545 P.

KEMPTON, R.A. The use of the bioplots in interpreting variety by environment interaction. Biometrics, Washington, 88: 705-15, 1984 . 
LIN, C.S. \& BINNS, M.R. A method of analyzing cultivar $x$ location $x$ years experiments: a new stability parameter. Theoretical Applied Genetics, Berlin, 76: 425-30, 1988a. LIN, C.S. \& BINNS, M.R. A superiority measure of cultivar performance for cultivar $x$ location data. Canadian Journal Science of Plant Science, Ottawa, 68: 193-8, $1988 b$.

LIN, S.M. \& NELSON, R.L. Effect of plant height and flowering date on seed yield of determinate soybean. Crop Science, Madison, 28: 218-22, 1988 .

MARIOTTI, J.A. Clonal selection across environments in sugar-cane. In: Internationl Society sugar Cane Thecnologists, 17. Manila, 1980. Proceedings. Mamila, I SSCT, 1980 . p. $1142-51$.

MARIOTTI, J.A. Fundamentos de Genética Biométrica; aplicaciones al mejoramiento genético vegetal. Washington, OEA, 1986 . $152 \mathrm{p}$.

MARTINS, P.S. \& VELlo, N.A. Performance and variability of agronomic characters in populations of stylosanthes guianensis (AVBL.) SW. In: INTERNATIONAL GRASSLAND CONGRESS, 14., Kentucky, 1981. Proceedings. s.n.t. $196-8 p$.

MINGXIANG, H. The effects of ecological environmental conditions on the chemical composition of soybean seeds. Soybean Science, 9(1): 41-8, 1990 . 
MORENO - GONZALES, J. Choice of environments in reciprocal recurrent selection programs. Theoretical Applied Genetics, Berlin, 71: 652-6, 1986 .

NACHIT, M.M.; NACHIT, G.; KETATA, H.; GAUCH JUNIOR, H.G.; ZOBEL, R.W. Use of AMMI and linear regression models to analyse genotype - environment interaction in durum wheat. Theoretical Applied Genetics, Berlin, 83: 597-601, 1992.

NOGUEIRA, S.S.S. Ciclo biológico, características fisiológicas, produção e composição química da semente dos cultivares de soja (Glycine max (L.) Merrill) UFV-1 e IAC-7 em diversas épocas de semeadura. Piracicaba, 1983. 96p. (Doutorado - Escola Superior de Agricultura "Luiz de Queiroz"/USP).

NTARE, B.R. \& AKENOVA, M. Yield stability in segregating populations the cowpea. Crop Science, Madison, 25: 20811,1985 .

PACOVA, B.E.V. Análise genética de progênies segregantes de soja apropriada para o consumo humano. Piracicaba, 1992. 216p. (Doutorado - Escola Superior de Agricultura "Luiz de Queiroz"/USP).

PATERSON, A.H.; TANKSLEY, S.D.; SORRELLS, M.E. DNA markerS im plant improvement. Advances in Agronomy, San Diego, 46: $39-90,1991$.

PEARSON, E.S. \& HARTLEY, H.O. Biometrika Tables for Statisticians. Cambridge, University Press, 1956. 329 p. 
PETERSON, C.J.; GRAYBOSCH, R.A.; BAENZIGER, P.S.; GROMBACHER, W.A. Genotype and environmet effects on quality characteristics of hard zed winter wheat. Crop Science, Madison, 32: 98-103, 1992.

POLLAK. L.M. \& PHAM, H.N. Classification of maize testing locations in Sub-Saharan Africa by using agroclimatic data. Maydica, Bergamo, 34: 43-51, 1989.

POWELl, W; CALIGARI, P.D.; PHILLIPS, M.S. ; JINKS, J.L. The measurement and interpretation of genotype by environment interaction in spring barley (Hordeum vulgare). Heredity, London, 56: 255-69, 1986 .

SAKIYAMA, N.S.; SEDIYAMA, T.; SEDIYAMA, C.S.; REIS, M.S. Interação genotípos $x$ ambientes e seus efeitos na escolha de localidades para avaliação de linhagens de soja (Glycine $\max$ (L.) Merrill). Revista Ceres, Viçosa, $35(201): 486-93,1988$.

SALVATORE, L. \& STEFANIA, G. Selections environment and environmental sensitivity in barley. Euphytica, Wageningen, 57: 157-67, 1991 .

SANTOS, M.X.; ZINSLY, J.R.; VENCOVSKY, R.;VELLO, N.A. Interação genótipos localidades em híbridos crípticos de milho $S_{1} \times S_{1}$, nas regiões sudeste e nordeste brasileira. Ciência e Cultura, São Paulo, 33(9): 1235-8, 1981 .

SAS InStitute. SAS.STAR User's guide. Realease 6.03 ed. 1983. SAS INSTITUTE, INC., CARY. NC. 
SATTERTHWAITE, F.E. An approximate distribution of estimates of variance components. Biometrics, Washingt on, 2: 110-4, 1946 .

SMITH, R.R. \& WEBER, C.R. Mass selection by specific gravity for protein and oil in soybean populations. Crop Science, Madison, 8: 373-7, 1968.

STUBER, C.W. Opportunities and challenges for improvement of quantitative traits. In: CONGRESSO LATINO-AMERICANO DE GeneticA, 10., Rio de Janeiro, 1992. Proceeding. Revista Brasileira de Genética, Suplemento 1, Ribeirão Preto, 15(1): 36-41, 1992 .

TOLEDO, J.F.F. Quantitative genetics in soybean breeding. In: WORLD SOYBEAN RESEARCH CONFERENCE, 4., Buenos Aires, 1989. Proceeding. Buenos Aires, Asociación Argentina de la Soja, 1989. p. 909-915.

TOLEDO, J.F.F.; ALMEIDA, L.A.; KIIHL, R.A.; MENOSSO, O.G. Ganho genético em soja no Estado do Paraná via melhoramento. Pesquisa Agropecuária Brasileira, Brasilia, 25(1): 89-94, 1990.

TROYER, A.F. \& ROSENBROOK, R.W. Utility of higher plant densities for corn performance testing. Crop science, Madison, 23: 863-7, 1983 .

TORRES, R.A.A. Estudo do controle genético da estabilidade fenotípica de cultivares de milho (Zea mays L.). Piracicaba, 1988. 133 p. (Doutorado - Escola Superior de Agricultura "Luiz de Queiroz"/USP). 
VELlo, N.A. \& PIRES, C.E.L.S. Estratégias para a seleção de parentais. In: CONGRESSO LATINO-AMERICANO DE GENETICA, 10., Rio de Janeiro, 1992. Proceeding. Revista Brasileira de Genética, Suplimento 1 , Ribeirão Preto, $15(1): 45-9,1992$.

VENCOVSKY, R. \& BARRIGA, P. Genética Biométrica no Fitome lhoramento. Ribeirão Preto, Sociedade Brasileira de Genética, 1992. $486 \mathrm{p}$.

VENCOVSKY, $R$ \& GERALDI, I.O. Um modelo multiplicativo aplicado à análise de produção de grãos. Relatório Científico do Departamento de Genética, Piracicaba, 11: $157-65,1977$.

VERNETTI, F.J.; GASTAL, M.F.C.; ZONTA, E.P. Estabilidade fenotípica de cultivares de soja no sudeste do Rio Grande do Sul. Pesquisa Agropecuária Brasileira, Brasília, 25(11): $1593-602,1990$.

WILCOX, R.J. Breeding soybeans for improved oil quantity and quality. In: WORLD SOYBEAN RESEARCH CONFERENCE, 3., Ames, 1984. Proceeding. London, Westview Press, 1985. p. $380-6$.

WILCOX, R.J. Soybean protein and oil quality. In: WORLD SOYBEAN RESEARCH CONFERENCE, 4., Buenos Aires, 1989. Proceeding. Buenos Aires, Asociación Argentina de la Soja, 1989. p. 28-39.

WRIGHT, A.J. The analys is and prediction of some two factor interactions in grass breeding. Journal Agricultural Science, Cambridge, 76: 301-6, 1971 . 
WRIGTH, S. Correlation and causation. Journal of Agricultural Research, Washington, 20(7): 557-85, 1921. XIANGXUN, M. ; SHUMING, W. ; A IPING, L.; HU, M. Prote in and oil content of soybean seed as influenced by years and location. Soybean Genetics Newsletter, Ames, 18: 113-6, 1991.

YAMADA, Y. Genotype by environment interaction and genetic correlation of the same trait under different environments. Japanese Journal Genetics, Mishima, 37: 498-509, 1962 .

YANG, R.C. \& BAKER, R.J. Genotype - environment interactions in two wheat crosses. Crop science, Madison, 31: 83-7, 1991 .

ZIMBACK, L. Cruzamento em cadeia entre genótipos adaptados e exóticos de soja com ênfase na produção de óleo. Piracicaba, 1993. 163 p. (Doutorado - Escola Superior de Agricultura "Luiz de Queiroz"/USP). 
TABELAS 
Tabela 1. Genótipos correspondentes ao grupo de maturidade precoce avaliados nos locais: Anhembi, ESALQ e Sertãozinho. Soja, semeadura entre $30 / 11$ e $12 / 12 / 1984$.

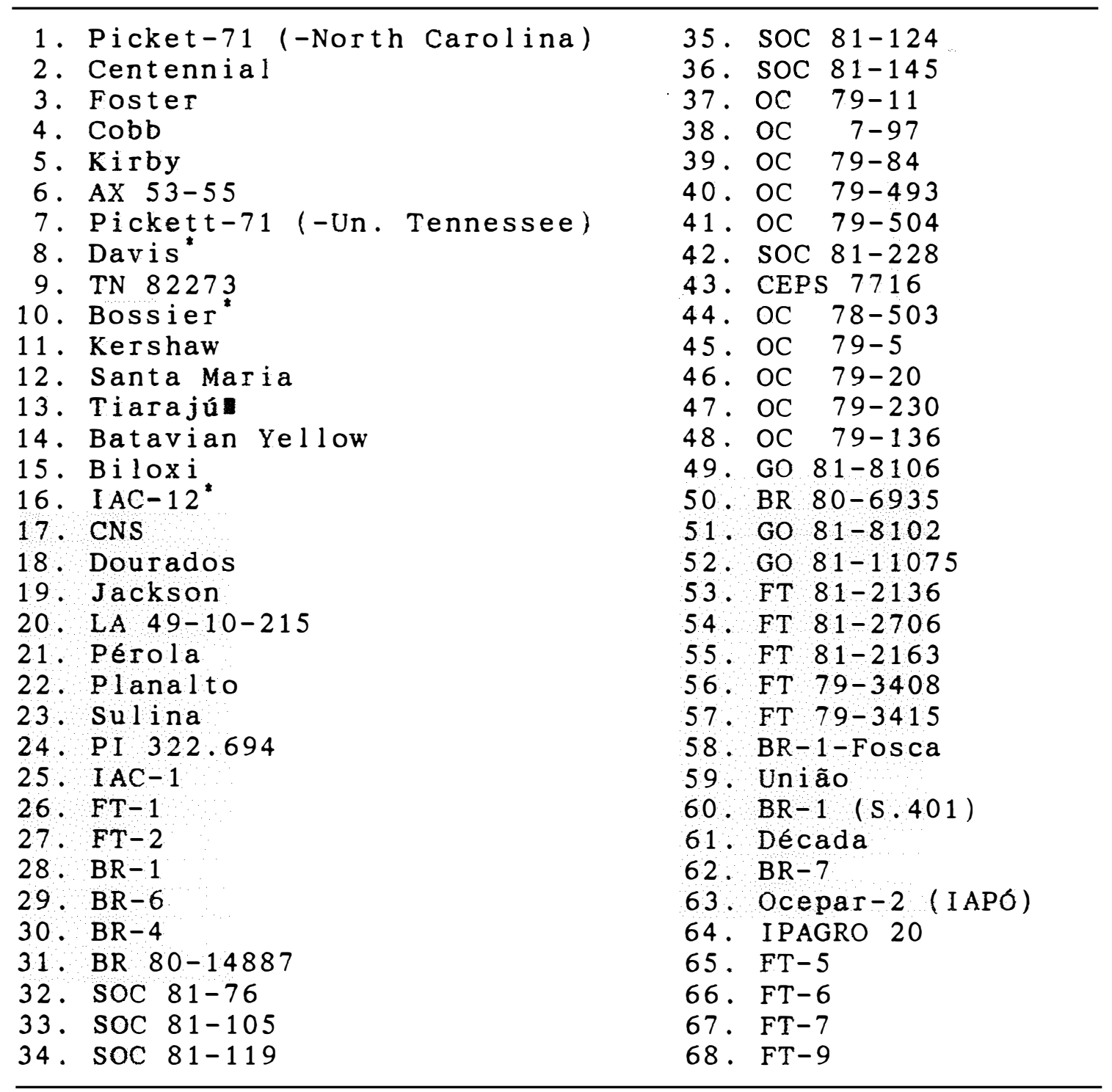

* Repete como testemunha padrão.

- Repete no grupo de maturidade intermediário como tratamento no 14 . 
Tabela 2. Genótipos correspondentes ao grupo de maturidade intermediário avaliados nos locais: Anhembi, ESALQ e Sertãozinho. Soja, semeadura entre 30/11 e $12 / 12 / 1984$.

\begin{tabular}{|c|c|}
\hline 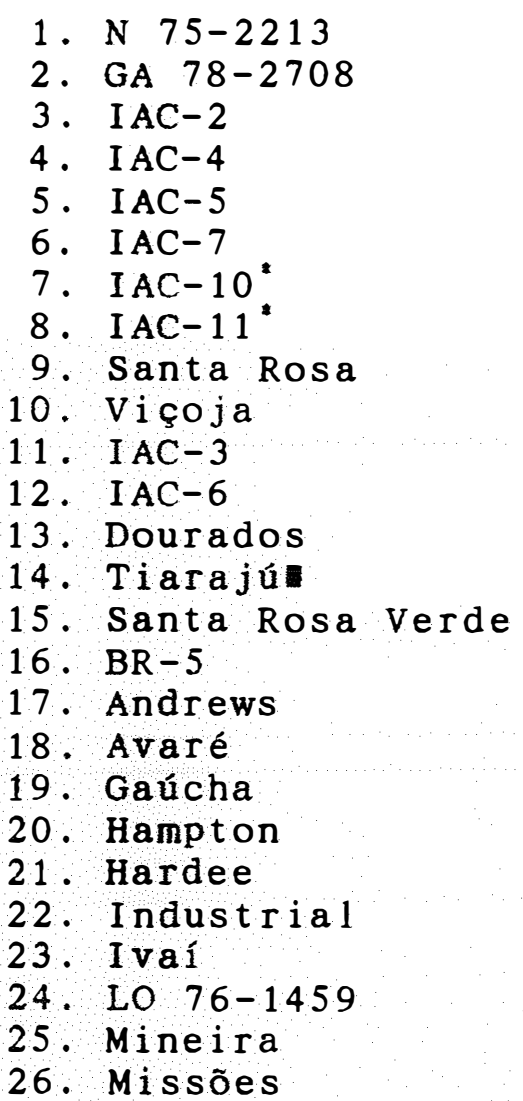 & 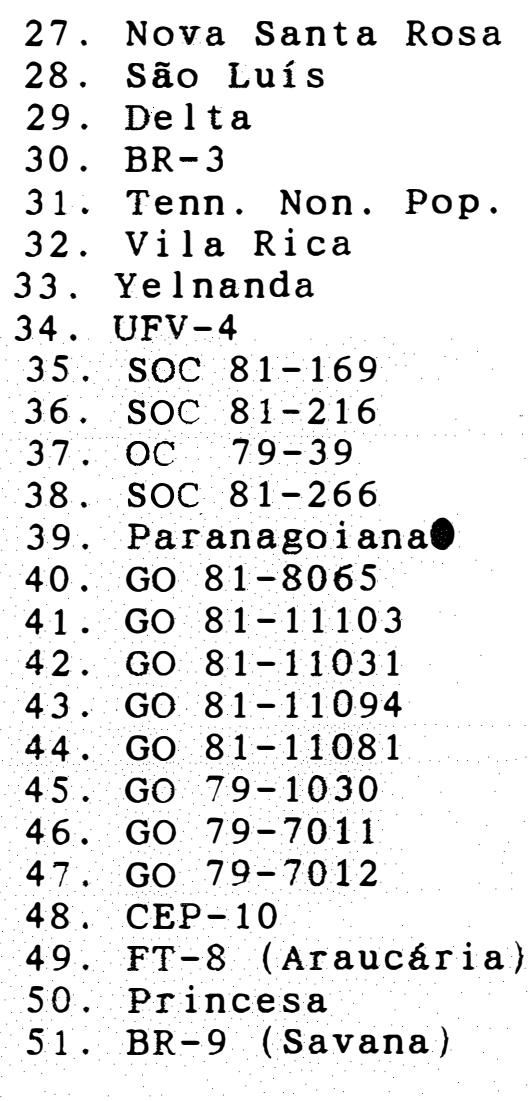 \\
\hline
\end{tabular}

- Repete como testemunha padrão.

- Repete no grupo de maturidade precoce como tratamento no 13.

- Repete no grupo de maturidade tardio como tratamento no 6. 
Tabela 3. Genótipos correspondentes ao grupo de maturidade tardio, avaliados nos locais: Anhembi, ESALQ e Sertãozinho. Soja, semeadura entre $30 / 11$ e $12 / 12 / 84$

\begin{tabular}{ll}
\hline 1. TN 82264 & 12. UFV-3 \\
2. Cristalina-1 (C) & 13. UFV-5 \\
3. Cristalina-2 (S) & 14. UFV-Araguaia \\
4. Doko & 15. GO 79-1039 \\
5. Numbaira & 16. GO 79-1084 \\
6. Paranagoiana & 17. EMPOGA 301 \\
7. PI 240.664 & 18. BR-10 (Teresina) \\
8. IAC-9 & 19. BR-11 (Carajás) \\
9. Tropical & 20. Timbira (C) \\
10. UFV-1 & 21. Timbira (S) \\
11. UFV-2 & 22. BR 79-63 \\
\hline
\end{tabular}

C: Vagem Clara

S: Vagem Escura

*: repete como testemunha padrão

- : reprete no grupo de maturidade intermediário como tratamento no 39 . 
Tabela 4. Informações gerais sobre os experimentos, incluindo três grupos de maturidade e três locais. Soja, semeadura entre $30 / 11$ e $12 / 12 / 1984$.

\begin{tabular}{|c|c|c|c|c|c|c|c|}
\hline $\begin{array}{l}\text { Grupo de } \\
\text { Maturidade }\end{array}$ & Local & $\begin{array}{l}\text { Múmero de } \\
\text { Genótipos }\end{array}$ & $\begin{array}{l}\text { Repeti } \\
\text { çöes }\end{array}$ & $\begin{array}{l}\text { Conjuntos } \\
\text { Erperimen } \\
\text { tais }\end{array}$ & $\begin{array}{l}\text { Tratamentos } \\
\text { dentro de } \\
\text { Conj. Exp. }\end{array}$ & Testemunhas & $\begin{array}{l}\text { Data de } \\
\text { Semeadura }\end{array}$ \\
\hline \multirow{3}{*}{ Precoce } & Anhembi & 68 & 2 & 4 & 17 & \multirow{3}{*}{$\begin{array}{l}\text { Davis } \\
\text { IAC- } 12 \\
\text { Bossier }\end{array}$} & $11 / 12 / 84$ \\
\hline & ESALQ & 68 & 2 & 4 & 17 & & $30 / 11 / 84$ \\
\hline & Sertãozinho & 68 & 2 & 4 & 17 & & $05 / 12 / 84$ \\
\hline \multirow{3}{*}{ Intermediário } & Anhembi & $\$ 1$ & 2 & 3 & 17 & \multirow{3}{*}{$\begin{array}{l}I A C-8 \\
I A C-10 \\
I A C-11\end{array}$} & $11 / 12 / 84$ \\
\hline & ESALQ & $\$ 1$ & 2 & 3 & 17 & & $04 / 12 / 84$ \\
\hline & Sertãozinho & 51 & 2 & 3 & 17 & & $06 / 12 / 84$ \\
\hline \multirow{3}{*}{ Tardio } & Anhembi & 22 & 2 & 2 & 11 & \multirow{3}{*}{$\begin{array}{l}\text { IAC-9 } \\
\text { Tropical } \\
\text { UFV-1 }\end{array}$} & $12 / 12 / 84$ \\
\hline & ESALQ & 22 & 2 & 2 & 11 & & $04 / 12 / 84$ \\
\hline & Sertãozinho & 22 & 2 & 2 & 11 & & $06 / 12 / 84$ \\
\hline
\end{tabular}


Tabela 5. Caracteres avaliados em cada experimento. Soja, $1984 / 85$.

\begin{tabular}{|c|c|c|c|c|c|c|c|c|c|c|c|c|}
\hline $\begin{array}{l}\text { Grupo de } \\
\text { Maturidade }\end{array}$ & Local Caracteres & $\mathrm{NDF}$ & $A P F$ & NDY & APN & $A C$ & AIV & $V_{A}$ & $P G$ & $10 \mathrm{~L}$ & PO & $\begin{array}{l}\text { No de Caract } \\
\text { Avaliados }\end{array}$ \\
\hline & Anheabi & - & - & $x$ & $x$ & $x$ & $x$ & $x$ & $x$ & $x$ & $x$ & 8 \\
\hline \multirow[t]{3}{*}{ Precoce } & ESALP & $x$ & $x$ & - & $x$ & $x$ & $x$ & $x$ & $x$ & $x$ & $x$ & 9 \\
\hline & Sertäozinho & $x$ & $x$ & $x$ & $x$ & $x$ & $x$ & $x$ & $x$ & $x$ & $x$ & 10 \\
\hline & Anhenoi & - & - & $x$ & $x$ & $x$ & $x$ & $x$ & $x$ & $x$ & $x$ & 8 \\
\hline \multirow[t]{3}{*}{ Internediário } & ESALQ & $x$ & $x$ & - & $x$ & $x$ & $x$ & $x$ & $x$ & $x$ & $x$ & 9 \\
\hline & Sertãozinho & $x$ & $x$ & $x$ & $x$ & $x$ & $x$ & $x$ & $x$ & $x$ & $x$ & 10 \\
\hline & Alueabi & - & - & $x$ & $x$ & $x$ & $x$ & $x$ & $x$ & $x$ & $x$ & 8 \\
\hline \multirow[t]{2}{*}{ Tardio } & ESALQ & $x$ & $x$ & $x$ & $x$ & $x$ & $x$ & $x$ & $x$ & $x$ & $x$ & 10 \\
\hline & Sertãozinho & $x$ & $x$ & $x$ & $x$ & $x$ & $x$ & - & $x$ & $x$ & $x$ & 9 \\
\hline
\end{tabular}

$X$ : Caráter avaliado

- : Caráter não avaliado

NDF : Número de dias para o Florescimento

APF : Altura da planta no Florescimento

NDM : Núnero de dias para aturidade

APM : Altura de planta na aturidade

Ac : Acanamento

AIV : Altura de inserção da primeira ragem

VA : Valor Agronônico

PG : Produtividade de Gräos

20L : Porcentagen de óleo

Po : Produtividade de óleo. 
Tabela 6. Esquema de ánalise de variância conjunta de locais e testemunhas com as esperanças matemáticas dos quadrados médios obtidos pela regra de BENNETT \& FRANKLIN (1963).

\begin{tabular}{|c|c|c|c|c|}
\hline $\begin{array}{l}\text { Eonte de } \\
\text { Variação }\end{array}$ & GL & QN & $E(Q N)$ & $F$ \\
\hline \multirow[b]{2}{*}{ Testeauntias (T) } & \multirow[b]{2}{*}{$I-1$} & \multirow{2}{*}{\multicolumn{2}{|c|}{$l_{1} \sigma^{2} e+s \sigma_{i j: p}^{2}+i r \sigma_{j p}^{2}+j s p V_{i}$}} & $l_{1}+l_{11}$ \\
\hline & & & & $l_{5}+l_{7}$ \\
\hline Conjuntos $|C|$ & $s-1$ & $l_{2}$ & $0^{2}+i \sigma_{j s: p}^{2}+i j p \sigma_{s}^{2}$ & $l_{2} / l_{6}$ \\
\hline \multirow{2}{*}{ Locais $(L)$} & \multirow{2}{*}{$P-1$} & \multirow{2}{*}{$l_{3}$} & \multirow{2}{*}{$\sigma^{2}{ }_{e}+i j \sigma_{s p}^{2}+i \sigma^{2} j s: p+i s \sigma_{j: p}^{2}+i j s V p$} & $l_{3}+l_{11}$ \\
\hline & & & & $l_{4}+l_{9}$ \\
\hline$B l o \cos (B) / L$ & $(J-1) p$ & $l_{4}$ & $\sigma^{2} e^{+} i \sigma^{2} j s: p+i s \sigma^{2} j: p$ & $\mathrm{P}_{4} / \mathrm{l}_{6}$ \\
\hline$\tau \times C$ & $(I-1)(s-1)$ & & $o^{2}+j p \sigma_{i s}^{2}$ & $P_{5} / P_{11}$ \\
\hline$C \times B / L$ & $(J-1)(s-1) p$ & $l_{6}$ & $\sigma^{2} e^{+}+i \sigma^{2} j s: p$ & $l_{6} l_{11}$ \\
\hline$P \perp B / L$ & $(I-1)(J-1) p$ & $l_{7}$ & $\sigma^{2} e+s o^{2} i j: p$ & $l_{7} / l_{11}$ \\
\hline$T \times L$ & $(1-1)(P-1)$ & $l_{\delta}$ & $\sigma_{e}^{2}+j \sigma_{i s p}^{2}+j s V_{i p}$ & $l_{8} \ell_{10}$ \\
\hline$C \times L$ & $(s-1) \mid p-1)$ & $l_{9}$ & $\sigma^{2} e^{+}+i j \sigma_{s p}^{2}$ & $l_{9} / l_{11}$ \\
\hline$I \times C \times L$ & $(I-1)(S-1)(P-1)$ & $l_{10}$ & $0^{2} e^{+j o}{ }^{2}$ isp & $l_{1 d} l_{11}$ \\
\hline$T \times C \times B / L$ & $(I-1)(J-1)(s-1) P$ & $P_{11}$ & $\sigma_{\mathrm{e}}^{2}$ & \\
\hline TOTAL & $1 J S P-1$ & & & \\
\hline
\end{tabular}


Tabela 7. Esquema de análise de variância individual para cada local, eliminando-se o efeito de conjun tos experimentais. As esperanças matematicas dos quadradros médios foram obtidas pela regra de BENNETT \& FRANKLIN (1963).

\begin{tabular}{lllll}
\hline $\begin{array}{l}\text { Fonte de } \\
\text { Variação }\end{array}$ & GL & QM & E(QM) & $F$ \\
\hline Genótipos (G) & I -1 & $Q_{1}$ & $\sigma_{e}^{2}+j V_{i}$ & $Q_{1} / Q_{3}$ \\
Blocos (B) & $J-1$ & $Q_{2}$ & $\sigma_{e}^{2}+i \sigma^{2}$ & $Q_{2} / Q_{3}$ \\
Resíduo & $(I-1)(J-1)$ & $Q_{3}$ & $\sigma_{e}^{2}$ & \\
\hline TOTAL & I J -1 & & & \\
\hline
\end{tabular}


Tabela 8. Esquema de análise de variância conjunta para os três locais, eliminando-se o efeito de conjuntos experimentais. As esperanças matemáticas dos quadrados médios foram obtidas pela regra de BENNETT \& FRANKLIN (1963).

\begin{tabular}{lllll}
\hline $\begin{array}{l}\text { Fontes de } \\
\text { Varição }\end{array}$ & GL & QM & $E(Q M)$ & $F$ \\
\hline Genót ipos (G) & $I-1$ & $Q_{1}$ & $\sigma_{e}^{2}+j p V_{i}^{\prime \prime}$ & $Q_{1} / Q_{5}$ \\
Locais (L) & $P-1$ & $Q_{2}$ & $\sigma_{e}^{2}+i \sigma_{j: p}^{2}+i j V_{p}$ & $Q_{2} / Q_{4}$ \\
G X L & $(I-1)(P-1)$ & $Q_{3}$ & $\sigma_{e}^{2}+j V_{i p}$ & $Q_{3} / Q_{5}$ \\
Blocos/L & $(J-1) P$ & $Q_{4}$ & $\sigma_{e}^{2}+i \sigma_{j: p}^{2}$ & $Q_{4} / Q_{5}$ \\
Resíduo Médio & $(I-1)(J-1) P$ & $Q_{5}$ & $\sigma_{e}^{2}$ & \\
\hline Total & IJP - 1 & & & \\
\hline
\end{tabular}


Tabela 9. Esquema de análise dos efeitos de grupos de maturidade, efeitos de locais e de interação Grupos de Maturidade $x$ Locais entre as médias de cada caráter avaliado nos três grupos de maturidade e três locais.

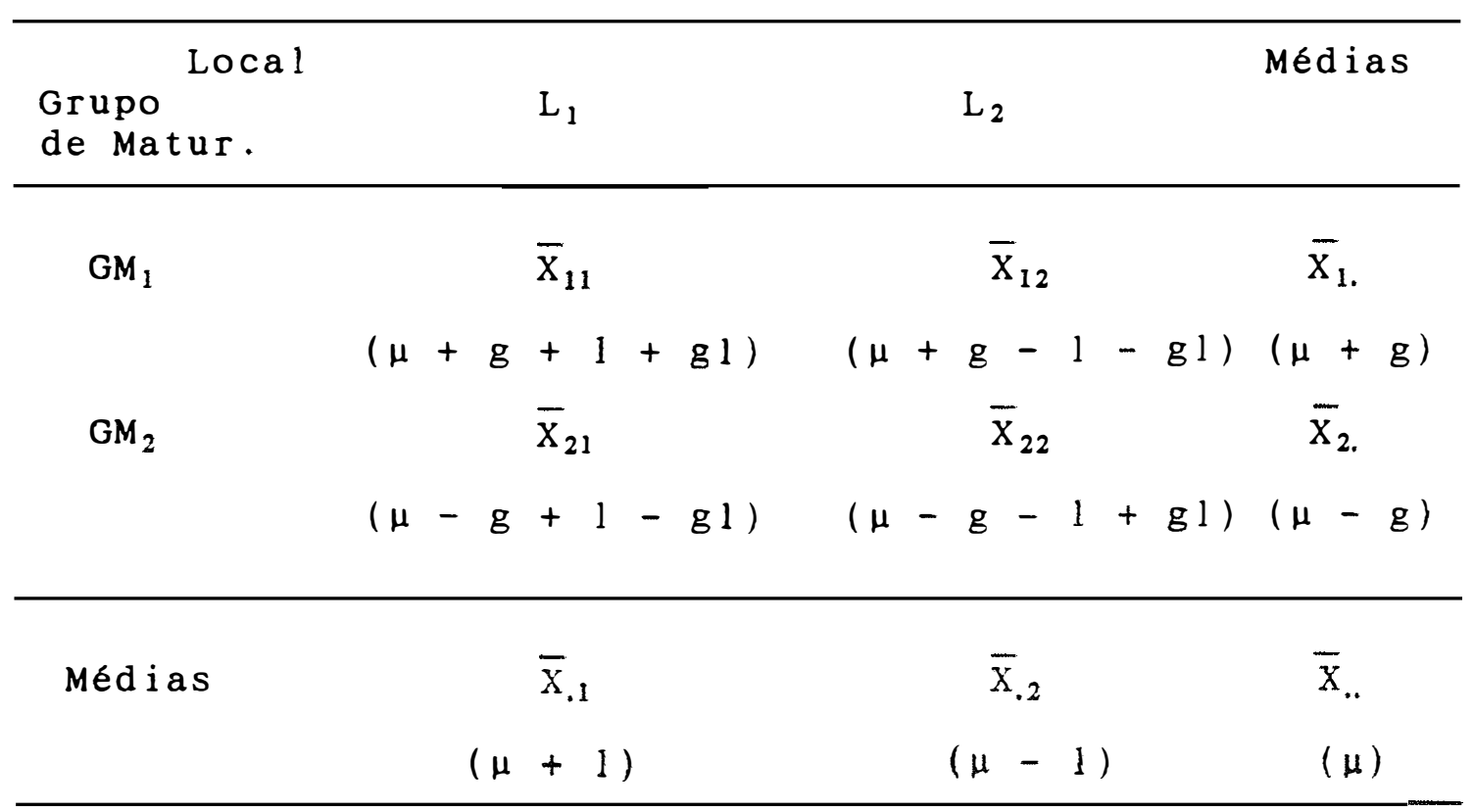


Tabela 10. Grupo de maturidade precoce: valores e significância dos quadrados médios obtidos da análise da variância de três caracteres das testemunhas. Soja, semeadura entre $30 / 11$ e $11 / 12 / 84$; em dois locais

\begin{tabular}{|c|c|c|c|c|c|}
\hline \multirow{2}{*}{$\begin{array}{l}\text { Fontes } \\
\text { de } \\
\text { Variação }\end{array}$} & \multirow{2}{*}{ GL } & \multicolumn{4}{|c|}{ Quadrados Médios dos Caracteres } \\
\hline & & $\begin{array}{l}\mathrm{NDF}^{\mathrm{a}} \\
\text { dias }\end{array}$ & $\begin{array}{l}\mathrm{APF}^{\mathrm{a}} \\
\mathrm{cm}\end{array}$ & $\begin{array}{l}\text { NDM } \\
\text { dias }\end{array}$ & \\
\hline Test emunhas $(\mathrm{T})$ & 2 & $360.27085 * *$ & $589.1458 * *$ & 95.0625 & ** \\
\hline Conjuntos (C) & 3 & $2.00000 \mathrm{~ns}$ & $15.2500 \mathrm{~ns}$ & 8.1875 & ns \\
\hline Locais $(\mathrm{L})$ & 1 & $12.00000 \mathrm{~ns}$ & $1323.0000 *$ & 2394.1875 & ** \\
\hline Blocos (B)/L & 2 & $0.75000 \mathrm{~ns}$ & $80.0417 \mathrm{~ns}$ & 7.6875 & ns \\
\hline $\mathrm{T} \times \mathrm{C}$ & 6 & $0.18750 \mathrm{~ns}$ & $36.9792 \mathrm{~ns}$ & 6.3958 & ns \\
\hline $\mathrm{B} \times \mathrm{C} / \mathrm{L}$ & 6 & $0.97222 \mathrm{~ns}$ & $61.4306 \mathrm{~ns}$ & 7.6875 & ns \\
\hline $\mathrm{T} \times \mathrm{B} / \mathrm{L}$ & 4 & $0.68750 \mathrm{~ns}$ & $23.5417 \mathrm{~ns}$ & 2.6875 & ns \\
\hline $\mathrm{T} \times \mathrm{L}$ & 2 & $16.18750 * *$ & 132.4375 ns & 23.8125 & $*$ \\
\hline$C \times L$ & 3 & $4.55557 *$ & $45.7222 \mathrm{~ns}$ & 1.5764 & ns \\
\hline $\mathrm{T} \times \mathrm{C} \times \mathrm{L}$ (Resíduo 2) & 6 & $0.82638 \mathrm{~ns}$ & $29.4931 \mathrm{~ns}$ & 3.7014 & ns \\
\hline$T \times B \times C / L$ (Resíduo 1) & 12 & 0.90972 & 23.7639 & 11.0208 & \\
\hline $\begin{array}{l}\text { Média }(\overline{\mathrm{X}}) \\
\mathrm{CV}_{1}(\%) \\
\mathrm{CV}_{2}(\%)\end{array}$ & & $\begin{array}{r}58.60 \\
1.63 \\
1.55\end{array}$ & $\begin{array}{l}44.00 \\
11.07 \\
12.33\end{array}$ & $\begin{array}{r}120.30 \\
2.76 \\
1.60\end{array}$ & \\
\hline
\end{tabular}

* e **: Significativo a $5 \%$ e $1 \%$ de probabilidade, pelo teste $\mathrm{F}$, respect ivamente

ns : Não significativo

NDF : Número de dias para florescimento

APF : Altura da planta no florescimento

NDM : Número de dias para maturidade

a : Locais: ESALQ E Sertãozinho

b : Locais: Anhembi e Sertãozinho. 
Tabela 11. Grupo de maturidade precoce: valores e significância dos quadrados médios obtidos da análise da variância de sete caracteres das testemunhas. Soja, semeadura entre $30 / 11$ e $11 / 12 / 84$. Locais : Anhembi, ESALQ, Sertãozinho.

\begin{tabular}{|c|c|c|c|c|c|c|c|c|}
\hline \multirow{2}{*}{$\begin{array}{c}\text { Fontes } \\
\text { de } \\
\text { Variação }\end{array}$} & \multirow{2}{*}{ GL - } & \multicolumn{7}{|c|}{ Quadrados Médios dos Caracteres } \\
\hline & & $\begin{array}{l}\text { APW } \\
\text { CE }\end{array}$ & $\begin{array}{c}\text { Ac } \\
\text { notas }\end{array}$ & $\begin{array}{r}\text { AIV } \\
\text { CI }\end{array}$ & $\begin{array}{c}\mathrm{VA} \\
\text { notas }\end{array}$ & $\begin{array}{l}\mathrm{PG} \\
\mathrm{Kg} / \mathrm{hg}\end{array}$ & $80 \mathrm{~L}$ & $\begin{array}{c}\text { PO } \\
\text { Ig/ha }\end{array}$ \\
\hline Testeaunhas (T) & 2 & 2608.1806 & 0.108624 & $790.1250 \$$ & $0.839851 \$$ & $1368493.60 \$$ & $1.39389 \mathrm{~ns}$ & $84316.75 \$$ \\
\hline Conjuntos (C) & 3 & $26.0140 \mathrm{~ns}$ & $0.001037 \mathrm{~ns}$ & $11.500 \mathrm{~ns}$ & $0.002371 \mathrm{~ns}$ & $58368.27 \mathrm{~ns}$ & $0.50704 \mathrm{~ns}$ & $5170.30 \mathrm{~ns}$ \\
\hline Locais (L) & 2 & $1069.4306 \$$ & 0.026578 & $129.500 \mathrm{~ns}$ & $0.131745 \mathrm{~ns}$ & $5939759.10 *$ & $6.76848 \mathrm{~ns}$ & $365515.59 \$$ \\
\hline Blocos $(B) / L$ & 3 & $66.0695 \mathrm{~ns}$ & $0.001971 \mathrm{~ns}$ & $53.2222 \mathrm{~ns}$ & 0.012038 & $239892.25 \mathrm{~ns}$ & $1.47806 \mathrm{~ns}$ & $11039.90 \mathrm{~ns}$ \\
\hline$I \times C$ & 6 & $31.2917 \mathrm{~ns}$ & $0.002229 \mathrm{~ns}$ & $11.4583 \mathrm{~ns}$ & $0.005917 \mathrm{~ns}$ & $113487.17 \mathrm{~ns}$ & $0.18093 \mathrm{~ns}$ & $5094.41 \mathrm{~ns}$ \\
\hline $\mathrm{B} I \mathrm{C} / \mathrm{L}$ & 9 & $60.2176 \mathrm{~ns}$ & $0.004872 \mathrm{~ns}$ & $26.6667+$ & $0.002992 \mathrm{~ns}$ & $169075.10 \mathrm{~ns}$ & $0.43324 \mathrm{~ns}$ & $10333.33 \mathrm{~ns}$ \\
\hline$I \perp B / L$ & 6 & $43.5694 \mathrm{~ns}$ & $0.002183 \mathrm{~ns}$ & $11.6805 \mathrm{~ns}$ & 0.013497 & $71126.33 \mathrm{~ns}$ & $0.54389 \mathrm{~ns}$ & $3936.76 \mathrm{~ns}$ \\
\hline$I \geq L$ & 4 & $55.5972 \mathrm{~ns}$ & 0.020470 & $26.7000 \mathrm{~ns}$ & $0.019653 \mathrm{~ns}$ & $1076878.10 \$$ & $1.491805 *$ & $63865.76 \neq$ \\
\hline$C \perp L$ & 6 & $20.8750 \mathrm{~ns}$ & $0.001312 \mathrm{~ns}$ & $10.3889 \mathrm{~ns}$ & 0.041509 & $197062.62 \mathrm{~ns}$ & 1.26329 & 6685.65 ns \\
\hline $\begin{array}{l}\text { TIICI L } \\
\text { (Residuo 2) }\end{array}$ & 12 & $55.9861 \mathrm{~ns}$ & $0.004824 \mathrm{~ns}$ & $14.1389 \mathrm{~ns}$ & 0.015775 & $157548.53 \mathrm{~ns}$ & $0.42634 \mathrm{~ns}$ & $7481.92 \mathrm{~ns}$ \\
\hline $\begin{array}{l}\text { T \& B \& C/L } \\
\text { (Residuo } 1 \text { ) }\end{array}$ & 18 & 32.9398 & $0.00775 !$ & 8.6806 & 0.005018 & 142828.72 & 0.33300 & 5223.28 \\
\hline Média $(\bar{X})$ & & 57.00 & 1.46 & 14. & $2.0 \mathrm{~J}$ & 2373.00 & 22.83 & 537.90 \\
\hline $\mathrm{CV}_{1}(\mathrm{x})$ & & 10.07 & 6.00 & 19.97 & 3.50 & 15.91 & 2.53 & 13.43 \\
\hline $\mathrm{CV}_{2}(x)$ & & 13.13 & 4.76 & 25.49 & 6.20 & 16.73 & 2.86 & 16.08 \\
\hline
\end{tabular}

\& e \$2, significativo a $5 \%$ e 1 de probabilidade, pelo teste $F$, respectivanente

ns : não significativo

APM : al tura da planta na aturidade

Ac : acanamento

AIV : altura da inserçâo da primeira vagen

$V A$ : valor agronôrico

PG a produtividade de grâos

\$OL : porcentage de oleo

PO : produtividade de oleo 
Tabela 12. Grupo de maturidade intermediário: valores e significância dos quadrados médios obtidos da análise da variância de três caracteres das testemunhas. Soja, semeadura entre 04/12 e $11 / 12 / 84$, em dois locais.

\begin{tabular}{|c|c|c|c|c|}
\hline \multirow{2}{*}{$\begin{array}{c}\text { Fontes } \\
\text { de } \\
\text { Variação }\end{array}$} & \multirow[b]{2}{*}{ GL } & \multicolumn{3}{|c|}{ Quadrados Médios dos Caracteres } \\
\hline & & $\begin{array}{l}\text { NDF } \\
\text { dias }\end{array}$ & $\begin{array}{l}\mathrm{APF} \\
\mathrm{cm}\end{array}$ & $\begin{array}{l}\text { NDM } \\
\text { dias }\end{array}$ \\
\hline Testemunhas $(\mathrm{T})$ & 2 & $126.77780 * *$ & $250.0278 \mathrm{~ns}$ & $178.5833 * *$ \\
\hline Conjuntos (C) & 2 & $1.02780 \mathrm{~ns}$ & $40.1944 \mathrm{~ns}$ & $0.2500 \mathrm{~ns}$ \\
\hline Locais $(\mathrm{L})$ & 1 & $56.25000 *$ & $2934.0278 *$ & $2352.2500 * *$ \\
\hline Blocos (B)/L & 2 & $0.13890 \mathrm{~ns}$ & $105.1389 *$ & $1.3611 \mathrm{~ns}$ \\
\hline $\mathrm{T} \times \mathrm{C}$ & 4 & $3.15278 \mathrm{~ns}$ & $189.1944 \mathrm{~ns}$ & $0.5834 \mathrm{~ns}$ \\
\hline $\mathrm{B} \times \mathrm{C} / \mathrm{L}$ & 4 & $3.80555 \mathrm{~ns}$ & $10.1389 \mathrm{~ns}$ & $2.4444 \mathrm{~ns}$ \\
\hline $\mathrm{T} \times \mathrm{B} / \mathrm{L}$ & 4 & $1.55555 \mathrm{~ns}$ & $58.1389 \mathrm{~ns}$ & $2.1944 \mathrm{~ns}$ \\
\hline $\mathrm{T} \times \mathrm{L}$ & 2 & $2.33335 \mathrm{~ns}$ & $66.6944 \mathrm{~ns}$ & $0.2500 \mathrm{~ns}$ \\
\hline$C \times L$ & 2 & $2.58335 \mathrm{~ns}$ & $175.8611 \mathrm{~ns}$ & $2.0833 \mathrm{~ns}$ \\
\hline $\mathrm{T} \times \mathrm{C} \times \mathrm{L}$ (Resíduo 2) & 4 & $3.04165 \mathrm{~ns}$ & $95.0278 \mathrm{~ns}$ & $0.5834 \mathrm{~ns}$ \\
\hline $\mathrm{T} \times \mathrm{B} \times \mathrm{C} / \mathrm{L}($ Resíduo 1 ) & 8 & 1.84722 & 47.3889 & 2.5278 \\
\hline $\begin{array}{l}\text { Média }(\bar{X}) \\
\mathrm{CV}_{1}(\%) \\
\mathrm{CV}_{2}(\%)\end{array}$ & & $\begin{array}{c}66.50 \\
2.04 \\
2.62\end{array}$ & $\begin{array}{l}64.50 \\
15.96 \\
22.13\end{array}$ & $\begin{array}{c}124.10 \\
1.28 \\
0.62\end{array}$ \\
\hline
\end{tabular}

* e **: Significativo a $5 \%$ e $1 \%$ de probabilidade, pelo teste $\mathrm{F}$ respect i vamente

ns : Não significativo

NDF : Número de dias para florescimento

APF : Altura da planta no florescimento

NDM : Número de dias para maturidade

a : Locais: ESALQ e Sertãozinho

b : Locais: Anhembi e Sertãozinho. 
Tabela 13. Grupo de maturidade intermediário: valores e significância dos quadrados médios obtidos da análise da variância de sete caracteres das testemunhas. Soja, semeadura entre $04 / 12$ e $11 / 12 / 84$. Locais: Anhembi, ESALQ, Sertãozinho.

\begin{tabular}{|c|c|c|c|c|c|c|c|c|}
\hline \multirow{2}{*}{$\begin{array}{c}\text { Fontes } \\
\text { de } \\
\text { Variação }\end{array}$} & \multirow{2}{*}{ GL } & \multicolumn{7}{|c|}{ Quadrados Védios dos Caracteres } \\
\hline & & $\begin{array}{l}\text { APM } \\
\text { CI }\end{array}$ & $\begin{array}{c}\text { Ac } \\
\text { notas }\end{array}$ & $\begin{array}{r}\text { AIV } \\
\text { CI }\end{array}$ & $\begin{array}{c}\text { Vh } \\
\text { notas }\end{array}$ & $\begin{array}{c}P G \\
\mathrm{Rg} / \mathrm{ha}\end{array}$ & 30 & $\begin{array}{c}\text { PO } \\
\mathrm{Xg} / \mathrm{ha}\end{array}$ \\
\hline Testenonhas ( $\mathrm{T}$ ) & 2 & 349.5555 ns & $0.004898 \mathrm{~ns}$ & $62.1667 \mathrm{~ns}$ & $0.006884 \mathrm{~ns}$ & $73847.10 \mathrm{~ns}$ & 3.28074 ns & $2314.28 \mathrm{~ns}$ \\
\hline Conjuntos $(\mathrm{C})$ & 2 & $5.0555 \mathrm{~ns}$ & $0.001813 \mathrm{~ns}$ & 10.1667 ns & $0.001211 \mathrm{~ns}$ & $23604.35 \mathrm{~ns}$ & $0.44241 \mathrm{~ns}$ & $1366.68 \mathrm{~ns}$ \\
\hline Locais (L) & 2 & $2123.5560 *$ & $0.167802 \mathrm{~ns}$ & $358.2222 \$$ & $0.073986 \mathrm{~ns}$ & $2781378.85 \approx$ & $20.46352 \$$ & 217460.59 \\
\hline Blocos $(B) / L$ & 3 & 215.4815 ns & $0.122491 \mathrm{~ns}$ & $7.3333 \mathrm{~ns}$ & 0.032918 & $7239.91 \mathrm{~ns}$ & $0.16093 \mathrm{~ns}$ & $465.59 \mathrm{~ns}$ \\
\hline$T \perp C$ & 4 & $73.4444 \mathrm{nS}$ & $0.083636 \mathrm{~ns}$ & $74.7500 \mathrm{~ns}$ & $0.011366 \mathrm{~ns}$ & $76486.23 \mathrm{~ns}$ & $0.39435 \mathrm{~ns}$ & 3821.08 ns \\
\hline $\mathrm{B} \times \mathrm{C} / \mathrm{L}$ & 6 & $92.7592 \mathrm{~ns}$ & $0.026934 \mathrm{~ns}$ & 14.4444 ns & $0.004115 \mathrm{~ns}$ & $219331.34 \mathrm{~ns}$ & $0.36148 \mathrm{~ns}$ & $8818.40 \mathrm{~ns}$ \\
\hline$T \mp B / L$ & 6 & $57.4815 \mathrm{~ns}$ & $0.014662 \mathrm{~ns}$ & $14.8333 \mathrm{nS}$ & $0.005525 \mathrm{~ns}$ & $64593.18 \mathrm{~ns}$ & $0.61037 \mathrm{~ns}$ & $5452.80 \mathrm{~ns}$ \\
\hline$T I L$ & 4 & $19.1111 \mathrm{~ns}$ & $0.015143 \mathrm{~ns}$ & $16.0556 \mathrm{~ns}$ & $0.022510 \$$ & $423563.73 \mathrm{~ns}$ & $1.11796 \mathrm{~ns}$ & $20469.16 \mathrm{~ns}$ \\
\hline$C \& L$ & 4 & $40.6111 \mathrm{~ns}$ & $0.047866 \mathrm{~ns}$ & $9.4722 \mathrm{~ns}$ & $0.000753 \mathrm{~ns}$ & $61626.53 \mathrm{~ns}$ & $0.42380 \mathrm{~ns}$ & $6271.45 \mathrm{~ns}$ \\
\hline $\begin{array}{l}\text { I } \subset \subset \text { I L } \\
\text { (Residuo 2) }\end{array}$ & 8 & $87.2500 \mathrm{~ns}$ & $0.025336 \mathrm{~ns}$ & $5.0139 \mathrm{~ns}$ & $0.001628 \mathrm{~ns}$ & $175421.88 \mathrm{~ns}$ & $0.31783 \mathrm{~ns}$ & $10968.95 \mathrm{~ns}$ \\
\hline $\begin{array}{l}I \perp B \perp C / L \\
\text { (Residuo L) }\end{array}$ & 12 & 31.7593 & 0.039300 & 27.4444 & 0.010965 & 99101.72 & 0.27093 & 5707.66 \\
\hline Média $(\bar{X})$ & & 80.70 & 1.65 & 21.22 & 2.23 & 2509.00 & 22.81 & 572.30 \\
\hline $\mathrm{CV}_{1}(\mathrm{n})$ & & 7.00 & 12.03 & 24.69 & 4.69 & 12.55 & 2.28 & 13.20 \\
\hline $\mathrm{Cl}_{2}(\mathrm{H})$ & & 11.58 & 9.66 & 10.55 & 1.81 & 16.70 & 2.47 & 18.30 \\
\hline
\end{tabular}

* e $\$$ : significativo a $5 \%$ e 1 de probabilidade, pelo teste $F$ respectivanente

ns : não significativo

APH : altura da planta na aturidade

Ac : acananento

AIV : altura da inserção da prineira vagea

VA : valor agronôrico

PG : produtividade de grãos

\$OL : porcentage de bleo

PO : produtividade de bleo 
Tabela 14. Grupo de maturidade tardio: valores e significância dos quadrados médios obtidos da analise da variância de três caracteres das testemunhas. Soja, semeadura entre 04/12 e 12/12/84, em dois locais:

\begin{tabular}{|c|c|c|c|c|}
\hline \multirow{2}{*}{$\begin{array}{l}\begin{array}{l}\text { Fontes } \\
\text { de }\end{array} \\
\text { Variação }\end{array}$} & \multirow{2}{*}{ G L- } & \multicolumn{3}{|c|}{ Quadradros Médios dos Caracteres } \\
\hline & & dias $^{\mathbf{a}}$ & $\begin{array}{l}\mathrm{APF} \\
\mathrm{cm}\end{array}$ & $\begin{array}{c}\mathrm{b} \\
\mathrm{VA} \\
\text { dias }\end{array}$ \\
\hline Testemunhas $(\mathrm{T}\rangle$ & 2 & $233.79165 * *$ & $1338.1667 \mathrm{~ns}$ & $0.005395 \mathrm{~ns}$ \\
\hline Conjuntos (C) & 1 & $9.37500 \mathrm{~ns}$ & $48.1667 \mathrm{~ns}$ & $0.000051 \mathrm{~ns}$ \\
\hline Locais (L) & 1 & $51.04170 \mathrm{~ns}$ & $28.1667 \mathrm{~ns}$ & $0.172551 \mathrm{~ns}$ \\
\hline Blocos (B) /L & 2 & $6.04167 \mathrm{~ns}$ & $62.1667 \mathrm{~ns}$ & $0.021012 * *$ \\
\hline $\mathrm{T} \times \mathrm{C}$ & 2 & 7.6250 ns & $325.1667 \mathrm{~ns}$ & $0.007274 \mathrm{~ns}$ \\
\hline$B \times C / L$ & 2 & $5.20834 \mathrm{~ns}$ & $360.1667 \mathrm{~ns}$ & $0.000037 \mathrm{~ns}$ \\
\hline $\mathrm{T} \times \mathrm{B} / \mathrm{L}$ & 4 & $12.29167 \mathrm{~ns}$ & $440.1667 \mathrm{~ns}$ & $0.011491 \mathrm{~ns}$ \\
\hline$T \times L$ & 2 & $21.79165 \mathrm{~ns}$ & $38.1667 \mathrm{~ns}$ & $0.040354 *$ \\
\hline$C \times L$ & 1 & $2.04170 \mathrm{~ns}$ & $37.5000 \mathrm{~ns}$ & $0.003105 \mathrm{~ns}$ \\
\hline T $\times C \times L$ (Resíduo 2) & 2 & $14.29165 \mathrm{~ns}$ & $486.5000 \mathrm{~ns}$ & $0.000633 \mathrm{~ns}$ \\
\hline $\mathrm{T} \times \mathrm{B} \times \mathrm{C} / \mathrm{L}$ (Resíduo 1) & 4 & 10.45833 & 247.1667 & 0.003892 \\
\hline $\begin{array}{l}\text { Média }(\bar{X}) \\
\mathrm{CV}_{1}(\%) \\
\mathrm{CV}_{2}(\%)\end{array}$ & & $\begin{array}{r}75.00 \\
4.31 \\
5.04\end{array}$ & $\begin{array}{l}81.40 \\
19.31 \\
27.09\end{array}$ & $\begin{array}{l}2.06 \\
3.03 \\
1.22\end{array}$ \\
\hline
\end{tabular}

* e **: Significativo a $5 \%$ e $1 \%$ de probabilidade, pelo teste $\mathrm{F}$ respect ivamente

ns : Não significativo

NDF : Número de dias para florescimento

APF : Altura da planta no florescimento

VA : Valor Agronômico

a : Locais: ESALQ, Sertãozinho

b : Locais: Anhembi, ESALQ 
Tabela 15. Grupo de maturidade tardio: valores e significância dos quadrados médios obtidos das análises da variância de sete caracteres das testemunhas. Soja, semeadura entre 04/12 e 12/12/84. Locais: Anhembi, ESALQ, Sertãozinho.

\begin{tabular}{|c|c|c|c|c|c|c|c|c|}
\hline \multirow{2}{*}{$\begin{array}{l}\text { Fontes } \\
\text { de } \\
\text { Variação }\end{array}$} & \multirow{2}{*}{ GL } & \multicolumn{7}{|c|}{ Quadrados Médios dos Caracteres } \\
\hline & & $\begin{array}{l}\text { Non } \\
\text { dias }\end{array}$ & $\begin{array}{l}\text { APY } \\
\text { CI }\end{array}$ & $\begin{array}{c}\text { Ac } \\
\text { notas }\end{array}$ & $\begin{array}{l}\text { AIV } \\
\text { CI }\end{array}$ & $\begin{array}{c}P G \\
K_{B} / h_{a}\end{array}$ & $\$$ & $\begin{array}{c}P_{0} \\
K_{g} / \mathrm{ha}\end{array}$ \\
\hline Testenunhas $(T)$ & 2 & $137.6944 \mathrm{~ns}$ & 922.3333 ns & $1.015274 \$$ & 233.3611 & $79780.20 \mathrm{~ns}$ & $3.64000 *$ & $13011.96 \mathrm{~ns}$ \\
\hline Conjuntos $(C)$ & 1 & 10.0277 ns & $40.1111 \mathrm{~ns}$ & $0.009506 \mathrm{~ns}$ & $14.6944 \mathrm{~ns}$ & $13.40 \mathrm{~ns}$ & 0.02717 ns & $53.78 \mathrm{~ns}$ \\
\hline Locais (L) & 2 & $431.1944 *$ & $1230.2500 *$ & $0.254499 \mathrm{~ns}$ & $334.3611 *$ & $2367391.00 \approx \$$ & 2.80750 & 91783.74 ns \\
\hline Blocos $(\mathrm{B}) / \mathrm{L}$ & 3 & 23.9166 ns & 119.1666 ns & $0.008367 \mathrm{~ns}$ & 17.8056 ns & 24816.29 ns & $0.18833 \mathrm{~ns}$ & $718.10 \mathrm{~ns}$ \\
\hline$T \geq C$ & 2 & 31.8612 ns & 318.7778 ns & $0.042043 \mathrm{~ns}$ & $0.3611 \mathrm{~ns}$ & $95061.35 \mathrm{~ns}$ & $0.15444 \mathrm{~ns}$ & $5322.28 \mathrm{~ns}$ \\
\hline $\mathrm{B} \perp \mathrm{C} / \mathrm{L}$ & 3 & 11.5834 ns & 433.7223 ns & $0.012470 \mathrm{~ns}$ & $14.7000 \mathrm{~ns}$ & $29325.93 \mathrm{~ns}$ & $0.86278 \mathrm{~ns}$ & 3689.37 ns \\
\hline$T \simeq B / L$ & 6 & 41.5000 ns & 470.8333 ns & $0.036593 \mathrm{~ns}$ & $6.6389 \mathrm{~ns}$ & $93540.86 \mathrm{~ns}$ & $0.51750 \mathrm{~ns}$ & $4136.69 \mathrm{~ns}$ \\
\hline$T \& L$ & 4 & 61.4828 ns & 89.5834 ns & $0.096303 \mathrm{~ns}$ & 32.0278 ns & 35052.88 ns & $0.06625 \mathrm{~ns}$ & $1205.35 \mathrm{~ns}$ \\
\hline$C I L$ & 2 & $31.3612 \mathrm{~ns}$ & 47.1944 ns & $0.044593 \mathrm{~ns}$ & 2.0278 ns & 7591.05 ns & $0.15528 \mathrm{~ns}$ & 8333.39 ns \\
\hline $\begin{array}{l}T \times C \times L \\
\text { (Resíduo 2) }\end{array}$ & 4 & 37.8194 ns & $361.8611 \mathrm{~ns}$ & $0.033499 \mathrm{~ns}$ & 17.1944 ns & $70414.95 \mathrm{~ns}$ & $0.72570 \mathrm{~ns}$ & $5433.76 \mathrm{~ns}$ \\
\hline $\begin{array}{l}T I B \text { I I C/L } \\
\text { (Resíduo } 1 \text { ) }\end{array}$ & 6 & 35.1666 & 270.0655 & 0.034793 & 14.1944 & 139320.36 & 0.81861 & 9219.83 \\
\hline Média $(\bar{X})$ & & 138.20 & 84.80 & 1.91 & 22.36 & 2694.00 & 21.90 & 589.70 \\
\hline $\mathrm{CV}_{1}(\mathrm{x})$ & & 4.29 & 19.37 & 9.73 & 17.75 & 19.85 & 4.13 & 16.28 \\
\hline $\mathrm{CV}_{2}(\mathrm{x})$ & & 4.45 & 22.42 & 9.55 & 19.54 & 9.85 & 3.90 & 12.50 \\
\hline
\end{tabular}

* e 7*: significativo a $5 \%$ e $1 \%$ de probabilidade, pelo teste $F$ respectivanente

ns : não significativo

NoM : número de dias para naturidade

APW : altura da planta na aturidade

Ac : acananto

AIV : altura de inserção da prineira vage

PG : produtividade de gräos

YOL : porcentage de óleo

PO : produtividade de óleo 
Tabela 16. Grupo de maturidade precoce: valores e significância dos quadrados médios obtidos da análise da variancia de oi to caracteres. Soja, semeadura $11 / 12 / 84$. Local: Anhembi.

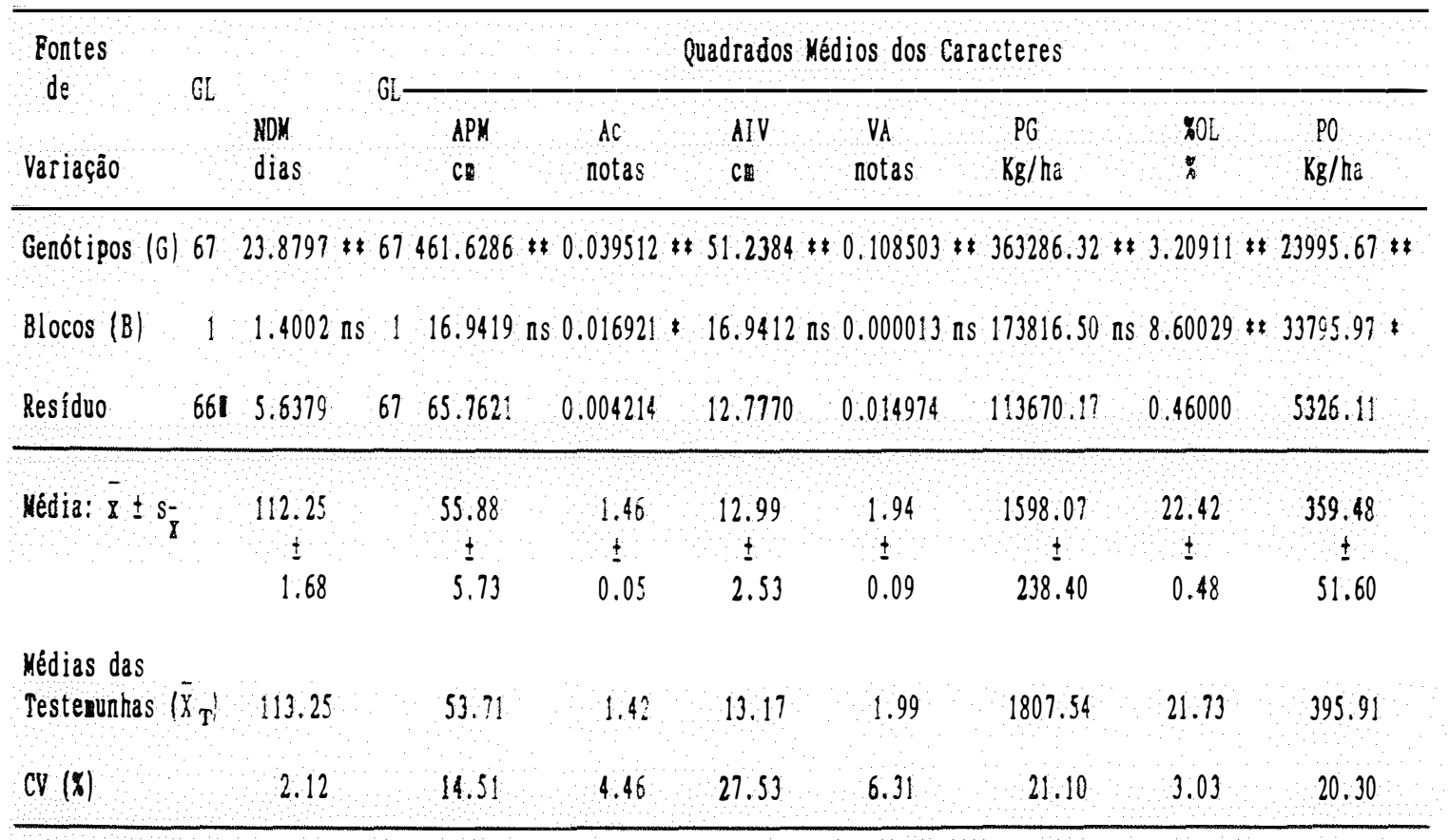

te ta significativo a sh e $1 \%$ de probabilidade pelo terte $F$, respectivanente.

ns, não significativo

NOM : núnero de dias para naturidade

APH : altura da planta na naturidade

Ac acananento

AIV : altura de inserçâo da prineira vagen

VA valor agronônico

PG : produtividade de grâo

\$OL : porcentage de óleo

PO : produtividade de 6 leo

1. substração de un grau de liberdade por parcela perdida (repetição 1 do genótipo no 48) para o caráter NDY 
Tabela 17. Grupo de maturidade precoce: Valores e signficância dos quadrados médios obtidos da análise da variância de dois caracteres. Soja, Semeadura $30 / 11 / 84$. Local: ESALQ.

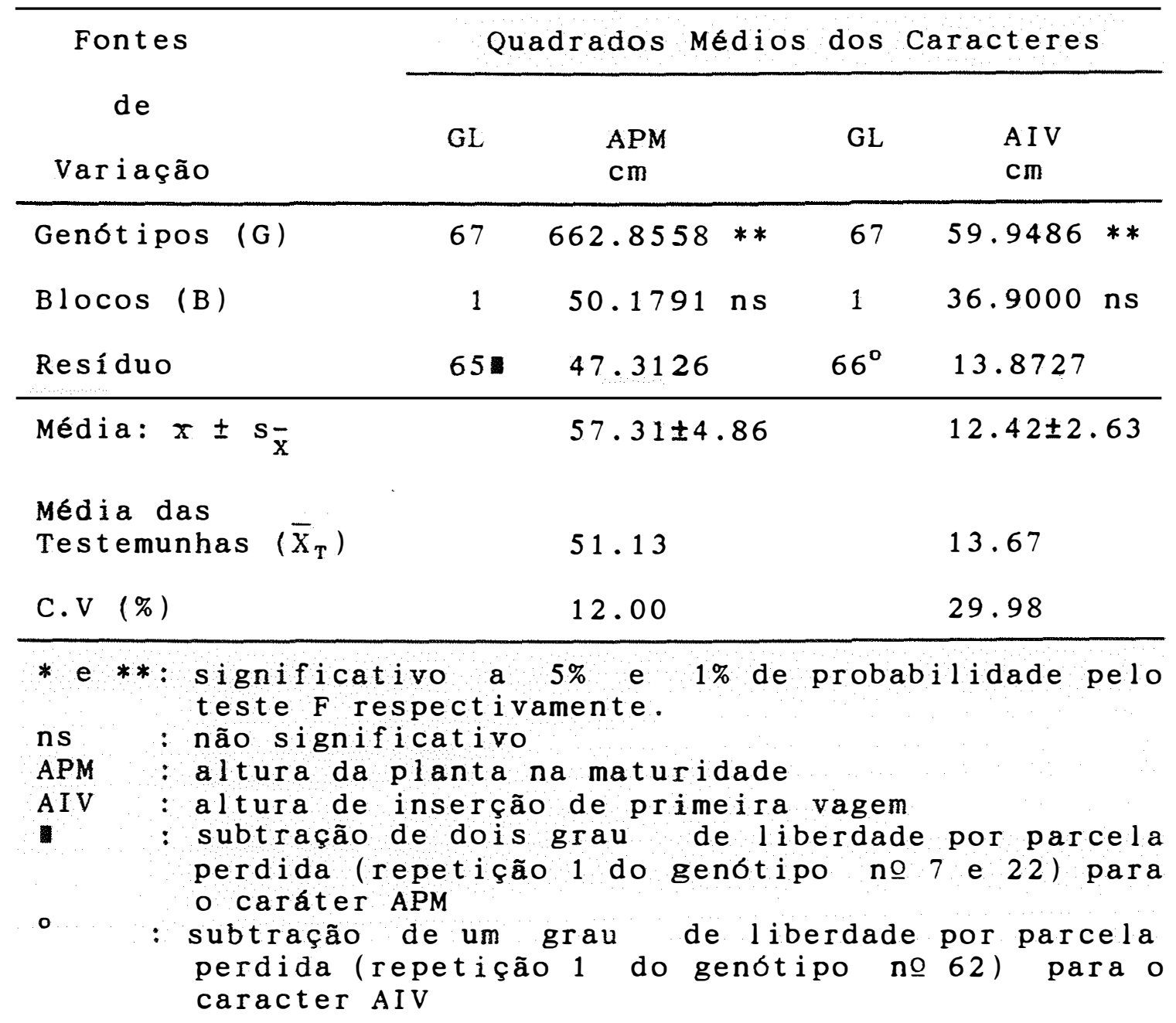


Tabela 18. Grupo de maturidade precoce: valores e significância dos quadrados médios obtidos da análise da variância de sete caracteres. Soja, semeadura 30/11/84. Loca 1: ESALQ.

\begin{tabular}{|c|c|c|c|c|c|c|c|c|c|}
\hline \multirow{2}{*}{$\begin{array}{l}\begin{array}{c}\text { Fontes } \\
\text { de }\end{array} \\
\text { Variação }\end{array}$} & \multicolumn{9}{|c|}{ Quadrados Médios dos Caracteres } \\
\hline & GL & $\begin{array}{l}\text { NDF } \\
\text { dias }\end{array}$ & $\begin{array}{l}\mathrm{APF} \\
\mathrm{C}\end{array}$ & GL & $\begin{array}{c}\text { Ac } \\
\text { notas }\end{array}$ & $\begin{array}{l}\text { VA } \\
\text { notas }\end{array}$ & $\begin{array}{c}\mathrm{PG} \\
\mathrm{Kg} / \mathrm{ha}\end{array}$ & 800 & $\begin{array}{l}\mathrm{PO} \\
\mathrm{Bg} / \mathrm{ha}\end{array}$ \\
\hline Genbtipos $(G)$ & 661 & $63.99276 \#$ & $152.8673 \approx *$ & 67 & 0.176052 & $0.052290 * *$ & $345023.80 \mathrm{~ns}$ & 3.83238 & $22461.45 *$ \\
\hline Blocos (B) & 1 & 0.74627 ns & $134.0000 *$ & 1 & $0.156333 \neq$ & $0.014330 \mathrm{~ns}$ & $3162240.03 \approx$ & 0.59559 ns & 150408.64 \\
\hline Resíduo & 661 & 2.41294 & 23.0455 & 67 & 0.029143 & 0.017313 & 247565.87 & 0.34305 & 13957.69 \\
\hline \multirow{2}{*}{\multicolumn{2}{|c|}{ Média: $\bar{I} \pm s_{\bar{y}}$}} & 57.10 & 37.40 & & 1.57 & 1.94 & 2223.96 & 23.51 & 520.94 \\
\hline & & \pm & $\stackrel{ \pm}{1.39}$ & & \pm & $\begin{array}{c} \pm \\
0.09\end{array}$ & $\stackrel{ \pm}{ \pm}$ & $\begin{array}{c} \pm \\
0.41\end{array}$ & $\begin{array}{c} \pm \\
83.54\end{array}$ \\
\hline \multicolumn{2}{|c|}{$\begin{array}{l}\text { Yédias das } \\
\text { Testenunhas }\left(\bar{x}_{T}\right)\end{array}$} & 59.08 & 38.7 & & 1.48 & 1.98 & 2568.17 & 23.41 & 601.59 \\
\hline $\operatorname{C.V}(\mathbf{x})$ & & 2.72 & 12.83 & & 10.87 & 6.78 & 22.37 & 2.49 & 22.68 \\
\hline
\end{tabular}

* e \$: significativo a 5\% e 1 de probabilidade pelo teste $F$, respectivanente.

ns : não significativo

NDF : número de dias para florescinento

APF : al tura da planta no florescinento

Ac : acamanto

$V A$ : valor agronônico

PG : produtividade de grâo

WOL : porcentager de óleo

Po : produtividade de óleo

1 : 0 genbtipo no 31 foi perdido nas duas repetiçôes para os caracteres: NDF e fDF. 
Tabela 19. Grupo de maturidade precoce: valores e significância dos quadrados médios obtidos da análise da variância de dez caracteres. Soja, semea dura 05/12/84. Local: Sertãozinho.

\begin{tabular}{|c|c|c|c|c|c|c|c|c|c|c|c|}
\hline \multirow{2}{*}{$\begin{array}{l}\text { Fontes } \\
\text { de } \\
\text { Variaçâo }\end{array}$} & \multirow{2}{*}{ GL } & \multicolumn{10}{|c|}{ Quadrados Médios dos Caracteres } \\
\hline & & $\begin{array}{l}\text { NDE } \\
\text { dias }\end{array}$ & $\begin{array}{l}\text { APF } \\
\text { CI }\end{array}$ & $\begin{array}{l}\text { NOM } \\
\text { dias }\end{array}$ & $\begin{array}{l}\text { APY } \\
\text { CI }\end{array}$ & $\begin{array}{l}\text { Ac } \\
\text { notas }\end{array}$ & $\begin{array}{l}\text { AIV } \\
\text { CII }\end{array}$ & $\begin{array}{l}V_{A} \\
\text { notas }\end{array}$ & $\begin{array}{l}P G \\
\mathrm{Kg} / \mathrm{ha}\end{array}$ & $80 \mathrm{~L}$ & $\begin{array}{l}\mathrm{PO} \\
\mathrm{Kg} / \mathrm{ha}\end{array}$ \\
\hline \multicolumn{2}{|l|}{ Genótipos $(G) 6$} & $43.62438 \$$ & $158.7051 * \$$ & $6747.8282 \neq \$$ & $613.1677 *$ & $0.133824 \$$ & $108.9069 \$$ & $0.073543 \$$ & $334580.59 \$ \$$ & \multicolumn{2}{|c|}{$3.71399 \neq \approx 20559.66 \approx \neq$} \\
\hline Blocos $(B)$ & 1 & 2.4179 Ins & $377.7985 \$$ & 181.0662 & $12.9706 \mathrm{~ns}$ & 0.322336 & $21.4412 \mathrm{~ns}$ & s $0.000027 n s$ & 508988.54 & 20.49882 & $1897.84 \mathrm{~ns}$ \\
\hline Resíduo & 66 & 0.94821 & 45.4197 & 6712.8124 & 91.7467 & 0.042261 & 46.1700 & 0.016070 & 121261.97 & 0.40300 & 6714.04 \\
\hline \multirow{2}{*}{\multicolumn{2}{|c|}{ Média: $8 \pm 8$}} & $\begin{array}{c}56.66 \\
\pm\end{array}$ & $\begin{array}{c}51.60 \\
\pm\end{array}$ & $\begin{array}{c}125.74 \\
\pm\end{array}$ & $\begin{array}{c}67.71 \\
\pm\end{array}$ & $\begin{array}{c}1.57 \\
\pm\end{array}$ & $\begin{array}{c}14.68 \\
\pm\end{array}$ & $\begin{array}{c}2.04 \\
\pm\end{array}$ & $\begin{array}{c}2478.13 \\
\vdots\end{array}$ & $\begin{array}{c}21.82 \\
\pm\end{array}$ & $\begin{array}{c}540.71 \\
\pm\end{array}$ \\
\hline & & 0.69 & 4.77 & 7.93 & 6.77 & 0.15 & 4.80 & 0.09 & 246.23 & 0.45 & 57.94 \\
\hline $\begin{array}{l}\text { Média das } \\
\text { Testenunhas () }\end{array}$ & & 58.08 & 49.29 & 127.08 & 67.50 & 1.48 & $14.6 ?$ & 2.11 & 2862.96 & 22.36 & 616.55 \\
\hline $\mathrm{CV}(\mathbf{x})$ & & 1.72 & 13.06 & 2.85 & 14.15 & 13.10 & 46.30 & 6.20 & 14.05 & 2.91 & 15.15 \\
\hline
\end{tabular}

* e \$: significativo a 5 e e lo probabilidade pelo teste $F$, respectivanente

ns : nåo significativo

NDF : núnero de dias para florescinento

$A P F \quad$ : al tura da planta no florescinento

NDM : núnero de dias para naturidade

APM : al tura da planta na aturidade

Ac : acamanento

AV : altura de inserção da prineira pagea

VA : valor agronônico

PG : produtividade de gräos

\$oL : porcentager de bleo

Po : produtividade de óleo

I : o genótipo no 31 foi perdido nas duas repetiçôes para os caracteres: NDF, APF. 
Tabela 20. Grupo de maturidade intermediário: valores e significância dos quadrados médios obtidos da análise da variância de sete caracteres. Soja, semeadura $11 / 12 / 84$. Local: Anhembi.

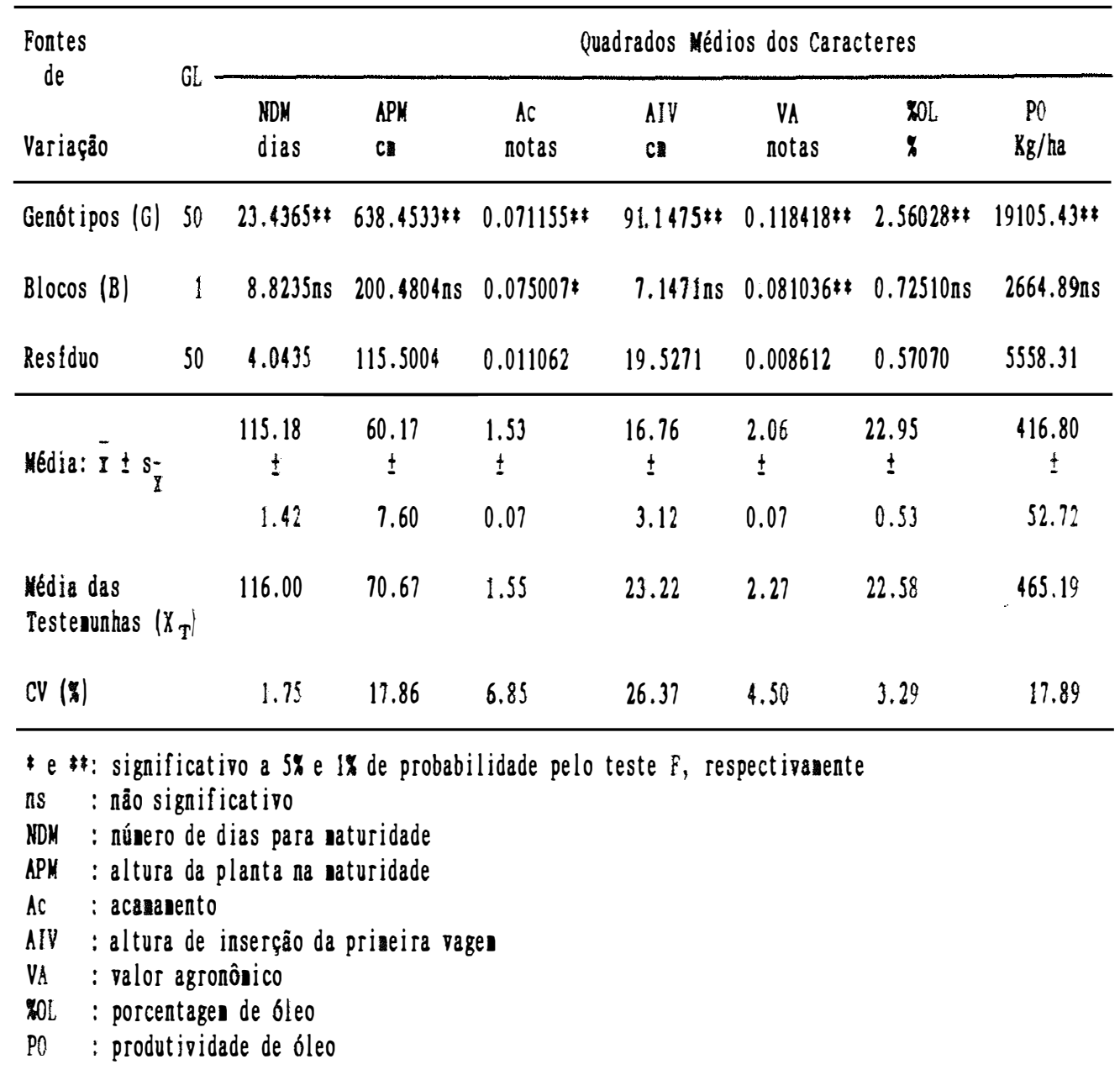


Tabela 21. Grupo de maturidade intermediario: valores e significância dos quadrados médios obtidos da análise da variância de sete caracteres. Soja, semeadura 04/12/84. Local: ESALQ.

\begin{tabular}{|c|c|c|c|c|c|c|c|c|}
\hline \multirow{2}{*}{$\begin{array}{l}\text { Fontes } \\
\text { de } \\
\text { Variaçäo }\end{array}$} & \multirow{2}{*}{$G$} & \multicolumn{7}{|c|}{ Quadrados Médios dos Caracteres } \\
\hline & & $\begin{array}{l}\text { NDF } \\
\text { dias }\end{array}$ & $\begin{array}{l}\mathrm{APF} \\
\mathrm{C}\end{array}$ & APY & Ac & AIV & $\begin{array}{l}\text { VA } \\
\text { notas }\end{array}$ & $80 \mathrm{~L}$ \\
\hline Genbtipos $(G)$ & 50 & $93.96628 \neq$ & $251.0769 \$$ & $878.0518 \$$ & $0.113981 *$ & $58.1529 \$$ & $0.102853 * \$$ & $1.73710 \$$ \\
\hline$B l o c o s(B)$ & 1 & $10.03922 \$$ & $736.0392 *$ & $942.1569 \neq$ & 0.124042 & $13.4216 \mathrm{~ns}$ & $0.001215 \mathrm{~ns}$ & $12.98980 \pm$ \\
\hline Resíduo & 50 & 1.07922 & 56.8000 & 83.3569 & 0.018365 & 17.0016 & 0.008047 & 0.68740 \\
\hline \multirow{2}{*}{\multicolumn{2}{|c|}{ Media: $\bar{I} \pm \mathrm{s}^{-}$}} & $\begin{array}{r}61.73 \\
\pm\end{array}$ & $\begin{array}{r}45.96 \\
\pm\end{array}$ & $\begin{array}{c}64.88 \\
\pm\end{array}$ & $\begin{array}{l}1.60 \\
\pm\end{array}$ & $\begin{array}{c}10.44 \\
\pm\end{array}$ & $\begin{array}{c}1.95 \\
\pm\end{array}$ & $\begin{array}{c}24.22 \\
\pm\end{array}$ \\
\hline & & 0.73 & 5.33 & 6.46 & 0.10 & 2.92 & 0.06 & 0.59 \\
\hline \multicolumn{2}{|c|}{$\begin{array}{l}\text { Médis das } \\
\text { Testenunhas }\left(X_{T}\right)\end{array}$} & 65.22 & 55.50 & 79.11 & 1.64 & 16.11 & 2.16 & 23.97 \\
\hline \multicolumn{2}{|l|}{$\mathrm{CV}(\mathbf{x})$} & 1.68 & 16.40 & 14.07 & 8.46 & 39.49 & 4.60 & 3.42 \\
\hline
\end{tabular}

\footnotetext{
I e $\$$ : significativo a $5 \%$ e 1 de probabilidade pelo teste $F$, respectivanente

ns : não significativo

NDP I núnero de dias para florescinento

APF a al tura da planta no florescinento

APH a altura da planta na saturidade

Ac : acananento

AIV : altura de inserção da prineira vage

VA : valor agronônico

*oL : porcentagen de 6leo
} 
Tabela 22. Grupo de maturidade intermediário: valores e significância dos quadrados médios obtidos da análise da variância de dez caracteres. Soja, semeadura 06/12/84. Local: Sertãozinho.

\begin{tabular}{|c|c|c|c|c|c|c|c|c|c|c|c|}
\hline \multirow{2}{*}{$\begin{array}{l}\text { Fontes } \\
\text { de } \\
\text { Variação }\end{array}$} & \multicolumn{11}{|c|}{ Quadrados Médios dos Caracteres } \\
\hline & & $\begin{array}{l}\text { NDF } \\
\text { dias }\end{array}$ & $\begin{array}{l}\mathrm{APF} \\
\mathrm{C}\end{array}$ & $\begin{array}{l}\text { NDW } \\
\text { dias }\end{array}$ & APM & $\begin{array}{c}\text { AC } \\
\text { notas }\end{array}$ & $\begin{array}{l}A I V \\
\text { CI }\end{array}$ & $\begin{array}{l}\text { VA } \\
\text { notas }\end{array}$ & $\begin{array}{l}\mathrm{PG} \\
\mathrm{Xg} / \mathrm{ha}\end{array}$ & $: 0 \mathrm{~L}$ & $\begin{array}{c}\mathrm{PO} \\
\mathrm{Xg} / \mathrm{ha}\end{array}$ \\
\hline Genótipos $|G|$ & 50 & 91.787064 & $464.3282 \$ 4$ & $66.2541^{\neq}$ & $\$ 702.4016 \$$ & $0.134924: 4$ & $77.3471 \$$ & $0.051895 *$ & 168976.21 & $1.72640 * 1$ & $11620.02 \$$ \\
\hline Blocos $(B)$ & 1 & $0.08824 \mathrm{~ns}$ & $61.1863 \mathrm{~ns}$ & $24.5098 *$ & 361.4118 & $0.262454 \$$ & $37.6863 \mathrm{~ns}$ & S 0.054650 & $10461.66 \mathrm{~ns}$ & $1.45992 *$ & $3684.77 \mathrm{~ns}$ \\
\hline Residuo & 50 & 1.72824 & 40.7863 & 4.1498 & 25.2918 & 0.015170 & 16.9063 & 0.012862 & 92556.12 & 0.54722 & 5492.78 \\
\hline \multirow{3}{*}{ Média: $\bar{I} \pm s_{\bar{I}}$} & & $\begin{array}{c}62.27 \\
+\end{array}$ & $\begin{array}{c}57.03 \\
+\end{array}$ & $\begin{array}{c}129.41 \\
+\end{array}$ & 77.20 & 1.67 & 17.77 & 2.07 & 2563.26 & 21.80 & $\begin{array}{c}559.67 \\
+\end{array}$ \\
\hline & & \pm & \pm & \pm & \pm & \pm & \pm & \pm & I & I & I \\
\hline & & 0.93 & 4.52 & 1.44 & 3.56 & 0.09 & 2.91 & 0.08 & 215.12 & 0.52 & 52.41 \\
\hline \multicolumn{2}{|l|}{$\begin{array}{l}\text { Média das } \\
\text { Testenunhas }\left(\bar{X}_{\mathrm{T}}\right)\end{array}$} & 67.72 & 73.56 & 132.22 & 92.22 & 1.75 & 20.17 & 2.27 & 2586.61 & 21.88 & 566.85 \\
\hline$C V(x)$ & & 2.11 & 11.20 & 1.57 & 6.51 & 7.40 & 23.15 & 5.48 & 11.87 & 3.39 & 13.24 \\
\hline \multicolumn{12}{|c|}{ 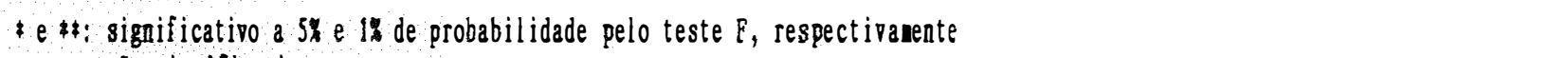 } \\
\hline \multicolumn{12}{|c|}{ ns : nẽo significativo } \\
\hline \multicolumn{12}{|c|}{ NDF a núnero de dias para florescinento } \\
\hline \multicolumn{12}{|c|}{ APF : altura da planta no florescinento } \\
\hline \multicolumn{12}{|c|}{ NDK : nónero de dias para naturidade } \\
\hline \multicolumn{12}{|c|}{ APM : altura da planta na naturidade } \\
\hline \multicolumn{12}{|c|}{ Ac : acananento } \\
\hline \multicolumn{12}{|c|}{ div a altura de inserçâo da prineira page } \\
\hline \multicolumn{12}{|c|}{ VA alor agronônico } \\
\hline \multicolumn{12}{|c|}{ PQ : produtividade de gräos } \\
\hline \multicolumn{12}{|c|}{ xoL : porcentage de 6leo } \\
\hline Po : produti & ridad & de de $6 l e 0$ & & & & & & & & & \\
\hline
\end{tabular}


Tabela 23. Grupo de maturidade tardio: valores e significância dos quadrados médios obtidos da análise da variância de oito caracteres. Soja, semeadura 12/12/84. Local: Anhembi.

\begin{tabular}{|c|c|c|c|c|c|c|c|c|c|}
\hline \multirow{2}{*}{$\begin{array}{l}\text { Fontes } \\
\text { de } \\
\text { Variação }\end{array}$} & \multicolumn{9}{|c|}{ Quadrados Médios dos Caracteres } \\
\hline & \multicolumn{2}{|c|}{$\begin{array}{l}\text { NDH } \\
\text { dias }\end{array}$} & $\begin{array}{l}\text { APK } \\
\text { CI }\end{array}$ & $\begin{array}{c}\text { Ac } \\
\text { notas }\end{array}$ & $\begin{array}{l}\text { AIV } \\
\text { CI }\end{array}$ & $\begin{array}{c}V_{A} \\
\text { notas }\end{array}$ & $\begin{array}{c}\mathrm{PG} \\
\mathrm{Kg} / \mathrm{ha}\end{array}$ & $\$$ & $\begin{array}{l}\mathrm{PO} \\
\mathrm{Kg} / \mathrm{ha}\end{array}$ \\
\hline Genotipo (G) & 21 & 115.0790 & 412.8831 & 0.136047 & $115.3680 *$ & 0.084437 & $524152.71 *$ & 4.17018 & 32149.75 \\
\hline Blocos $(B)$ & 1 & $0.2045 \pi$ & 567.3636 & $0.039002 \mathrm{~ns}$ & $26.2727 n$ & $0.013651 \mathrm{~ns}$ & $1106013.09 *$ & 0.84568 & 63450.00 \\
\hline Resíduo & 21 & 5.2522 & 29.1255 & 0.054800 & 34.2727 & 0.026647 & 155743.14 & 0.53806 & 7697.37 \\
\hline \multirow[t]{2}{*}{ Média: $\bar{z} \pm s$} & & 136.71 & 79.68 & 1.70 & 21.73 & 2.15 & 2228.00 & 22.03 & 495.65 \\
\hline & & $\begin{array}{l} \pm \\
1.62\end{array}$ & $\begin{array}{c} \pm \\
3.82\end{array}$ & $\begin{array}{l} \pm \\
0.17\end{array}$ & $\begin{array}{c} \pm \\
4.14\end{array}$ & $\begin{array}{l} \pm \\
0.12\end{array}$ & $\stackrel{ \pm}{ \pm}$ & $\begin{array}{c} \pm \\
0.52\end{array}$ & $\underset{62.04}{ \pm}$ \\
\hline \multicolumn{10}{|l|}{ Médias das } \\
\hline Teste nunhas & $\left(\bar{X}_{T}\right)$ & 131.33 & 74.17 & 1.76 & 24.17 & 2.14 & 2339.67 & 22.46 & 527.00 \\
\hline $\operatorname{CV}(x)$ & & 1.68 & 6.77 & 13.76 & 26.94 & 7.59 & 17.71 & 3.33 & 17.70 \\
\hline
\end{tabular}

\footnotetext{
e \$: significativo a $5 \%$ e $1 \%$ de probabilidade pelo teste $F$, respectivamente.

ns : não significativo

NOM : núnero de dias para aturidade

APM : al tura da planta na aturidade

Ac : acananento

AIV : altura de inserção da prineira vagea

VA : valor agronônico

PG : produtividade de grão

WOL : porcentager de óleo

PO : produtividade de óleo
} 
Tabela 24. Grupo de maturidade tardio: valores e significância dos quadrados médios obtidos da análise da variância de sete caracteres. Soja, semeadura 04/12/84. Loca 1: ESALQ.

\begin{tabular}{|c|c|c|c|c|c|c|c|c|}
\hline \multicolumn{3}{|l|}{ Fontes } & \multicolumn{6}{|c|}{ Quadrados Médios dos Caracteres } \\
\hline Yariação & & $\begin{array}{l}\text { NDF } \\
\text { dias }\end{array}$ & $\begin{array}{l}\mathrm{APF} \\
\mathrm{C}\end{array}$ & $\begin{array}{c}\text { AC } \\
\text { notas }\end{array}$ & $\begin{array}{l}\text { VA } \\
\text { notas }\end{array}$ & $\begin{array}{c}\mathrm{PG} \\
\mathrm{Kg} / \mathrm{ha}\end{array}$ & $* 0 \mathrm{~L}$ & $\begin{array}{c}\mathrm{PO} \\
\mathrm{Kg} / \mathrm{ha}\end{array}$ \\
\hline Genótipos (G) & 21 & $125.52056 * 7$ & 634.8442 & $0.129388 \neq \#$ & $0.047755 \$ 4$ & $916563.42 * 4$ & $2.23771 * *$ & $47178.14 \$ 4$ \\
\hline Blocos $(B)$ & 1 & $0.56818 \mathrm{~ns}$ & $218.2727 \mathrm{~ns}$ & $0.013545 n s$ & $0.000270 \mathrm{~ns}$ & $3421.45 \mathrm{~ns}$ & $0.32818 \mathrm{~ns}$ & $7.00 \mathrm{~ns}$ \\
\hline Residuo & 21 & 16.85390 & 173.1300 & 0.043479 & 0.008583 & 185624.98 & 0.38771 & 10447.90 \\
\hline \multirow{3}{*}{\multicolumn{2}{|c|}{ Nédia: $\bar{I} \pm s$}} & 74.11 & 86.77 & 2.00 & 1.95 & 3025.05 & 21.24 & 645.47 \\
\hline & & \pm & \pm & \pm & \pm & \pm & \pm & \pm \\
\hline & & 2.90 & 9.30 & 0.15 & 0.07 & 304.65 & 0.44 & 72.28 \\
\hline \multicolumn{2}{|c|}{$\begin{array}{l}\text { Yédia das } \\
\text { Testenunhas }\left(X_{T}\right)\end{array}$} & 73.58 & 80.33 & 2.07 & 1.98 & 3192.25 & 21.61 & 689.62 \\
\hline \multicolumn{2}{|l|}{$C V\left(\begin{array}{l}n \\
0\end{array}\right)$} & 5.54 & 15.16 & 10.43 & 4.75 & 14.24 & 2.93 & 15.84 \\
\hline \multicolumn{9}{|c|}{ * e $\$$ : significativo a $5 \%$ e $1 \%$ de probabilidade pelo teste $F$, respectivanente } \\
\hline \multicolumn{9}{|c|}{ ns : não significativo } \\
\hline \multicolumn{9}{|c|}{ APF : al tura da planta no florescimento } \\
\hline \multicolumn{9}{|c|}{ Ac : acananento } \\
\hline \multicolumn{9}{|c|}{ VA : valor agronônico } \\
\hline \multicolumn{9}{|c|}{ PG : produtividade de grãos } \\
\hline \multicolumn{9}{|c|}{ Wol : porcentage de óleo } \\
\hline PO : produ & tivid & de de óleo & & & & & & \\
\hline
\end{tabular}


Tabela 25. Grupo de maturidade tardio: valores e significância dos quadrados médios obtidos da análise da variância de oito caracteres. Soja, semeadura 06/12/84. Local: Sertãozinho.

\begin{tabular}{|c|c|c|c|c|c|c|c|c|c|}
\hline \multirow{2}{*}{$\begin{array}{l}\text { Pontes } \\
\text { de } \\
\text { Variação }\end{array}$} & \multirow{2}{*}{ GL. } & \multicolumn{8}{|c|}{ Quadrados Médios dos Caracteres } \\
\hline & & $\begin{array}{l}\text { NDE } \\
\text { dias }\end{array}$ & $\begin{array}{l}\mathrm{APF} \\
\mathbf{c}\end{array}$ & $\begin{array}{l}\text { NDH } \\
\text { dias }\end{array}$ & $\begin{array}{l}\text { APM } \\
\text { CI }\end{array}$ & $\begin{array}{c}\mathrm{Ac} \\
\text { notas }\end{array}$ & $\begin{array}{l}\text { AIV } \\
\text { CI }\end{array}$ & $\begin{array}{c}\mathrm{PG} \\
\mathrm{Kg} / \mathrm{ha}\end{array}$ & $\begin{array}{c}\mathrm{PO} \\
\mathrm{Kg} / \mathrm{ha}\end{array}$ \\
\hline Genótipos $|G|$ & 21 & $141.33009 \$$ & $491.4632 \$ 4$ & $117.8355 \$$ & $562.3117 * \sharp$ & $0.145433 * \pm$ & $74.8918 ¥ \#$ & $246228.06 \$ \#$ & 15528.6274 \\
\hline$B l o \cos (B)$ & 1 & $0.02273 \mathrm{~ns}$ & $327.2727 \neq$ & $0.0000 \mathrm{~ns}$ & $1060.3636 \$$ & $0.16105 \operatorname{lns}$ & $176.0000 \$$ & $300135.36 \neq$ & $45533.16 \$ 4$ \\
\hline Residuo & 21 & 3.92749 & 46.5108 & 4.9524 & 66.6970 & 0.042067 & 20.8595 & 38895.51 & 1255.39 \\
\hline \multirow{3}{*}{\multicolumn{2}{|c|}{ Média: $\bar{z} \pm s_{\bar{X}}$}} & 76.61 & 85.27 & 142.82 & 96.32 & 1.88 & 24.23 & 2394.36 & 505.47 \\
\hline & & \pm & \pm & \pm & \pm & \pm & \pm & \pm & \pm \\
\hline & & 1.40 & 4.82 & 1.57 & 5.71 & 0.15 & 3.23 & 139.46 & 25.05 \\
\hline $\begin{array}{l}\text { Média das } \\
\text { Testenunhas }\left(\bar{X}_{\mathrm{T}}\right.\end{array}$ & & 76.17 & 82.50 & 140.83 & 93.91 & $1.8 ?$ & 26.50 & 2550.00 & 552.52 \\
\hline $\mathrm{CV}(\mathbf{x})$ & & 2.59 & 7.80 & 1.56 & 8.48 & 10.93 & 18.83 & 8.24 & 7.01 \\
\hline
\end{tabular}

* e *: significativo a 5 e 10 de probabilidade pelo teste $F$, respectivanente

ns : não significativo

NDF : núnero de dias para florescinento

APF : al tura da planta no florescirento

NDM : núnero de dias para aturidade

APM : al tura da planta na aturidade

Ac : acananento

AIV : altura de inserção da prineira vages

PG : produtividade de grãos

PO : produtividade de óleo 
Tabela 26. Grupo de maturidade precoce: valores e significância dos quadrados médios obtidos da análise da variância de quatro caracteres. Soja, semeadura entre $30 / 11$ e $11 / 12 / 84$. Locais: Anhembi, ESALQ e Sertãozinho.

\begin{tabular}{|c|c|c|c|c|c|c|c|}
\hline \multirow{3}{*}{$\begin{array}{c}\text { Fontes } \\
\text { de }\end{array}$} & \multicolumn{7}{|c|}{ Quadrados médios dos caracteres } \\
\hline & \multirow{3}{*}{ GL } & a & $\mathbf{a}$ & \multicolumn{3}{|c|}{ b } & \multirow{3}{*}{ APH } \\
\hline & & NDF & $A P F$ & GL & NDV & GL & \\
\hline Variação & & dias & c⿴囗十 & & dias & & \\
\hline Genótipos $(G)$ & $66^{\star}$ & $102.58503 \$$ & $276.4734 \notin$ & 67 & $49.2816 \neq$ & 67 & 1539.8206 \\
\hline Locais (L) & 1 & $10.88060 \mathrm{~ns}$ & $13512.7202 *$ & 1 & 12330.4375 & 2 & $5654.2283 \neq$ \\
\hline$G \perp L$ & 66 & $5.03211 \neq \$$ & $35.0989 \mathrm{~ns}$ & 67 & $22.4263 \neq$ & 134 & $98.9157 \$ \#$ \\
\hline$B / 0 \cos / L$ & 2 & $1.58209 \mathrm{~ns}$ & $259.8993 \approx \#$ & 2 & $41.2332 \div$ & 3 & $26.6970 \mathrm{~ns}$ \\
\hline Resíduo Médio & 132 & 1.68057 & 34.2326 & $193^{\circ}$ & 9.2521 & $199^{\circ}$ & 68.4845 \\
\hline \multicolumn{2}{|l|}{ Nédia: $\bar{X} \pm \mathrm{s}_{\mathrm{X}}^{-}$} & $56.88 \pm 1.12$ & $44.50 \pm 2.96$ & & $119.00 \pm 2.37$ & & $60.30 \pm 4.97$ \\
\hline \multicolumn{2}{|c|}{$\begin{array}{l}\text { Média das } \\
\text { Testeaunhas }\left(\bar{X}_{\mathrm{T}}\right)\end{array}$} & 58.58 & 44.04 & & 120.17 & & 57.45 \\
\hline \multicolumn{2}{|l|}{$\operatorname{cr}:$} & 2.28 & 13.15 & & 2.56 & & 13.72 \\
\hline \multicolumn{8}{|c|}{$*$ e $\neq \neq$ : significativo } \\
\hline \multicolumn{8}{|c|}{ ns : não significationo } \\
\hline \multicolumn{8}{|c|}{ NDF : número de dias para florescimento } \\
\hline \multicolumn{8}{|c|}{ APF : altura da planta no florescimento } \\
\hline \multicolumn{8}{|c|}{ NDM a número de dias para maturidade } \\
\hline \multicolumn{8}{|c|}{ APV : altura da planta na maturidade } \\
\hline \multirow{2}{*}{\multicolumn{8}{|c|}{$\begin{array}{l}1 \quad \text { o genotipo no } 31 \text { foi perdido nas duas repeticões nos dois locais: ESALQ e Sertãozinho. } \\
\text { subtrafáo de un grau de liberdade por parcela perdida, genótipo no 48, local: anhe }\end{array}$}} \\
\hline & & & & & & & \\
\hline \multicolumn{8}{|c|}{$\begin{array}{l}\text { * subtrafáa de dois graus de liberdade por parcela perdida, Genótipos no } 7 \text { e } 22 \text {, local: } \\
\text { ESAlQ. }\end{array}$} \\
\hline \multicolumn{8}{|c|}{ a : locais: ESALQ e Sertãozinho } \\
\hline : locais: & Anheab & i e Sertãozinho & & & & & \\
\hline
\end{tabular}


Tabela 27. Grupo de maturidade precoce: valores e significância dos quadrados médios obtidos da análise da variância de seis caracteres. Soja, semeadura entre $30 / 11$ e $11 / 12 / 84$. Locais: Anhembi, ESALQ e Sertãozinho.

\begin{tabular}{|c|c|c|c|c|c|c|c|c|c|}
\hline \multirow{2}{*}{$\begin{array}{l}\text { Fontes } \\
\text { de } \\
\text { Variaçâo }\end{array}$} & \multicolumn{9}{|c|}{ Quadrados ádios dos caracteres } \\
\hline & GL & $\begin{array}{c}\text { As } \\
\text { notas }\end{array}$ & GL & AIV & GL & $\begin{array}{l}\text { VA } \\
\text { notas }\end{array}$ & $\begin{array}{l}\mathrm{PG} \\
\mathrm{Kg} / \mathrm{ha}\end{array}$ & $\begin{array}{l}0 \mathrm{OL} \\
x\end{array}$ & $\begin{array}{l}\mathrm{PO} \\
\mathrm{Kg} / \mathrm{ha}\end{array}$ \\
\hline Genótipos (G) & 67 & $0.262985 \$$ & 67 & $156.7793 \$$ & 67 & 0.150048 & 598250.90 & 8.907201 & $\$ 40267.93 * 4$ \\
\hline Locais (L) & 2 & $0.584961 \mathrm{~ns}$ & 2 & $186.7566 \mathrm{~ns}$ & 2 & 0.502604 & $27898993.10 *$ & 99.94422 & * 1344188.51 \\
\hline GIL & 134 & 0.043201 & 134 & $31.6564:$ & 134 & $0.042143 * *$ & $222319.90 *$ & 0.92414 & $\$ \# \quad 13374.42 \$ \#$ \\
\hline Blocos/L & 3 & $0.165197 \$$ & 3 & $25.0941 \mathrm{~ns}$ & 3 & $0.004790 \mathrm{~ns}$ & 1281681.59 & 9.89824 & $\$ \quad 62034.15 \$$ \\
\hline Residuo Médio & 201 & 0.025206 & 2001 & 24.3261 & 201 & 0.016192 & 160832.70 & 0.40202 & 8665.95 \\
\hline \multirow{2}{*}{ Média, $\mathrm{I} \pm \mathrm{s}$} & & $\begin{array}{c}1.53 \\
\pm\end{array}$ & & $\begin{array}{c}13.36 \\
\pm\end{array}$ & & $\begin{array}{c}1.97 \\
\pm\end{array}$ & $\begin{array}{r}2100.05 \\
\pm\end{array}$ & $\begin{array}{c}22.58 \\
\pm\end{array}$ & $\begin{array}{c}473.71 \\
\pm\end{array}$ \\
\hline & & 0.08 & & 2.30 & & 0.08 & 192.49 & 0.39 & 47.21 \\
\hline $\begin{array}{l}\text { Média das } \\
\text { Testenunhas }\left(\overline{\mathbb{X}}_{\mathrm{T}}\right)\end{array}$ & & 1.46 & & 13.84 & & 2.03 & 2412.89 & 22.50 & 537.95 \\
\hline$C V(\mathbf{n})$ & & 10.36 & & 36.91 & & 6.43 & 19.10 & 2.81 & 19.65 \\
\hline
\end{tabular}

* e \$: significativo a $5 \%$ e $1 \%$ de probabilidade pelo teste $F$, respectivanente

ns : não significativo

Ac : acananento

AV : altura de inserção da prineira vage

VA : valor agronônico

PG : produtividade de grãos

WoL : porcentager de 61 eo

Po : produtividade de 6 leo

- a substraçáo de un grau de liberdade por parcela perdida (repetição 1 do genótipo no 62) para o caráter AIV no local ESALQ. 
Tabela 28. Grupo de maturidade intermediário: valores e significância dos quadrados médios obtidos da análise da variância de três caracteres. Soja, semeadura entre $04 / 12$ e $11 / 12 / 84$, em dois locais.

\begin{tabular}{|c|c|c|c|c|c|c|c|}
\hline \multirow{2}{*}{$\begin{array}{c}\begin{array}{c}\text { Fontes } \\
\text { de }\end{array} \\
\text { Variação }\end{array}$} & \multirow{2}{*}{ GL- } & \multicolumn{6}{|c|}{ Quadrados Médios dos Caracteres } \\
\hline & & $\begin{array}{l}\mathrm{NDF}^{\mathbf{a}} \\
\text { dias }\end{array}$ & & $\begin{array}{l}\mathrm{APF}^{\mathbf{a}} \\
\mathrm{cm}\end{array}$ & & $\begin{array}{l}\text { b } \\
\text { NDM } \\
\text { dias }\end{array}$ & \\
\hline Genót ipos (G) & 50 & 183.60490 & $* *$ & 638.1049 & $* *$ & 63.0871 & ** \\
\hline Locais (L) & 1 & 14.82843 & ns & 6248.2402 & ns & 10334.8235 & ** \\
\hline G $\times L$ & 50 & 2.14843 & $*$ & 77.3002 & $*$ & 26.6035 & ** \\
\hline Blocos/L & 2 & 5.06373 & $*$ & 398.6128 & $* *$ & 16.6667 & $*$ \\
\hline Resíduo Médio & 100 & 1.40373 & & 48.7928 & & 4.0967 & \\
\hline Média $\bar{x} \pm s \bar{x}$ & & $\begin{array}{c}62.00 \\
\pm \\
0.73\end{array}$ & & $\begin{array}{c}51.50 \\
\pm \\
4.40\end{array}$ & & $\begin{array}{c}122.29 \\
\pm \\
2.58\end{array}$ & \\
\hline Média das Testemunhas & $\left(\overline{\mathrm{X}}_{\mathrm{T}}\right)$ & 66.47 & & 64.53 & & 124.11 & \\
\hline $\mathrm{CV} \quad(\%)$ & & 1.91 & & 13.56 & & 1.66 & \\
\hline
\end{tabular}

* e **: Significativo a $5 \%$ e $1 \%$ de probabilidade, pelo teste $\mathrm{F}$, respect i vamente

ns : Não significativo

NDF : Número de dias para florescimento

APF : Altura da planta no florescimento

NDM : Número de dias para maturidade

a : Locais: ESALQ e Sertãozinho

b : Locais: Anhembi e Sertãozinho. 
Tabela 29. Grupo de maturidade intermediario: valores e significância dos quadrados médios obtidos da análise da variância de sete caracteres. Soja, semeadura entre $04 / 12$ e $11 / 12 / 84$. Locais: Anhembi, ESALQ, Sertãozinho.

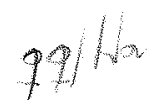

\begin{tabular}{|c|c|c|c|c|c|c|c|c|}
\hline \multirow{2}{*}{$\begin{array}{c}\text { Pontes } \\
\text { de } \\
\text { Variação }\end{array}$} & \multirow{2}{*}{ GL } & \multicolumn{7}{|c|}{ Quadrados Médios dos Caracteres } \\
\hline & & $\begin{array}{l}\text { APM } \\
\text { CI }\end{array}$ & $\begin{array}{c}\text { dc } \\
\text { notas }\end{array}$ & $\begin{array}{l}\text { AIV } \\
\text { CI }\end{array}$ & $\begin{array}{c}\text { VA } \\
\text { notas }\end{array}$ & $\begin{array}{c}\mathrm{PG} \\
\mathrm{Kg} / \mathrm{ha}\end{array}$ & 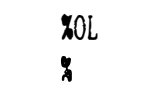 & $\begin{array}{c}\mathrm{PO} \\
\mathrm{Kg} / \mathrm{ha}\end{array}$ \\
\hline Genótipos (G) & so & $2041.1292 \$$ & 0.258662 & $190.0509 \approx$ & 0.223401 & $426280.30 \div$ & $4.08466 \$$ & 29239.46 \\
\hline Locais (L) & 2 & 7885.7288 & 0.432986 ns & $1606.7876 \$$ & 0.452240 & $20599743.57 \notin$ & $148.9319 \quad * 4$ & 1217533.36 \\
\hline$G: L$ & 100 & 88.8888 ns & $0.030699 \$$ & $18.2942 \mathrm{~ns}$ & 0.024883 & 234174.72 ns & $0.96956 \$$ & $13000.69 \mathrm{~ns}$ \\
\hline Blocos/L & 3 & $501.3497 \$$ & 0.153834 & 19.4183 ns & $0.045634 \$$ & $398640.24 \mathrm{nS}$ & $5.05804 \$ 4$ & 9447.28 ns \\
\hline Resíduo Médio & 150 & 74.7163 & 0.014866 & 17.8116 & 0.009840 & 185214.63 & 0.60177 & 10460.90 \\
\hline & & 67.42 & 1.60 & 14.99 & 2.03 & 2329.29 & 22.99 & 535.97 \\
\hline \multirow[t]{2}{*}{ Média I $\pm \mathrm{s}_{\mathrm{I}}$} & & \pm & \pm & \pm & \pm & \pm & \pm & \pm \\
\hline & & 3.85 & 0.07 & 1.75 & 0.06 & 197.56 & 0.40 & 46.55 \\
\hline \multicolumn{2}{|l|}{ Médias das } & & & & & & & \\
\hline \multicolumn{2}{|c|}{ Testenunhas $\left(\bar{X}_{T}\right)$} & 80.67 & 1.65 & 19.83 & 2.23 & 2509.20 & 22.81 & 572.29 \\
\hline \multicolumn{2}{|l|}{$C V(y)$} & 12.82 & 7.62 & 28.16 & 4.89 & 18.48 & 3.37 & 19.08 \\
\hline
\end{tabular}

* e \$: significativo a 5\% e 1 h de probabilidade, pelo teste F, respectivanente

ns : não significativo

APM : altura da planta na naturidade

Ac : acananento

AIV : altura da inserção da prineira vagen

VA : valor agronônico

PG : produtividade de grâos

\$oL : porcentager de bleo

Po : produtividade de óleo 
Tabela 30. Grupo de maturidade tardio: valores e significância dos quadrados médios obtidos da análise da variância de três caracteres. Soja, semeadura entre 04/12 e 12/12/84, em dois locais.

\begin{tabular}{|c|c|c|c|c|}
\hline Fontes & & Quadrados & Médios dos Ca & acteres \\
\hline $\begin{array}{c}\text { de } \\
\text { Variação }\end{array}$ & GL & $\begin{array}{l}\text { a } \\
N D F \\
\text { dias }\end{array}$ & $\begin{array}{l}\mathrm{a} \\
\mathrm{APF} \\
\mathrm{cm}\end{array}$ & $\begin{array}{l}\text { b } \\
\text { VA } \\
\text { notas }\end{array}$ \\
\hline Genót ipos (G) & 21 & $257.70779 * *$ & $993.9502 * *$ & $0.111765 * *$ \\
\hline Loca is (L) & 1 & $137.50000 * *$ & $49.5000 \mathrm{~ns}$ & $0.865659 * *$ \\
\hline$G \times L$ & 21 & $9.14286 \mathrm{~ns}$ & $132.3571 \mathrm{~ns}$ & $0.020427 \mathrm{~ns}$ \\
\hline Blocos/L & 2 & $0.29546 \mathrm{~ns}$ & $272.7727 \mathrm{~ns}$ & $0.006960 \mathrm{~ns}$ \\
\hline Resíduo Médio & 42 & 10.39069 & 109.8204 & 0.017615 \\
\hline \multirow[t]{2}{*}{ Média $\bar{x} \pm s_{\bar{x}}$} & & $\begin{array}{c}75.36 \\
\pm\end{array}$ & $\begin{array}{c}86.02 \\
\pm\end{array}$ & $\begin{array}{c}2.05 \\
\pm\end{array}$ \\
\hline & & 1.51 & 5.75 & 0.07 \\
\hline Média das Testemunhas & $\left(\overline{\mathrm{X}}_{\mathrm{T}}\right)$ & 74.88 & 81.42 & 2.06 \\
\hline CV (\%) & & 4.28 & 12.18 & 6.47 \\
\hline
\end{tabular}

* e **: Significativo a $5 \%$ e $1 \%$ de probabilidade, pelo teste $\mathrm{F}$, respect ivamente

ns . : Não significativo

NDF : Número de dias para florescimento

APF : Altura da planta no florescimento

VA : Valor agronônico

a : Locais: ESALQ e Sertãozinho

b : Locais: Anhembi e ESALQ 
Tabela 31. Grupo de maturidade tardio: valores e significância dos quadrados médios obtidos da análise da variância de sete caracteres. Soja, semeadura entre 04/12 e 12/12/84. Locais: Anhembi, ESALQ, Sertãozinho.

\begin{tabular}{|c|c|c|c|c|c|c|c|c|}
\hline \multirow{2}{*}{$\begin{array}{l}\text { Fontes } \\
\text { de } \\
\text { Variação }\end{array}$} & \multirow{2}{*}{$G L-$} & \multicolumn{7}{|c|}{ Quadrados nédios dos caracteres } \\
\hline & & $\begin{array}{l}\text { NDM } \\
\text { dias }\end{array}$ & APY & $\begin{array}{l}\text { Ac } \\
\text { notas }\end{array}$ & AlV & $\begin{array}{l}\mathrm{PG} \\
\mathrm{Kg} / \mathrm{ha}\end{array}$ & $80 \mathrm{~L}$ & $\begin{array}{l}\mathrm{PO} \\
\mathrm{Kg} / \mathrm{ha}\end{array}$ \\
\hline Genótipos $(G)$ & 21 & $372.2626 \approx$ & 1447.5859 & $0.307960 \approx$ & $164.4203 \$$ & $1230094.79 \$$ & 12.24778 & 70814.47 \\
\hline Locais (L) & 2 & 580.4621 ns & $4497.8182 \mathrm{~ns}$ & 0.989704 & $996.7803 \div$ & 7778597.73 : & $33.95553 \mathrm{~ns}$ & $309048.01 \mathrm{~ns}$ \\
\hline 611 & 42 & $66.2161 \mathrm{~ns}$ & $138.1356 \mathrm{~ns}$ & $0.051454 \mathrm{~ns}$ & 60.6216 & 228424.70 & $3.36426 \mathrm{~ns}$ & 12021.02 \\
\hline Blocos/(L) & 3 & 182.0758 : & $717.6061 *$ & $0.071199 \mathrm{~ns}$ & 101.4318 & 469856.64 & 8.00409 & $36330.05 *$ \\
\hline Resíduo Kédio & 63 & 60.5361 & 155.5743 & 0.046782 & 35.7175 & 126754.54 & 2.69711 & 6466.89 \\
\hline \multirow{2}{*}{ Média $I \pm 8_{I}$} & & $\begin{array}{c}140,90 \\
\pm\end{array}$ & $\begin{array}{c}91.32 \\
\pm\end{array}$ & $\begin{array}{c}1.86 \\
\pm\end{array}$ & $\begin{array}{c}20.33 \\
\pm\end{array}$ & $\begin{array}{c}2549.14 \\
t\end{array}$ & $\begin{array}{c}21.18 \\
\pm\end{array}$ & $\begin{array}{c}548.86 \\
\pm\end{array}$ \\
\hline & & 3.32 & 4.80 & 0.09 & 3.18 & 195.12 & 0.75 & 44.76 \\
\hline \multicolumn{9}{|l|}{ Média das } \\
\hline Testenuntas $\left(X_{T}\right.$ & & 138.19 & 84.92 & 1.90 & 22.36 & 2693.97 & 21.90 & 589.71 \\
\hline CV $(x)$ & & 5.52 & 13.66 & 11.63 & 29.40 & 13.97 & 7.75 & 14.65 \\
\hline
\end{tabular}

t e $\$$ : significativo a $5 \%$ e $1 \%$ de probabilidade, pelo teste $F$, respectivanente

ns : nâo significativo

NOH ; núnero de dias para naturidade

APY a altura da planta na raturidade

Ac : acalanento

AIV : altura da inserçâo da prineira vagel

PG : produtividade de grâos

*oL : porcentager de óleo

PO : produtividade de bleo 
Tabela 32. Coeficiente de variaça experimental dos caracteres nas análises da variância individuais e conjuntas em três grupos de maturidade e três loca is.

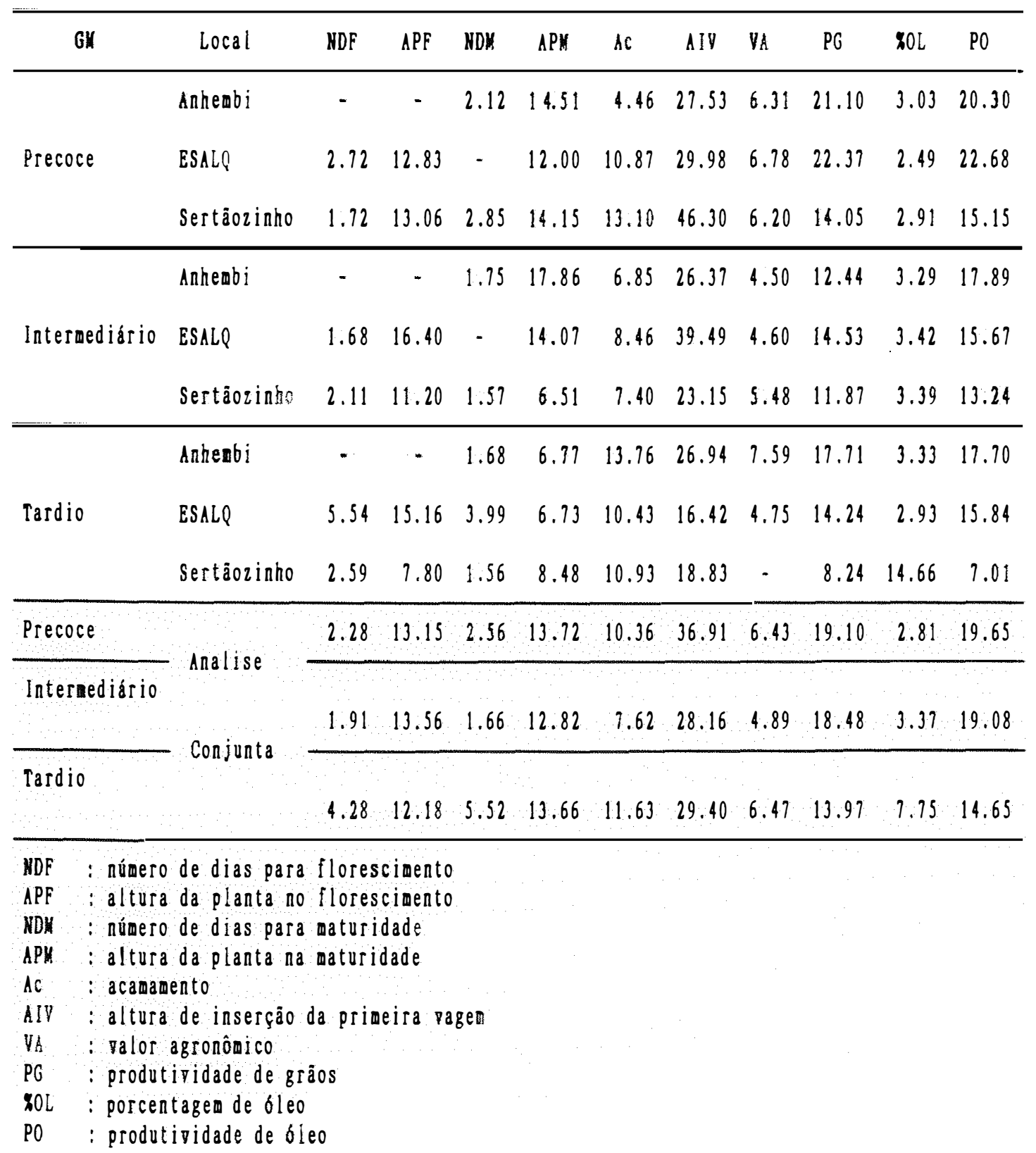


Tabela 33. Grupo de maturidade precoce: quadrados médios das interações genótipos x locais, proporções das variações genéticas e variâncias experimentais e correlações genéticas de um caráter medido em dois locais. Soja $1984 / 85$.

\begin{tabular}{|c|c|c|c|c|}
\hline & Locais & Anhenbi e ESALQ & Anhenbi e Sertãozinho & ESALQ e Sertãozinho \\
\hline Carater & QII ${ }_{G L_{1}}$ & $Q_{G \times L} \quad V_{G} \quad \sigma_{0}^{2} I_{G}$ & 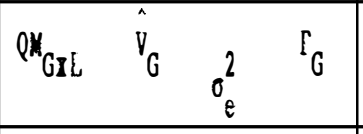 & $\begin{array}{lll}Q_{G X L} & V_{G} & 2 \\
& & o_{8}^{2} \\
\end{array}$ \\
\hline & 222319.90 & $\begin{array}{|ccc|}260716 * & 2560 * & 0.5991 \\
& 0.460 * 2 & 78 * \\
\end{array}$ & \begin{tabular}{ccr|}
$171490 * 1170 \mathrm{~ns}$ & $0.769 \mathrm{I}$ \\
$0.937 \mathrm{~ns}$ & $99 \times$ \\
\end{tabular} & \begin{tabular}{|ccc}
$234753 \mathrm{~ns}$ & $045 \mathrm{ins}$ & 0.7291 \\
& $2.042 * 2$ & $78 \%$ \\
\end{tabular} \\
\hline $\begin{array}{l}\text { ntage } \\
\text { eo }\end{array}$ & 0.924 & $\begin{array}{rr}.2389 \$ 0.788 \mathrm{~ns} & 0.7370 \\
1.341 \mathrm{~ns} & 97 \% \\
\end{array}$ & $\begin{array}{cr}0.830 \mathrm{~ns} & 0.8281 \\
1.14 \mathrm{nns} & 98 \% \\
\end{array}$ & $\begin{array}{rrr}0.5710 * 1.054 \mathrm{~ns} & 0.9421 \\
& 0.851 \mathrm{~ns} & 99 \% \\
\end{array}$ \\
\hline $\begin{array}{l}\text { Produtividade } \\
\text { de oleo }\end{array}$ & $13374.42 * t$ & $\left|\begin{array}{ccc}16771 * \approx 2200 * & 0.5130 \\
& 0.382 * \approx & 86 \%\end{array}\right|$ & $\begin{array}{ccc}10108 * & 1348 \mathrm{~ns} & 0.757 \mathrm{I} \\
0.793 \mathrm{~ns} & 96 \%\end{array}$ & $\begin{array}{ccc}13245 \mathrm{~ns} & 0614 \mathrm{~ns} & 0.7621 \\
& 2.079 \approx \neq & 89 \pi\end{array}$ \\
\hline
\end{tabular}

$\$, \$$ : Significativo a $5 \%$ e $1 \%$ de probabilidade, pelo teste $F$, respectivanente

ns : não significativo pelo teste F;

QM Gr: Quadrado ádio das interaçōes genótipos I locais (3 locais)

QHe : Quadrado nédio das interaçōes genótipos y locais (2 locais)

$\hat{\nabla}_{G}$ : Couponenute quadrático da variação genotípica

$0_{e}^{2}$ : variância experinental

$I_{G}$ : coeficiente de correlação genética de un mesıo carater nedido en dois locais

I : significativanente diferente de zero (0), e nåo significativanente diferente de un (1), pelo teste "t", respectivanente;

- significativanente diferente de zero (0), e significativanente diferente de (1), pelo teste " $t$ ", respectivanente. 
Tabela 34. Grupo de maturidade Intermediário: Quadrados médios das interações genótipos $x$ locais, proporções das variações genéticas e variâncias experimentais e correlações genéticas de um carater medido em dois locais. Soja $1984 / 85$.

\begin{tabular}{|c|c|c|c|c|}
\hline & Locais & Anhenbi e ESALQ & Anhenbi e Sertãozinho & ESALQ e Sertãozinho \\
\hline Carater & QIII GX, & $\mathrm{NH}_{G \mathrm{~L}} \quad \mathrm{~V}_{G} \quad \mathrm{o}_{\mathrm{e}}^{2} \mathrm{I}_{G}$ & 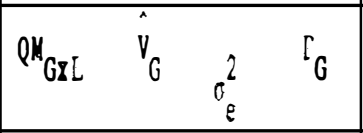 & 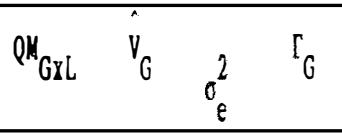 \\
\hline $\begin{array}{l}\text { Produtividade } \\
\text { de Grãos }\end{array}$ & $234174.72 n s$ & $\begin{array}{r}231810 \mathrm{~ns} 2064 \mathrm{~ns} \\
0.353 * 4\end{array}$ & $\begin{array}{r}191172 * \approx 2333 * *- \\
0.572 * \neq\end{array}$ & $\begin{array}{cc}270542 \mathrm{~ns} & \begin{array}{c}1566 \mathrm{~ns} \\
1618 *\end{array} \\
\end{array}$ \\
\hline $\begin{array}{l}\text { Porcentages } \\
\text { de óleo }\end{array}$ & $0.9695621 *$ & $\begin{array}{ccc}0.9386 * & 1.905 \mathrm{~ns} & 0.836 \mathrm{I} \\
& 0.830 \mathrm{~ns} & 96 \% \\
\end{array}$ & $\begin{array}{|ccc|}1.0423 * * & 1.687 \mathrm{~ns} & 0.7191 \\
& 1.04 \mathrm{Jns} & 89 * \\
\end{array}$ & $\begin{array}{ccc}0.9457 * & 0.886 \mathrm{~ns} & 0.705 \mathrm{I} \\
& 1.256 \mathrm{~ns} & 99 \pi \\
\end{array}$ \\
\hline $\begin{array}{l}\text { Produtividade } \\
\text { de óleo }\end{array}$ & $13000.69 \mathrm{~ns}$ & $\begin{array}{cc}11397 \mathrm{~ns} & 1275 \mathrm{~ns} \\
& 0.552 *\end{array}$ & $\begin{array}{rrr}11.942 * 2211 * & 0.376+ \\
& 1011 \text { ns } & 89 x \\
\end{array}$ & $\begin{array}{cc}15664 \mathrm{~ns} & 1734 \mathrm{~ns} \\
& 1832^{*} \\
\end{array}$ \\
\hline
\end{tabular}

\$, \$\# : Significativo a $5 \%$ e 1 de probabilidade, pelo teste $F$, respectivanente

ns : não significativo pelo teste $\mathrm{F}$;

QMGZL: Quadrado nédio das interações genótipos I locais (3 locais)

QHaZL: Quadrado rédio das interaçōes genotipos I locais (2 loca is)

$\hat{v}_{G} \quad$ : Couponente quadrático da variação genotípica

$0_{e}^{2}$ : variância esperinental

$\Gamma_{G}$ : coeficiente de correlação genética de uı nesıo caráter nedido el dois locais

- significativanente diferente de zero (0), e não significativanente diferente de un(1), pelo teste " $t$ ", respect ivanente;

$+\quad$ aão significativanente diferente de zero (0), e significativanente diferente de uı (I), pelo teste " $t$ ", respectivanente. 
Tabela 35. Grupo de maturidade Tardio: Quadrados médios das interações genótipos x locais, proporções das variações genéticas e variâncias experimentais e correlações genéticas de um caráter medido em dois locais. Soja $1984 / 85$.

\begin{tabular}{|c|c|c|c|c|}
\hline & Locais & Anhe bi e BSALQ & Anhenbi e Sertäozinho & ESALQ e Sertäozinho \\
\hline Carater & $\mathrm{QH}_{\mathrm{GXL}}$ & QNG $\quad \hat{V}_{G} \quad \hat{\sigma}^{2} I_{G}$ & 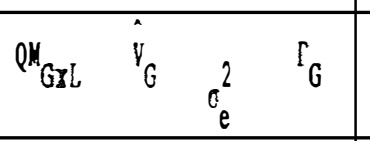 & 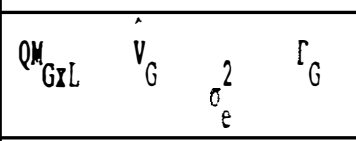 \\
\hline & 228424.70 & $\begin{array}{ccc}216374 \mathrm{~ns} & 0.504 \mathrm{~ns} & 0.9701 \\
0.839 \mathrm{~ns} & 34 \mathrm{n} \\
\end{array}$ & $231680 * \approx=\begin{array}{cc}1777 n s & 0.5551 \\
4004 * \pm\end{array}$ & \begin{tabular}{|rrr}
$237221 *$ & $3525 * \pm$ & 0.8841 \\
$91 \%$ & $4772 * \pm$ & $36 \%$ \\
\end{tabular} \\
\hline $\begin{array}{l}\text { intage } \\
\text { eo }\end{array}$ & $3.364260 \mathrm{~ns}$ & 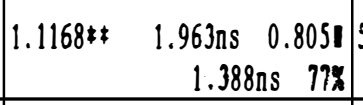 & $\begin{array}{cc}5.2262 \mathrm{~ns} & 0.999 \mathrm{~ns} \\
& 0.061 \pm \pm \\
\end{array}$ & $\begin{array}{cc}3.7500 \mathrm{uns} & 0.509 \mathrm{~ns} \quad 0.871 \mathrm{~ns} \\
& 0.044 \pm\end{array}$ \\
\hline $\begin{array}{l}\text { Produtividade } \\
\text { de 6leo }\end{array}$ & $12021.02 \approx$ & $\begin{array}{ccc}11856 \mathrm{~ns} & 0.666 \mathrm{~ns} & 0.928 \mathrm{I} \\
& 0.737 \mathrm{~ns} & 78 \mathrm{n}\end{array}$ & $\begin{array}{ccc}12787 * * & 1713 \mathrm{~ns} & 0.5921 \\
6.13 * t & 92 \%\end{array}$ & $\begin{array}{c}2573 * \quad 0.8711 \\
8.322 * * \quad 53 *\end{array}$ \\
\hline
\end{tabular}

\$, $\$$ : Significativo a $5 \%$ e 10 de probabilidade, pelo teste $F$, respectivanente

ns : näo significativo pelo teste F;

QH GrL: Quadrado ádio das interaçōes genótipos I locais (3 locais)

QM GrL: Quadrado rédio das interaçōes genbtipos \& locais (2 locais)

$\hat{V}_{G}$ : Cosponente quadrático da variação genotípica

$0_{e}^{2}$ : variância experinental

$I_{G}:$ coeficiente de correlação genética de un resso caráter medido el dois locais

- : significativanente diferente de zero $(0)$, e nåo significativanente diferente de un $(1)$, pelo teste " $t$ ", respectivanente; 
Tabela 36. Valor médio, efeito de grupo de maturidade, efeito médio de local e efeito de interação grupos de maturidade $x$ locais entre as médias dos caracteres, nas combinações de dois grupos de maturidade em dois locais. Soja, semeadura entre $30 / 11$ e $12 / 12 / 84$.

\begin{tabular}{|c|c|c|c|c|c|c|}
\hline Caráter & $\begin{array}{l}\text { Grupos de } \\
\text { Maturidade }\end{array}$ & Locais & Média & $\begin{array}{l}\text { Efeito de Grupo } \\
\text { de maturidade }\end{array}$ & $\begin{array}{l}\text { Efeito Médio } \\
\text { de local }\end{array}$ & interação GM I L \\
\hline \multirow{3}{*}{ Produti- } & \multirow{3}{*}{$\begin{array}{l}\text { Precoce } \\
\quad I \\
\text { Intermediário }\end{array}$} & $\begin{array}{l}\text { Anhe bi } \\
\text { ESALQ }\end{array}$ & 2061.66 & 150.64 & 357.03 & 44.09 \\
\hline & & $\begin{array}{l}\text { Anhembi } \\
\text { Sertãozinho }\end{array}$ & 2112.66 & 74.56 & 408.04 & 32.00 \\
\hline & & $\begin{array}{l}\text { ESALQ } \\
\text { Sertãozinho }\end{array}$ & 2469.70 & 118.65 & 51.00 & 76.08 \\
\hline \multirow[t]{2}{*}{ vidade } & \multirow{3}{*}{$\begin{array}{l}\text { Precoce } \\
\quad \\
\text { Tardio }\end{array}$} & $\begin{array}{l}\text { Anhembi } \\
\text { ESALQ }\end{array}$ & 2268.71 & 357.78 & 355.74 & 42.79 \\
\hline & & $\begin{array}{l}\text { Anhembi } \\
\text { Sertãozinho }\end{array}$ & 2174.64 & 136.54 & 261.61 & 178.43 \\
\hline de & & $\begin{array}{l}\text { ESALQ } \\
\text { Sertäozinho }\end{array}$ & 2530.38 & 179.33 & 94.13 & $221.2 ?$ \\
\hline Grãos & Intermediáric & $\begin{array}{l}\text { Anhembi } \\
\text { ESALQ }\end{array}$ & 2419.41 & 207.11 & 399.82 & 1.30 \\
\hline \multirow{2}{*}{$\mathrm{kg} / \mathrm{ha}$} & I & $\begin{array}{l}\text { Anhembi } \\
\text { Sertãozinho }\end{array}$ & 2249.20 & 61.98 & 229.61 & 146.43 \\
\hline & & $\begin{array}{l}\text { ESALQ } \\
\text { Sertäorinho }\end{array}$ & 2649.02 & 60.68 & 170.21 & 145.13 \\
\hline Porcen- & & $\begin{array}{l}\text { Anhembi } \\
\text { ESALQ }\end{array}$ & 22.28 & 0.31 & 0.59 & 0.045 \\
\hline de & $\frac{1}{\text { Intermediáric }}$ & $\begin{array}{l}\text { Anhembi } \\
\text { Sertãozinho }\end{array}$ & 22.25 & 0.13 & 0.44 & 0.14 \\
\hline oleo: & & $\begin{array}{l}\text { ESALQ } \\
\text { Sertäozinho }\end{array}$ & 22.84 & 0.17 & 1.03 & 0.18 \\
\hline
\end{tabular}


... cont inuação

\begin{tabular}{|c|c|c|c|c|c|c|}
\hline Caráter & $\begin{array}{l}\text { Grupos de } \\
\text { Maturidade }\end{array}$ & Locais & Média & $\begin{array}{l}\text { Efeito de Grupo } \\
\text { de oaturidade }\end{array}$ & $\begin{array}{l}\text { Efeito Médio } \\
\text { de local }\end{array}$ & interação GM y L \\
\hline \multirow[t]{2}{*}{ Porcen- } & \multirow{4}{*}{$\begin{array}{c}\text { Precoce } \\
I\end{array}$} & Anhembi & & & & \\
\hline & & ESALQ & 22.30 & 0.67 & 0.08 & 0.47 \\
\hline \multirow{2}{*}{ tagel } & & Anhe $b i$ & & & & \\
\hline & & Sertäozinho & 21.64 & 0.48 & 0.59 & 0.29 \\
\hline de & Tardio & $\begin{array}{l}\text { ESALQ } \\
\text { Sertãozinho }\end{array}$ & 21.71 & 0.95 & 0.66 & 0.18 \\
\hline \multirow{3}{*}{ oleo } & \multirow{4}{*}{$\begin{array}{l}\text { Intermed } \\
\quad 1 \\
\text { Tardio }\end{array}$} & Anhembi & & & & \\
\hline & & ESALQ & 22.61 & 0.98 & 0.12 & 0.52 \\
\hline & & $\begin{array}{l}\text { Anheabi } \\
\text { Sertäozinho }\end{array}$ & 21.79 & 0.61 & 0.73 & 0.15 \\
\hline$x$ & & $\begin{array}{l}\text { ESALQ } \\
\text { Sertãoz inho }\end{array}$ & 21.89 & 1.13 & 0.84 & 0.36 \\
\hline \multirow{3}{*}{ Produti- } & \multirow{3}{*}{$\begin{array}{l}\text { Precoce } \\
\quad I \\
\text { Intermediário }\end{array}$} & $\begin{array}{l}\text { Anhembi } \\
\text { ESALP }\end{array}$ & 482.16 & 41.95 & 94.02 & 13.29 \\
\hline & & $\begin{array}{l}\text { Anhembi } \\
\text { Sertäozinho }\end{array}$ & 469.17 & 19.07 & 81.03 & 9.59 \\
\hline & & $\begin{array}{l}\text { ESALQ } \\
\text { Sertãozinho }\end{array}$ & 563.19 & 32.36 & 13.00 & 22.88 \\
\hline vidade & \multirow{3}{*}{$\begin{array}{l}\text { Precoce } \\
\quad 1 \\
\text { Tardio }\end{array}$} & $\begin{array}{l}\text { Anhembi } \\
\text { ESALQ }\end{array}$ & 505.39 & 65.18 & 77.82 & 2.91 \\
\hline de & & $\begin{array}{l}\text { Anhembi } \\
\text { Sertäozinho }\end{array}$ & 475.33 & 25.23 & 47.76 & 42.85 \\
\hline \multirow{3}{*}{ oleo } & & $\begin{array}{l}\text { ESALQ } \\
\text { Sertãozinho }\end{array}$ & 553.15 & 22.32 & 30.06 & 39.49 \\
\hline & \multirow{3}{*}{$\begin{array}{c}\text { Interme } \\
1 \\
\text { Tardio }\end{array}$} & $\begin{array}{l}\text { Anhembi } \\
\text { ESALQ }\end{array}$ & 547.34 & 23.23 & 91.11 & 16.20 \\
\hline & & $\begin{array}{l}\text { Anhembi } \\
\text { Sertãozinho }\end{array}$ & 494.40 & 6.16 & 38.17 & 33.26 \\
\hline $\mathrm{Bg} / \mathrm{ha}$ & & $\begin{array}{l}\text { ESALQ } \\
\text { Sertãorinho }\end{array}$ & 553.15 & 22.32 & 30.06 & 39.94 \\
\hline
\end{tabular}


Tabela 37. Valores e significância das médias dos caracteres em cada grupo de maturidade e local pelo procedimento de TUKEY de aplitude estandartizada e valores médios dos caracteres em cada grupo de maturidade nos três locais, para genótipos e testemunhas. Soja, semeadura entre $30 / 11$ e $12 / 12 / 84$.

\begin{tabular}{|c|c|c|c|c|c|c|c|c|c|c|c|}
\hline \multirow[b]{2}{*}{ GH } & \multirow{3}{*}{$\begin{array}{l}\text { Experinento } \\
\text { Anhenbi } \\
\text { ESALP } \\
\text { Sertäozinho }\end{array}$} & \multicolumn{10}{|c|}{ Média dos Caracteres } \\
\hline & & NDF & APF & NDM & APM & Ac & AIV & VA & PG & $80 \mathrm{~L}$ & PO \\
\hline Precoce & & 57.10 & 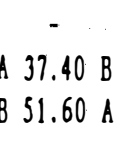 & $\begin{array}{c}112.25 \\
- \\
125.74\end{array}$ & $\begin{array}{l}55.88 \mathrm{~B} \\
57.31 \mathrm{~B} \\
67.71 \mathrm{~A}\end{array}$ & $\begin{array}{l}1.46 \mathrm{~B} \\
1.57 \mathrm{~A} \\
1.57 \mathrm{~A}\end{array}$ & $\begin{array}{l}12.99 \mathrm{~B} \\
12.42 \mathrm{~B} \\
14.68\end{array}$ & $\begin{array}{l}\text { B } 1.94 \mathrm{~B} \\
\mathrm{~B} 1.94 \mathrm{~B} \\
\mathrm{~A} 2.04 \mathrm{~A}\end{array}$ & $\begin{array}{l}1598.07 \\
2223.96 \\
2478.13\end{array}$ & $\begin{array}{l}22.42 \mathrm{~B} \\
23.51 \mathrm{~A} \\
21.82 \mathrm{C}\end{array}$ & $\begin{array}{l}359.48 \cdot \mathrm{B} \\
520.94 \mathrm{~A} \\
540.71 \mathrm{~A}\end{array}$ \\
\hline Interaediário & $\begin{array}{l}\text { Anhenti } \\
\text { ESALP } \\
\text { Sertäorinho }\end{array}$ & $\begin{array}{c}- \\
61.73 \mathrm{~B} \\
62.27 \mathrm{~A}\end{array}$ & $\begin{array}{c}- \\
\text { B } 45.96 \mathrm{~B} \\
57.03 \mathrm{~A}\end{array}$ & $\begin{array}{c}115.18 \\
- \\
129.41\end{array}$ & $\begin{array}{l}60.17 \mathrm{C} \\
64.88 \mathrm{~B} \\
77.20 \mathrm{~A}\end{array}$ & $\begin{array}{l}1.53 \mathrm{C} \\
1.60 \mathrm{~B} \\
1.87 \mathrm{~A}\end{array}$ & $\begin{array}{l}16.76 \\
10.44 \\
17.77\end{array}$ & $\begin{array}{l}\text { A } 2.06 \mathrm{~A} \\
\mathrm{~B} 1.95 \mathrm{~B} \\
\text { A } 2.07 \mathrm{~A}\end{array}$ & $\begin{array}{l}1811.18 \\
2613.42 \\
2563.26\end{array}$ & $\begin{array}{l}22.95 \mathrm{~B} \\
24.22 \mathrm{~A} \\
21.80 \mathrm{C}\end{array}$ & $\begin{array}{l}416.80 \mathrm{C} \\
631.41 \mathrm{~A} \\
559.67 \mathrm{~B}\end{array}$ \\
\hline Tardio & $\begin{array}{l}\text { Anhenbi } \\
\text { ESALP } \\
\text { Sertäozinho }\end{array}$ & $74.11 \mathrm{~B}$ & $\begin{array}{l}- \\
86.77 \mathrm{~A} \\
\mathrm{~A} 85.27 \mathrm{~A}\end{array}$ & $\begin{array}{l}136.71 \\
143.16 \\
142.82\end{array}$ & $\begin{array}{l}79.68 \mathrm{~B} \\
97.96 \mathrm{~A} \\
96.32 \mathrm{~A}\end{array}$ & $\begin{array}{l}1.70 \mathrm{C} \\
2.00 \mathrm{~A} \\
1.88 \mathrm{~B}\end{array}$ & $\begin{array}{l}21.73 \\
15.02 \\
24.23\end{array}$ & $\begin{array}{l}\text { A } 2.15 \mathrm{~A} \\
\text { B } 1.95 \mathrm{~B} \\
\mathrm{~A}-\end{array}$ & $\begin{array}{l}2228.00 \\
3025.05 \\
2394.36 \mathrm{~B}\end{array}$ & $\begin{array}{l}22.03 \mathrm{~A} \\
21.24 \mathrm{~A} \\
20.28 \mathrm{~B}\end{array}$ & $\begin{array}{l}495.65 \mathrm{~B} \\
645.47 \mathrm{~A} \\
505.47 \mathrm{~B}\end{array}$ \\
\hline Precoce & & 56.88 & 44.50 & 119.0 & 63.30 & 1.53 & 13.36 & 1.97 & 2100.05 & 22.58 & 473.71 \\
\hline Internediário & & 62.00 & 51.50 & 122.29 & 67.42 & 1.60 & 14.99 & 2.03 & 2329.29 & 22.99 & 535.97 \\
\hline Tardio & & 75.36 & 86.02 & 140.90 & 91.32 & 1.86 & 20.33 & 2.05 & 2549.14 & 21.18 & 548.86 \\
\hline Precoce & & 58.60 & 44.00 & 120.30 & 57.00 & 1.46 & 14.75 & 2.03 & 2373.00 & 22.83 & 537.90 \\
\hline Internediário & Testewunha & 66.50 & 64.50 & 124.10 & 80.70 & 1.65 & 21.22 & 2.23 & 2509.00 & 22.81 & 572.30 \\
\hline Tardio & & 75.00 & 81.40 & 138.20 & 84.80 & 1.91 & 22.36 & 2.06 & 2694.00 & 21.90 & 589.70 \\
\hline 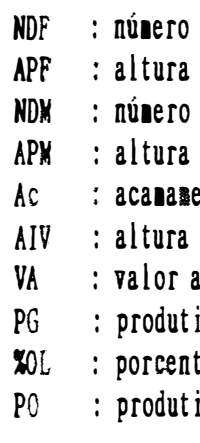 & $\begin{array}{l}\text { de dias para } \\
\text { da planta no } \\
\text { de dias para } \\
\text { da planta na } \\
\text { manto } \\
\text { de inserçâo } \\
\text { agronônico } \\
\text { ividade de gr } \\
\text { tage de óleo } \\
\text { ividade de } 61\end{array}$ & $\begin{array}{l}\text { floresc } \\
0 \text { floresc } \\
\text { a naturid } \\
\text { a naturid } \\
\text { da prime } \\
\text { rãos } \\
0 \\
\text { leo }\end{array}$ & $\begin{array}{l}\text { cinento } \\
\text { cinento } \\
\text { dade } \\
\text { dade } \\
\text { eira vage }\end{array}$ & & & & & & & & \\
\hline
\end{tabular}


Tabela 38. Valores médios de locais para todos os caracteres, em base às médias de cada grupos de maturidade, semeadura entre $30 / 11$ e $12 / 12 / 84$.

\begin{tabular}{|c|c|c|c|c|c|c|c|c|c|c|}
\hline \multirow[b]{2}{*}{ Local } & \multicolumn{10}{|c|}{ Caracteres } \\
\hline & NDF & $A P F$ & NDH & APM & $A C$ & AIV & VA & $P G$ & $30 t$ & PO \\
\hline Anhembi & - & - & 121.38 & 65.24 & 1.56 & 17.16 & 2.05 & 1879.08 & 22.47 & 423.98 \\
\hline ESALQ & 64.31 & 56.71 & 143.16 & 73.38 & 1.72 & 12.63 & 1.95 & 2620.81 & 22.99 & 599.28 \\
\hline Sertãozinho & 65.18 & 64.63 & 132.66 & 80.41 & 1.71 & 18.89 & 2.06 & 2478.58 & 21.30 & 535.28 \\
\hline
\end{tabular}

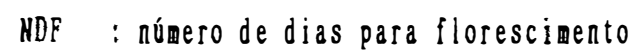

$\triangle P F$ : altura da planta no florescimento

NDY : número de dias para maturidade

APN : altura da planta na maturidade

Ac: acamamento

AIV : altura de insergaa da primeira vage

Vh : valor agronôtico

PO : produtividade de grãos

\$OL : porcentager de 6leo

Po : produtividade de bleo 
Tabela 39. Estimativas dos coeficientes de correlações gené-

ticas $\left(\Gamma_{\mathrm{g}}\right)$ ao nível de locais individuais e reunidos entre todos os possíveis pares formados com dez caracteres. Grupos de Maturidade: Precoce, Intermediário e Tardio. Soja, semeadura entre $30 / 11$ e $12 / 12 / 84$.

\begin{tabular}{|c|c|c|c|c|c|c|c|c|c|c|c|c|}
\hline \multirow{3}{*}{$\begin{array}{c}\text { Pares } \\
\text { de } \\
\text { Caract. }\end{array}$} & \multicolumn{4}{|c|}{ PRECOCE } & \multicolumn{4}{|c|}{ INTERMEdIÁRIO } & \multicolumn{4}{|c|}{ TARDIO } \\
\hline & \multicolumn{4}{|c|}{$\Gamma_{G}$} & \multicolumn{4}{|c|}{$\Gamma_{G}$} & \multicolumn{4}{|c|}{$\Gamma_{G}$} \\
\hline & Anheno $\mathrm{i}$ & BSALQ & $\begin{array}{l}\text { Sertão } \\
\text { zinho }\end{array}$ & $\begin{array}{l}\text { Locais } \\
\text { Reuni- } \\
\text { dos }\end{array}$ & Anhenbi & BSALQ & $\begin{array}{l}\text { Sertão } \\
\text { zinho }\end{array}$ & $\begin{array}{l}\text { Locais } \\
\text { Reuni- } \\
\text { dos }\end{array}$ & Anhenbi & ESALQ & $\begin{array}{l}\text { Sertão } \\
\text { zinho }\end{array}$ & $\begin{array}{l}\text { Locais } \\
\text { Reuni- } \\
\text { dos }\end{array}$ \\
\hline $\mathrm{PG} / \mathrm{KOL}$ & $0.641 \neq$ & $0.146 \mathrm{~ns}$ & $0.477 * 4$ & $0.449 * *$ & - & - & $0.428 \mathrm{~ns}$ & - & $0.655 \$$ & $0.194 \mathrm{~ns}$ & - & 0.354 \\
\hline $\mathrm{PG} / \mathrm{PO}$ & $0.996 * \$$ & $0.908 * \approx$ & $0.931 *$ & $0.945 * \approx$ & - & - & $0.941 *$ & - & $0.978 \$$ & $0.972 *$ & 0.922 & $=0.962 *$ \\
\hline $\mathrm{PG} / \mathrm{KDF}$ & - & 1.030 & 1.090 & $-0.190 \mathrm{~ns}$ & - & - & $-0.007 \mathrm{~ns}$ & - & - & $0.551^{*}$ & $-0.112 \mathrm{ss}$ & $\mathrm{s} \quad 0.252 \mathrm{~ns}$ \\
\hline $\mathrm{PG} / \mathrm{APF}$ & - & 1.340 & 1.290 & $-0.321 \%$ & - & - & $-0.162 \mathrm{~ns}$ & - & - & $0.344 \mathrm{~ns}$ & $-0.058 \mathrm{~ns}$ & s 0.171 as \\
\hline $\mathrm{PG} / \mathrm{NDN}$ & $-0.568 \$$ & - & $-0.284 n s$ & $-0.485 *$ & - & - & $0.576 \neq 4$ & - & $-0.221 \mathrm{~ns}$ & - & $-0.150 \mathrm{~ns}$ & $s-0.147 \mathrm{as}$ \\
\hline$P G / A P M$ & $0.475 *$ & $0.526 \approx$ & $-0.055 \mathrm{~ns}$ & $0.309 *$ & - & - & $-0.298 \mathrm{~ns}$ & - & $0.649 * \approx$ & - & $0.226 \mathrm{~ns}$ & $\begin{array}{ll}0.500 \mathrm{~ns}\end{array}$ \\
\hline $\mathrm{PG} / \mathrm{Ac}$ & $0.010 \mathrm{~ns}$ & $-0.167 \mathrm{~ns}$ & $-0.274 n s$ & $-0.270 \mathrm{cs}$ & - & - & $-0.597 * z$ & - & $0.148 n s$ & $0.408 \mathrm{~ns}$ & $-0.033 \mathrm{~ns}$ & s $0.111 \mathrm{~ns}$ \\
\hline$P G / V A$ & $0.721 \neq$ & $0.216 \mathrm{as}$ & $0.450 \$$ & $0.561 * 4$ & - & - & $0.158 \mathrm{as}$ & - & 1.0002 & $0.784 \$ \$$ & - & 0.93944 \\
\hline $\mathrm{PG} / \mathrm{AIV}$ & $0.592 \neq$ & $0.122 \mathrm{~ns}$ & $0.095 \mathrm{~ns}$ & 0.284 & - & - & $-0.012 \mathrm{~ns}$ & $\because$ & $0.550 \mathrm{~ns}$ & - & $0.295 \mathrm{~ns}$ & S $0.624 * 4$ \\
\hline$\times 0 L / P O$ & 0.710 & $0.548 \neq$ & $0.775 *$ & $0.699 * *$ & $0.559 \notin$ & - & 0.70848 & $0.685 \pm$ & $0.796 \$$ & $0.418 \mathrm{as}$ & - & 0.56344 \\
\hline$\times 0 L / \mathrm{KDF}$ & - & $-0.478 * \pm$ & $-0.245 \mathrm{~ns}$ & $-0.389 \notin *$ & - & $0.312 n s$ & $-0.061 \mathrm{~ns}$ & $0.128 \mathrm{~ns}$ & - & $-0.021 \mathrm{~ns}$ & - & - \\
\hline$\times 0 L / A P F$ & - & $-0.505 \approx$ & $-0.408 * z$ & $-0.439 * \approx$ & - & $0.500 \mathrm{~ns}$ & $-0.174 \mathrm{~ns}$ & $0.167 \mathrm{~ns}$ & - & $0.373 \mathrm{~ns}$ & - & - \\
\hline NOL/NDN & $-0.143 \mathrm{~ns}$ & - & $-0.206 \mathrm{~ns}$ & $-0.182 n s$ & $-0.011 \mathrm{~ns}$ & - & $0.123 \mathrm{~ns}$ & $0.206 \mathrm{~ns}$ & $-0.779 \$ *$ & & - & - \\
\hline XoL/APN & $-0.005 n s$ & $-0.229 \mathrm{~ns}$ & $-0.140 \mathrm{~ns}$ & $-0.160 \mathrm{~ns}$ & $0.448 *$ & $0.334:$ & $-0.119 n s$ & $0.280 \mathrm{~ns}$ & $0.040 \mathrm{~ns}$ & - & - & - \\
\hline $0 \mathrm{DL} / \mathrm{Ac}$ & $-0.237 n s$ & $-0.592 * 2$ & $-0.551^{* 1}$ & $-0.550 * 4$ & $0.070 \mathrm{~ns}$ & $0.304 \mathrm{~ns}$ & $-0.120 \mathrm{~ns}$ & 0.181 ns & $-0.195 \mathrm{~ns}$ & $0.275 \mathrm{~ns}$ & . & $0.093 \mathrm{~ns}$ \\
\hline XOL/VA & $0.142 n s$ & $0.274 \mathrm{~ns}$ & $0.231 \mathrm{~ns}$ & $0.077 \mathrm{~ns}$ & $0.416 \$$ & $0.215 \mathrm{~ns}$ & $-0.091 \mathrm{~ns}$ & $0.210 \mathrm{~ns}$ & $0,417 \mathrm{~ns}$ & $0.199 \mathrm{~ns}$ & . & $0.175 n s$ \\
\hline$x_{0 L} / \mathrm{AIV}$ & $-0.090 \mathrm{~ns}$ & $-0.457 * 4$ & $-0.250 \mathrm{~ns}$ & -0.296 & $0.593 * \approx$ & $0.264 \mathrm{~ns}$ & $-0.279 n \mathrm{~s}$ & $0.255 \mathrm{~ns}$ & $0.076 \mathrm{~ns}$ & - & - & - \\
\hline $\mathrm{PO} / \mathrm{NDF}$ & - & $0.794 * 4$ & $-0.391 *$ & $0.144 \mathrm{as}$ & - & - & $-0.013 \mathrm{~ns}$ & - - & - & 0.510 & $-0.200 \mathrm{~ns}$ & s. $0,173 n s$ \\
\hline $\mathrm{PO} / \mathrm{APF}$ & - & 0.683 & -0.6 & -0.1 & - & - & -0. & - & - & $0.417 \mathrm{~ns}$ & -0 & s. $0.216 n s$ \\
\hline PO/NDY & $-0.572 \neq$ & - & -0 & -0.3 & $0: 027 \mathrm{as}$ & - & & 0.620 & $-0.380 \mathrm{~ns}$ & - & $-0.350 \mathrm{~ns}$ & $8-0.300 \mathrm{~ns}$ \\
\hline PO/APN & $0.419 \notin$ & $0.139 \mathrm{~ns}$ & $-0.106 \mathrm{~ns}$ & & $8 n s$ & 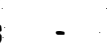 & & $0.593 * 4$ & $0.525 t$ & - & 3ns & \\
\hline $\mathrm{PO} / \mathrm{AC}$ & $-0.022 \mathrm{~ns}$ & $-0.383 *$ & -0.44 & -0.3 & $0.403 *$ & - & -0. & $0.286 \mathrm{~ns}$ & $0.066 \mathrm{~ns}$ & $0.458 \mathrm{~ns}$ & $-0.364 n \mathrm{~s}$ & 19ns \\
\hline PO/VA & $0.635 \neq$ & $0.273 \mathrm{~ns}$ & & & $0.854 *$ & - & & $0.777 *$ & $0.972 *$ & $0.674:$ & $=$ & \\
\hline PO/AIV & $0.471 \neq$ & $-0.110 \mathrm{~ns}$ & $-0.028 \mathrm{~ns}$ & $0.123 \mathrm{~ns}$ & $0.906 *$ & - & $-0.339 n s$ & 0.741 & $0.456 \mathrm{~ns}$ & - & $160 \mathrm{~ns}$ & S $0.544:$ \\
\hline $\mathrm{NDF} / \mathrm{APF}$ & - & 0.793 & 0.677 & 0.498 & - & 0.960 & 0.930 & 0.634 & - & 0.898 & 3 & 0.600 \\
\hline NDF/NDN & - & - & 0.206 & 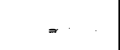 & - & - & 0.718 & - & - & - & 0.921 & - \\
\hline $\mathrm{NDF} / \mathrm{APN}$ & - & 0.4 & 0.637 & & - & 0.700 & 0.789 & 0.757 & - & - & 0.784 & - \\
\hline $\mathrm{NDP} / \mathrm{AC}$ & - & 0.504 & 0. & $v_{0}$ & - & 0.577 & 0.722 & 0.683 & - & 0.841 & 0.854 & 0.903 \\
\hline $\mathrm{NDF} / \mathrm{VA}$ & - & -0.123 & 0.500 & 0.241 & - & 0.784 & 0.628 & 0.748 & - & 0.662 & - & - \\
\hline NDF/AIV & - & 0.781 & 0.398 & 0.729 & - & 0.940 & 0.826 & 0.883 & - & - & 0.756 & - \\
\hline
\end{tabular}


... cont inuação

\begin{tabular}{|c|c|c|c|c|c|c|c|c|c|c|c|c|}
\hline \multirow{3}{*}{$\begin{array}{c}\text { Pares } \\
\text { de } \\
\text { Caract. }\end{array}$} & \multicolumn{4}{|c|}{ PRECOCE } & \multicolumn{4}{|c|}{ IRTERMEDI ARIO } & \multicolumn{4}{|c|}{ TAROIO } \\
\hline & \multicolumn{4}{|c|}{$\Gamma_{G}$} & \multicolumn{4}{|c|}{$\Gamma_{G}$} & \multicolumn{4}{|c|}{$r_{G}$} \\
\hline & Anheribi & ESLAQ & $\begin{array}{l}\text { Sertão } \\
\text { zinho }\end{array}$ & $\begin{array}{l}\text { Locais } \\
\text { Reuni- } \\
\text { dos }\end{array}$ & Anhenbi & ESALQ & $\begin{array}{l}\text { Sertão } \\
\text { zinho }\end{array}$ & $\begin{array}{l}\text { Loca is } \\
\text { Reuni- } \\
\text { dos }\end{array}$ & ANEEVBI & ESALQ & $\begin{array}{l}\text { SERTYO } \\
\text { ZINPDO }\end{array}$ & $\begin{array}{l}\text { Loca is } \\
\text { Reuni- } \\
\text { dos }\end{array}$ \\
\hline$\triangle P F / L D A$ & - & - & 0.063 & - & - & - & 0.707 & - & - & - & 0.734 & - \\
\hline APF/APY & - & 0.587 & 0.439 & 0.590 & - & 0.804 & 0.808 & 0.780 & - & - & 0.935 & - \\
\hline APF/AC & - & 0.692 & 0.931 & 0.801 & - & 0.714 & 0.757 & 0.745 & - & 0.871 & 0.994 & 0.965 \\
\hline $\mathrm{APF} / \mathrm{VA}$ & - & -0.034 & 0.144 & 0.084 & - & 0.821 & 0.449 & 0.681 & - & 0.551 & - & - \\
\hline APF/AIV & - & 0.743 & 0.723 & 0.793 & - & 0.978 & 0.803 & 0.881 & - & - & 0.796 & - \\
\hline $\mathrm{NDN} / \mathrm{APK}$ & -0.510 & - & -0.141 & -0.242 & 0.077 & - & 0.476 & 0.390 & 0.454 & - & 0.489 & - \\
\hline $\mathrm{NDM} / \mathrm{dc}$ & -0.177 & - & 0.144 & -0.007 & -0.168 & - & 0.421 & 0.250 & 0.731 & - & 0.620 & 0.538 \\
\hline $\mathrm{NDH} / \mathrm{VA}$ & -0.648 & - & -0.143 & -0.375 & -0.219 & - & -0.223 & 0.193 & -0.227 & - & - & - \\
\hline NDN/AIV & -0.603 & - & 0.016 & -0.239 & 0.014 & - & 0.494 & 0.357 & 0.452 & - & 0.615 & - \\
\hline APN/AC & 0.531 & 0.696 & 0.858 & 0.712 & 0.652 & 0.791 & 0.877 & 0.799 & 0.941 & - & 0.729 & 0.910 \\
\hline $\mathrm{APN} / \mathrm{VA}$ & 0.786 & 0.411 & 0.755 & 0.754 & 0.900 & 0.808 & 0.782 & 0.872 & 0.488 & - & - & - \\
\hline APN/AIV & 0.900 & 0.783 & 0.751 & 0.884 & 1.000 & 0.980 & 0.974 & 0.966 & 0.955 & - & 0.815 & 0.934 \\
\hline$A C / V A$ & 0.233 & -0.154 & 0.138 & 0.148 & 0.471 & 0.397 & 0.410 & 0.519 & 0.112 & 0.235 & - & 0.164 \\
\hline $\mathrm{AC} / \mathrm{AIV}$ & 0.455 & 0.634 & 0.750 & 0.683 & 0.496 & 0.747 & 0.763 & 0.731 & 1.000 & - & 0.620 & 0.771 \\
\hline $\mathrm{VA} / \mathrm{AIV}$ & 0.891 & 0.220 & 0.497 & 0.775 & 0.961 & 0.915 & 0.836 & 0.934 & 0.104 & $\therefore$ & - & - \\
\hline
\end{tabular}

* e \$: significativo a $5 \%$ e is de probabilidade pelo teste $t$, respectivanente

ns: não significativo

HOF : aúnero de dias para florescinento

APF : altura da planta no florescinento

YON : núnero de dias para naturidade

APY : altura da planta na saturidade

Ac : acananento

AIV : altura de inserção da prineira vagen

VA : valor agronônico

PG $\quad$ produtividade de grõos

*oL : porcentager de óleo

po : produtividade de bleo 
Tabela 40 . Estimativas dos coeficientes de correlações fenotípicas $\left(\Gamma_{F}\right)$ ao nível de locais individuais e reunidos, entre todos os possíveis pares formados com dez caracteres. Grupos de maturidade: Precoce, Intermediário e Tardio. Soja, semeadura entre $30 / 11$ e $12 / 12 / 84$.

\begin{tabular}{|c|c|c|c|c|c|c|c|c|c|c|c|c|}
\hline \multirow{3}{*}{$\begin{array}{c}\text { Pares } \\
\text { de } \\
\text { Caract. }\end{array}$} & \multicolumn{4}{|c|}{ PRECOCE } & \multicolumn{4}{|c|}{ INTERYEDI LRIO } & \multicolumn{4}{|c|}{ TARDIO } \\
\hline & \multicolumn{4}{|c|}{$\Gamma_{F}$} & \multicolumn{4}{|c|}{$\Gamma_{F}$} & \multicolumn{4}{|c|}{$\Gamma_{F}$} \\
\hline & Anheabi & ESLAP & $\begin{array}{l}\text { Sertão } \\
\text { zinho }\end{array}$ & $\begin{array}{l}\text { Locais } \\
\text { Reuni- } \\
\text { dos }\end{array}$ & Anhe bi & ESALQ & $\begin{array}{l}\text { Sertão } \\
\text { zinho }\end{array}$ & $\begin{array}{l}\text { Locais } \\
\text { Reuni- } \\
\text { dos }\end{array}$ & Anhe abi & ESALQ & $\begin{array}{l}\text { Sertão } \\
\text { zinho }\end{array}$ & $\begin{array}{l}\text { Locais } \\
\text { Reuni- } \\
\text { dos }\end{array}$ \\
\hline $\mathrm{PG} / \mathrm{NOL}_{\mathrm{O}}$ & 0.518 & 0.098 & 0.362 & 0.384 & - & - & 0.336 & - & 0.540 & 0.248 & - & 0.270 \\
\hline $\mathrm{PG} / \mathrm{PO}$ & 0.964 & 0.951 & 0.937 & 0.945 & - & - & 0.949 & - & 0.979 & 0.975 & 0.848 & 0.958 \\
\hline PG/NDF & - & 1.560 & 1.070 & -0.573 & - & - & -0.004 & - & - & 0.375 & -0.108 & 0.203 \\
\hline$P G / A P P$ & $\therefore$ & 1.900 & 1.600 & -0.472 & - & - & -0.088 & - & - & 0.213 & -0.002 & 0.141 \\
\hline PG/NDY & -0.244 & - & -0.152 & -0.321 & - & - & 0.400 & - & -0.172 & - & -0.140 & -0.124 \\
\hline PG/APY & 0.483 & 0.267 & -0.005 & 0.283 & - & - & -0.186 & - & 0.475 & - & 0.209 & 0.405 \\
\hline $\mathrm{PG} / \mathrm{AC}$ & 0.028 & -0.047 & -0.206 & -0.214 & - & - & -0.363 & - & 0.141 & 0.201 & -0.054 & 0.082 \\
\hline $\mathrm{PG} / \mathrm{VA}$ & 0.651 & 0.279 & 0.389 & 0.514 & - & - & 0.134 & - & 0.833 & 0.728 & - & 0.850 \\
\hline PG/AIV & 0.475 & 0.176 & 0.076 & 0.254 & - & - & -0.044 & - & 0.423 & - & 0.192 & 0.489 \\
\hline$\times 0 \mathrm{~L} / \mathrm{PO}$ & 0.624 & 0.363 & 0.639 & 0.624 & 0.456 & - & 0.610 & 0.533 & 0.696 & 0.453 & - & 0.493 \\
\hline$\times 0 \mathrm{~L} / \mathrm{NDF}$ & 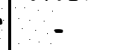 & -0.445 & -0.234 & -0.382 & - & 0.230 & -0.052 & 0.107 & - & -0.124 & - & - \\
\hline$\times 0 \mathrm{~L} / \mathrm{APF}$ & - & -0.453 & -0.294 & -0.393 & - & 0.248 & -0.151 & 0.111 & - & 0.208 & - & - \\
\hline XOL/NDY & -0.120 & - & -0.137 & -0.147 & -0.020 & - & 0.129 & 0.189 & -0.689 & - & - & - \\
\hline YOL/APV & -0.013 & -0.214 & -0.111 & -0.150 & 0.338 & 0.252 & -0.069 & 0.255 & 0.016 & - & - & - \\
\hline$\$ 0 L / A c$ & -0.220 & -0.508 & -0.152 & -0.514 & 0.074 & 0.125 & -0.155 & 0.142 & -0.223 & 0.080 & - & -0.105 \\
\hline $\mathrm{NOL} / \mathrm{YA}$ & 0.151 & 0.227 & 0.158 & 0.072 & 0.339 & 0.209 & -0.006 & 0.202 & 0.336 & -0.051 & - & 0.182 \\
\hline XOL/AIV & -0.053 & -0.374 & 0.197 & -0.266 & 0.434 & 0.147 & -0.200 & 0.217 & 0.055 & - & - & - \\
\hline PO/YDF & - & 0.176 & -0.342 & 0.008 & - & - & -0.009 & - & - & 0.320 & -0.206 & 0.123 \\
\hline $\mathrm{PO} / \mathrm{APF}$ & - & 0.228 & -0.412 & -0.144 & - & - & -0.117 & - & - & 0.248 & -0.031 & 0.170 \\
\hline PO/NDN & -0.357 & - & -0.166 & -0.278 & 0.261 & - & 0.392 & 0.534 & -0.309 & - & -0.309 & -0.254 \\
\hline PO/APY & 0.448 & 0.128 & -0.032 & 0.154 & 0.151 & - & -0.175 & 0.504 & 0.391 & - & 0.250 & 0.391 \\
\hline $\mathrm{PO} / \mathrm{AC}$ & -0.007 & -0.178 & -0.318 & -0.326 & 0.359 & - & -0.372 & 0.267 & 0.027 & 0.213 & -0.314 & -0.050 \\
\hline PO/VA & 0.600 & 0.308 & 0.375 & 0.448 & 0.800 & - & 0.068 & 0.646 & 0.782 & 0.650 & - & 0.778 \\
\hline PO/AIV & 0.406 & 0.058 & -0.004 & 0.129 & 0.687 & - & -0.249 & 0.576 & 0.307 & - & 0.110 & 0.421 \\
\hline $\mathrm{NDF} / \mathrm{APF}$ & - & 0.729 & 0.542 & 0.460 & - & 0.856 & 0.889 & 0.612 & - & 0.851 & 0.841 & 0.594 \\
\hline $\mathrm{NDE} / \mathrm{NDN}$ & - & - & 0.172 & - & - & - & 0.692 & - & - & - & 0.877 & - \\
\hline NOE/APY & - & 0.434 & 0.569 & 0.534 & - & 0.663 & 0.769 & 0.740 & - & - & 0.735 & - \\
\hline $\mathrm{NDF} / \mathrm{AC}$ & - & 0.454 & 0.609 & 0.579 & - & 0.537 & 0.679 & 0.659 & - & 0.798 & 0.718 & 0.836 \\
\hline
\end{tabular}

continus ... 
... continuação

\begin{tabular}{|c|c|c|c|c|c|c|c|c|c|c|c|c|}
\hline \multirow{3}{*}{$\begin{array}{c}\text { Pares } \\
\text { de } \\
\text { Caract. }\end{array}$} & \multicolumn{4}{|c|}{ PRRCOCE } & \multicolumn{4}{|c|}{ IITERMEDIARIO } & \multicolumn{4}{|c|}{ TARD10 } \\
\hline & \multicolumn{4}{|c|}{$\Gamma_{F}$} & \multicolumn{4}{|c|}{$\Gamma_{F}$} & \multicolumn{4}{|c|}{$\Gamma_{F}$} \\
\hline & Anhenbi & ESLAQ & $\begin{array}{l}\text { Sertâo } \\
\text { zinho }\end{array}$ & $\begin{array}{l}\text { Locais } \\
\text { Reuni- } \\
\text { dos }\end{array}$ & Anheabi & ESALQ & $\begin{array}{l}\text { Sertâo } \\
\text { zinho }\end{array}$ & $\begin{array}{l}\text { Locais } \\
\text { Reuni- } \\
\text { dos }\end{array}$ & ANEEWBI & ESALQ & $\begin{array}{l}\text { SERTAOO } \\
\text { ZINHO }\end{array}$ & $\begin{array}{l}\text { Loca is } \\
\text { Reuni- } \\
\text { dos }\end{array}$ \\
\hline NDF/VA & - & -0.071 & 0.446 & 0.227 & - & 0.748 & 0.532 & 0.719 & - & 0.462 & 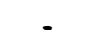 & - \\
\hline NDF/AIV & - & 0.652 & 0.172 & 0.623 & - & 0.802 & 0.734 & 0.821 & - & - & 0.676 & - \\
\hline APF/:DON & - & - & 0.127 & - & - & - & 0.658 & - & - & - & 0.695 & - \\
\hline APF/APY & - & 0.546 & 0.510 & 0.555 & - & 0.745 & 0.754 & 0.762 & - & - & 0.835 & - \\
\hline $\mathrm{APF} / \mathrm{AC}$ & - & 0.594 & 0.673 & 0.707 & - & 0.677 & 0.718 & 0.724 & - & 0.760 & 0.792 & 0.863 \\
\hline $\mathrm{APF} / \mathrm{VA}$ & - & 0.035 & 0.117 & 0.091 & - & 0.699 & 0.371 & 0.628 & - & 0.339 & - & - \\
\hline APF/AIV & - & 0.566 & 0.515 & 0.631 & - & 0.802 & 0.693 & 0.806 & - & - & 0.604 & - \\
\hline NDW/APM & -0.382 & - & -0.025 & -0.168 & 0.090 & - & 0.456 & 0.372 & 0.415 & - & 0.456 & - \\
\hline $\mathrm{NDW} / \mathrm{AC}$ & -0.143 & - & 0.149 & -0.018 & 0.114 & - & 0.373 & 0.232 & 0.521 & - & 0.537 & 0.481 \\
\hline NDW/VA & -0.546 & - & -0.083 & -0.318 & 0.175 & - & 0.183 & 0.182 & -0.147 & - & - & - \\
\hline $\mathrm{NDM} / \mathrm{AIV}$ & -0.466 & - & 0.007 & -0.191 & 0.033 & - & 0.416 & 0.326 & 0.393 & - & 0.485 & - \\
\hline $\mathrm{APM} / \mathrm{AC}$ & 0.483 & 0.642 & 0.686 & 0.672 & 0.552 & 0.737 & 0.803 & 0.767 & 0.811 & - & 0.603 & 0.833 \\
\hline $\mathrm{APM} / \mathrm{VA}$ & 0.804 & 0.370 & 0.621 & 0.715 & 0.831 & 0.754 & 0.686 & 0.847 & 0.345 & - & - & - \\
\hline $\mathrm{APN} / \mathrm{AIV}$ & 0.800 & 0.712 & 0.136 & 0.791 & 0.841 & 0.842 & 0.864 & 0.912 & 0.841 & - & 0.702 & 0.861 \\
\hline$A c / V A$ & 0.211 & -0.111 & 0.145 & 0.141 & 0.429 & 0.301 & 0.294 & 0.483 & -0.080 & 0.058 & - & 0.052 \\
\hline $\mathrm{Ac} / \mathrm{AIV}$ & 0.379 & 0.533 & 0.477 & 0.603 & 0.415 & 0.664 & -0.013 & 0.692 & 0.725 & - & 0.466 & 0.662 \\
\hline VA/AIV & 0.767 & 0.200 & 0.339 & 0.682 & 0.822 & 0.739 & 0.644 & 0.870 & 0.230 & - & - & - \\
\hline
\end{tabular}

MDP : núnero de dias para florescinento

APF : altura da planta no florescinento

HON : núnero de dias para asturidade

APN : altura da planta na aturidade

Ac : acasanento

AIV : altura de inserção da prineita vages

VA : valor agronônico

PG : produtividade de grâos

*OL : porcentages de óleo

Po : produtividade de oleo 
Tabela 41. Estimativas dos coeficiêntes de determinação genotípica (b), obtidos ao nível de médias de parcelas para dez caracteres dos grupos de maturi dade Precoce, Intermediário e Tardios, avaliados em três locais. Soja, Semeadura entre $30 / 11$ e $12 / 12 / 84$

\begin{tabular}{|c|c|c|c|c|c|c|c|c|c|c|c|}
\hline $\begin{array}{l}\text { Grupo de } \\
\text { Maturidade }\end{array}$ & Local & NDF & APF & NDN & APN & $A C$ & AIV & Vh & $P G$ & NOL & Po \\
\hline \multirow{3}{*}{ Precoce } & Anhenbi & - & - & 0.6180 & 0.7506 & 0.8073 & 0.6008 & 0.7575 & 0.5234 & 0.7500 & 0.6367 \\
\hline & ESALQ & 0.9273 & 0.7380 & - & 0.8668 & 0.7159 & 0.6241 & 0.5025 & 0.1645 & 0.8357 & 0.2335 \\
\hline & Sertåozinho & 0.9575 & 0.5550 & 0.5774 & 0.7400 & 0.5200 & 0.4046 & 0.6413 & 0.4680 & 0.8042 & 0.5077 \\
\hline \multirow{3}{*}{ Internediário } & Anhenbi & - & - & 0.7057 & 0.6936 & 0.7309 & 0.6471 & 0.8644 & 0.7001 & 0.6354 & 0.5493 \\
\hline & ESALQ & 0.9773 & 0.6310 & - & 0.8266 & 0.7225 & 0.5783 & 0.8549 & 0.2855 & 0.4330 & 0.3455 \\
\hline & Sertåozinho & 0.9631 & 0.8385 & 0.8821 & 0.9305 & 0.7979 & 0.6413 & 0.6028 & 0.2922 & 0.5186 & 0.3581 \\
\hline \multirow{3}{*}{ Tardio } & Anbenbi & - & - & 0.9127 & 0.8682 & 0.4257 & 0.5419 & 0.5202 & 0.5419 & 0.7714 & 0.6137 \\
\hline & ESALP & 0.7632 & 0.5714 & 0.7554 & 0.8919 & 0.4970 & 0.8645 & 0.6953 & 0.6632 & 0.7046 & 0.6374 \\
\hline & Sertåozinho & 0.9459 & 0.8271 & 0.9193 & 0.7879 & 0.5513 & 0.5651 & - & 0.7272 & 0.1711 & 0.8504 \\
\hline \multicolumn{2}{|l|}{ Precoce } & 0.9678 & 0.7796 & 0.6869 & 0.9148 & 0.8251 & 0.7314 & 0.8052 & 0.5762 & 0.9136 & 0.6458 \\
\hline \multicolumn{2}{|l|}{ Internediário } & 0.9848 & 0.8579 & 0.8780 & 0.9294 & 0.8913 & 0.8286 & 0.9156 & 0.3942 & 0.7432 & 0.4730 \\
\hline \multicolumn{2}{|l|}{ Tardio } & 0.9225 & 0.8010 & 0.6878 & 0.8059 & 0.7362 & 0.6433 & 0.7277 & 0.8132 & 0.6391 & 0.8326 \\
\hline \multicolumn{12}{|c|}{ : núnero de dias para florescinento } \\
\hline \multicolumn{12}{|c|}{ inento } \\
\hline \multicolumn{12}{|c|}{ de dias para naturidade } \\
\hline \multicolumn{12}{|c|}{ altura da planta na aturidade } \\
\hline \multicolumn{12}{|c|}{ acananento } \\
\hline \multicolumn{12}{|c|}{ altura de inserção da prineira vages } \\
\hline \multicolumn{12}{|c|}{ valor agronôrico } \\
\hline \multicolumn{12}{|c|}{ produtividade de grãos } \\
\hline \multicolumn{12}{|c|}{ porcentage de óleo } \\
\hline PO : produt & ividade de oleo & & & & & & & & & & \\
\hline
\end{tabular}


Tabela 42. Produtividade de Grãos (Kg/ha): Valores médios dos dez genótipos superiores de cada grupo de maturidade, avaliados em três locais com duas repetições por local. Soja, semeadura entre $30 / 11$ e $12 / 12 / 84$.

\begin{tabular}{|c|c|c|c|c|c|c|c|c|c|c|c|}
\hline \multicolumn{4}{|c|}{ Precoce } & \multicolumn{4}{|c|}{ Internediário } & \multicolumn{4}{|l|}{ Tardio } \\
\hline Genótipo & N & Média & TUKEY & Genótipo & N & Média & TOKEY & Genotipo & $N$ & Média T & TUKEY \\
\hline 27. FT-2 & 6 & 2586.30 & $A$ & 36. SOC 81-216 & 6 & 2877.00 & $A$ & 17. EMGOPA 301 & 6 & 2949.30 & $A$ \\
\hline 04. $\operatorname{cobb}$ & 6 & 2575.70 & $A$ & 51. BR-9 (SAVANA) & 6 & 2801.30 & B & 03. CRISTALIMA-2 (S) & 6 & 2927.00 & $\Lambda$ \\
\hline 56. IT 79-3408 & 6 & 2544.30 & 1 & 49. TT-8 (ARAUCARIA) & 6 & 2773.00 & B. & 14. UFV ARAGUAIA & 6 & 2910.50 & 1 \\
\hline 33. SOC 81105 & 6 & 2526.30 & $A$ & 39. PARANAGOIANA & 6 & 2679.80 & C & 10. OFV -1 & 6 & 2903.50 & $B$ \\
\hline 32. SOC 8176 & 6 & 2460.50 & $A$ & 34. UFV-4 & 6 & 2668.70 & $c$ & 05. NUYBAIRA & 6 & 2882.70 & B \\
\hline 22. PLANALTO & 6 & 2455.70 & $A$ & 38. SOC $81-266$ & 6 & 2656.30 & c & 13. OFV -5 & 6 & 2861.00 & B \\
\hline 37. OC 7911 & 6 & 2394.50 & B & 45. $6079-1030$ & 6 & 2627.80 & c & 11. UFV-2 & 6 & 2825.30 & B \\
\hline 23. SOLINA & 6 & 2387.70 & B & 10. VIÇOJA & 6 & 2578.50 & D & 18. BR-10 (TERESINA) & 6 & 2789.70 & B \\
\hline 59. ONILO & 6 & 2385.80 & B & 28. SAO LUIS & 6 & 2554.80 & 0 & 08. IAC-9" & 6 & 2764.30 & $B$ \\
\hline 08. DAVIS & 6 & 2382.80 & B & 41. co 81-11103 & 6 & 2545.30 & 0 & 02. CRISTALINA-1.6 (C) & 16 & 2694.50 & $B$ \\
\hline
\end{tabular}

As nédias seguidas de sesıa letra não diferea entre si (TUKEY 5X)

N: no de obserraçōes

*: repetido cono testewunhe conva. 
Tabela 43. Porcentagem de 61 eo $(\%)$ : valores médios dos dez genótipos superiores de cada grupo de maturidade, avaliados em três locais com duas repetições por local. Soja, semeadura entre $30 / 11$ e $12 / 12 / 84$

\begin{tabular}{|c|c|c|c|c|c|c|c|c|c|c|c|}
\hline \multicolumn{4}{|l|}{ Precoce } & \multicolumn{4}{|c|}{ Interuediário } & \multicolumn{4}{|c|}{ Tardio } \\
\hline Genotipo & $N$ & nédia & TUKEY & Genótipo & $N$ & Nédia & TYKEY & Genotipo & $N$ & Média & TUKEY \\
\hline 34. SOC 81119 & 6 & 24.483 & A & 49. FT-8 (ARAOCÁRIA) & 6 & 24.850 & 1 & 12. OFV -3 & 6 & 22.883 & $A$ \\
\hline 04. cobb & 6 & 24.417 & $B$ & 39. PARAMAGOIAKA & 6 & 24.350 & $B$ & 06. PARANAGOIANA: & 6 & 22.667 & $A$ \\
\hline 39. OC 7984 & 6 & 24.133 & $c$ & 47. 60 79-7012 & 6 & 24.067 & $c$ & 17. EKGOPA 301 & 6 & 22.667 & $A$ \\
\hline 60. BR- $(15.401)$ & 6 & 23.900 & 0 & 21. HARDEE & 6 & 24.050 & 0 & 08. $1 A C-9^{*}$ & 6 & 22.517 & $\therefore$ \\
\hline 54. FT 81-2706 & 6 & 23.883 & $E$ & 40. $60.81-8065$ & 6 & 24.000 & $E$ & 11. OFV-2 & 6 & 22.333 & $A$ \\
\hline 22. PLANALTO & 6 & 23.783 & $F$ & 36. SOC $81-216$ & 6 & 23.883 & $F$ & 02. CRISTALIRA-1 (C) & 6 & 22.200 & $A$ \\
\hline 32. SOC 8176 & 6 & 23.783 & $F$ & 20. HALPTON & 6 & 23.883 & f & 03. CRISTALIMA-2 (S) & 16 & 22.150 & 1 \\
\hline 37. OC 7911 & 6 & 23.767 & $G$ & 43, $6081-11094$ & 6 & 23.817 & $F$ & 14. OFV-ARAGOAJA & 6 & 21.733 & $A$ \\
\hline 63. OCEPAR-2 (IAPO) & 16 & 23.750 & $G$ & 34. OFV-4 & 6 & 23.783 & $G$ & 15. 60 79-1039 & 6 & 21.667 & A \\
\hline 21. PEROLA & 6 & 23.733 & 6 & 14. TIARAJO & 6 & 23.717 & 6 & 09. TROPICAL" & 6 & 21.633 & $B$ \\
\hline
\end{tabular}

As ádias sequidas de nesa letra aão diferes entre si (TOKEY 5\%)

N: no de observaçōes

\$: repetido cono testenuaha conun.

$\because$ repete no grupo de naturidade internediśrio e tardio 
Tabela 44. Produtividade de oleo (Kg/ha): valores médios dos dez genótipos superiores de cada grupo de maturidade, avaliados em três locais com duas repetições por local. Soja, semeadura entre $30 / 11$ e $12 / 12 / 84$

\begin{tabular}{|c|c|c|c|c|c|c|c|c|c|c|c|}
\hline \multicolumn{4}{|l|}{ Precoce } & \multicolumn{4}{|c|}{ Internediério } & \multicolumn{4}{|c|}{ Tardio } \\
\hline Genotipo & $N$ & Média & TYREY & Genotipo & $N$ & Nédia & TYXEY & Genótipo & N & Media & TUXEY \\
\hline 04. Cobb & 6 & 629.56 & $A$ & 49. FT-8 (ARAOCARIA) & 6 & 684.95 & A & 17. EMGOPA 301 & 6 & 669.60 & $A$ \\
\hline 37. OC 7911 & 6 & 605.92 & B & 36. SOC $81-216$ & 6 & 683.35 & 1 & 03. CRISTALINA-2 (S) & 6 & 648.743 & $A$ \\
\hline 56. ET 79-3408 & 6 & 591.06 & $c$ & 39. PARANACOIANA & 6 & 651.21 & $B$ & 11. ORV-2 & 6 & 635.01 & $A$ \\
\hline 22. PLAHALTO & 6 & 583.71 & $D$ & 51. BR-9 (SAVANA) & 6 & 647.78 & $B$ & 14. OPV-ARAGOAIA & 6 & 632.15 & $A$ \\
\hline 32. $50 C-8176$ & 6 & 583.20 & 0 & 34. OPV-4 & 6 & 637.55 & $c$ & 08. $\quad$ IAC- $9^{2}$ & 6 & 627.56 & $A$ \\
\hline 27. $\mathrm{FT}-2$ & 6 & 575.20 & $D$ & 38. S0C 81-266 & 6 & 622.54 & 0 & 10. OPV-1 & 6 & 603.34 & B \\
\hline 63. OCEPAR-2 (IAPO) & 6 & 562.71 & $D$ & 45. $6079-1030$ & 6 & 612.11 & $D$ & 18. BR-10 (TERESINA) & 6 & 601.71 & B \\
\hline 60. $B R-1-S .401$ & 6 & 558.10 & 0 & 10. $6081-8065$ & 6 & 608.11 & $D$ & 02. CRISTALINA-1 (C) & 6 & 600.04 & $B$ \\
\hline 46. OC 7920 & 6 & 557.20 & $D$ & 46. $6079-7011$ & 6 & 593.59 & $D$ & 06. PARANAGOIANA & 6 & 600.00 & $B$ \\
\hline 45. OC 795 & 6 & 556.32 & 0 & 43. $60.81-11094$ & 6 & 593.27 & $D$ & 12. OPV -3 & 6 & 589.73 & B \\
\hline
\end{tabular}

As aédias seguidas de nesıa letra não difere entre si (TOKEY 5\%)

H: no de obserpaçōes

\$: repetido cono testemuna conus.

$\because$ repete no grupo de aturidade internediário e tardio. 
Tabela 45. Produtividade de grãos $\mathrm{Kg} / \mathrm{ha}$ : genótipos superiores às médias das melhores testemunhas em dois e três locais. Soja, semeadura entre $30 / 11$ e $12 / 12 / 84$.

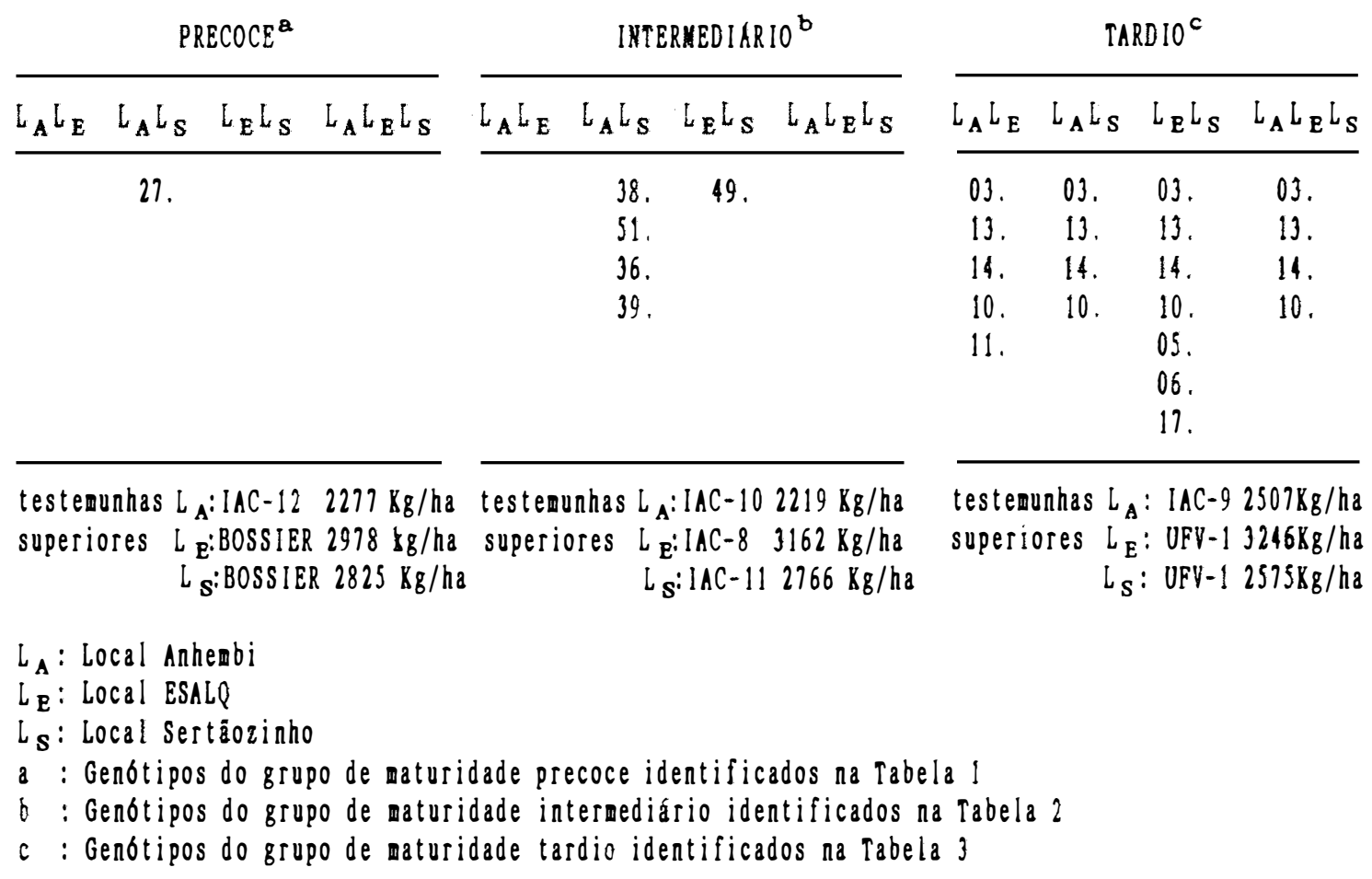


Tabela 46. Porcentagem de 61 eo (\%): genótipos superiores às médias das melhores testemunhas em dois e três locais. Soja, semeadura entre $30 / 11$ e $12 / 12 / 84$.

\begin{tabular}{|c|c|c|c|c|c|c|c|c|c|c|c|}
\hline \multicolumn{4}{|c|}{ PRECOCE ${ }^{\mathrm{a}}$} & \multicolumn{4}{|c|}{ IKT ERMEDIARIO ${ }^{b}$} & \multicolumn{4}{|c|}{ TARDIO ${ }^{c}$} \\
\hline$L_{A} L_{E}$ & $L_{A} L_{S}$ & $L_{E} L_{S}$ & $L_{A} L_{E} L_{S}$ & $L_{A} L_{E}$ & $L_{A} L_{S}$ & $\mathrm{~L}_{E} \mathrm{~L}_{\mathrm{S}}$ & $L_{A} L_{E} L_{S}$ & $\mathrm{~L}_{A} \mathrm{~L}_{E}$ & $L_{A} L_{S}$ & $L_{E} L_{S}$ & $L_{A} L_{E} L_{S}$ \\
\hline $\begin{array}{l}04 . \\
63 . \\
32 . \\
34 . \\
22 . \\
46 . \\
21 . \\
60 . \\
40 . \\
43 . \\
54 . \\
52 .\end{array}$ & $\begin{array}{l}04 . \\
63 . \\
32 . \\
34 . \\
22 . \\
46 . \\
21 . \\
60 . \\
35 . \\
13 .\end{array}$ & $\begin{array}{l}04 . \\
63 . \\
32 . \\
34 . \\
22 . \\
46 . \\
21 . \\
60 . \\
44 . \\
43 . \\
37 . \\
39 . \\
30 . \\
55 . \\
03 .\end{array}$ & $\begin{array}{l}04 . \\
63 . \\
32 . \\
34 . \\
22 . \\
46 . \\
21 . \\
60 .\end{array}$ & $\begin{array}{l}49 . \\
20 . \\
40 . \\
39 . \\
14 . \\
34 . \\
03 . \\
17 . \\
47 . \\
45 . \\
14 . \\
06 . \\
05 .\end{array}$ & $\begin{array}{l}49 . \\
20 . \\
40 . \\
39 . \\
14 . \\
10 . \\
36 .\end{array}$ & $\begin{array}{l}49 . \\
20 . \\
40 . \\
39 . \\
14 . \\
38 . \\
21 . \\
37 .\end{array}$ & $\begin{array}{l}49 . \\
20 . \\
40 . \\
39 . \\
14 .\end{array}$ & $\begin{array}{l}17 . \\
06 . \\
03 . \\
08 .\end{array}$ & $\begin{array}{l}17 . \\
06 .\end{array}$ & $\begin{array}{l}17 . \\
06 .\end{array}$ & $\begin{array}{l}17 . \\
06 .\end{array}$ \\
\hline $\begin{array}{l}\text { testea } \\
\text { super } \mathrm{i}\end{array}$ & $\begin{array}{l}\text { unhas } \\
\text { ores }\end{array}$ & $\begin{array}{l}\text { IAC- } 12 \\
: \text { BOSS IE } \\
\text { :BOSSIE }\end{array}$ & $\begin{array}{r}23.03 \% \\
R 23.94 \% \\
R \quad 22.50 \%\end{array}$ & $\begin{array}{l}\text { tested } \\
\text { super }\end{array}$ & $\begin{array}{l}\text { unhas } \\
\text { ores }\end{array}$ & $\begin{array}{l}: I A C-11 \\
: I A C-1 \\
\text { : } I A C-1\end{array}$ & $\begin{array}{r}22.88 \% \\
124.37 \% \\
022.47 \%\end{array}$ & $\begin{array}{l}\text { tested } \\
\text { supe }\end{array}$ & $\begin{array}{l}\text { unhas } \\
\text { iores }\end{array}$ & $\begin{array}{l}\text { :Tropic } \\
\text { E:IAC-9 } \\
\text { s: IAC-9 }\end{array}$ & $\begin{array}{r}21.85 \% \\
22.03 \% \\
22.08 \%\end{array}$ \\
\hline
\end{tabular}

$\mathrm{L}_{\mathrm{A}}$ : Local Anhe abi

$\mathrm{L}_{\mathrm{E}}$ : Local ESALQ

$L_{s}$ : Local Sertiozinho

a : Genótipos do grupo de aturidade precoce identificados na tabela 1

$b$ : Genótipos do grupo de aturidade interaediário identificados na tabela 2

c : Genótipos do grupo de aturidade tardio identificados na Tabela 3 
Tabela 47. Produtividade de 61 eo $\mathrm{Kg} / \mathrm{ha}:$ genótipos superiores às médias das melhores testemunhas em dois e três locais. Soja, semeadura entre $30 / 11$ e $12 / 12 / 84$.

$\frac{\operatorname{PRECOCE}^{a}}{\mathrm{~L}_{A} \mathrm{~L}_{E} \quad \mathrm{~L}_{A} \mathrm{~L}_{S} \quad \mathrm{~L}_{E} \mathrm{~L}_{S} \quad \mathrm{~L}_{A} \mathrm{~L}_{E} \mathrm{~L}_{S}}$

$\frac{\text { INTERMEDIARIO }{ }^{b}}{L_{A} L_{E} \quad L_{A} L_{S} \quad L_{E} L_{S} \quad L_{A} L_{E} L_{S}}$

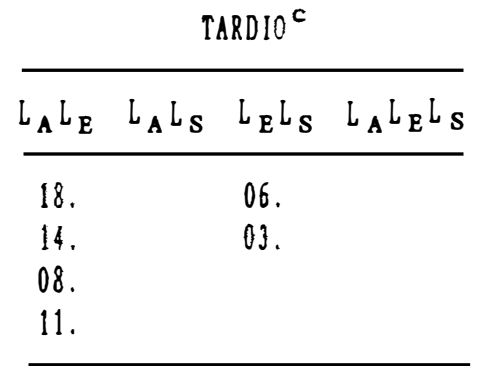

32.

04.

34

38.

49.

51.

22.

36.

test enunhas $L_{A}: I A C-12 \quad 493 \mathrm{Kg} / \mathrm{ha}$

testewunhas $L_{\mathbf{A}}: I A C-10499 \mathrm{Kg} / \mathrm{ha}$

teste wunhas $L_{A}: I A C-9570 \mathrm{Kg} / \mathrm{ha}$

superiores $L_{E}:$ BOSSIER $716 \mathrm{Kg} / \mathrm{ha}$

superiores $L_{E}: 1 A C-8 \quad 751 \mathrm{Kg} / \mathrm{ha}$

superiores $L_{E}: U F V-1706 \mathrm{Kg} / \mathrm{ha}$

$\mathrm{L}_{\mathrm{S}}$ : BOSSIER $635 \mathrm{Kg} / \mathrm{ha}$

$\mathrm{L}_{\mathrm{s}}$ : IAC-11 $617 \mathrm{~kg} / \mathrm{ha}$

$\mathrm{L}$ s:UFV $-1566 \mathrm{Kg} / \mathrm{ha}$

$\mathrm{L}_{A}$ : Local Anhe obi

$L_{E}:$ Local ESALQ

$L_{s}:$ Local Sertãozinho

a : Genotipos do grupo de aturidade precoce identificados na Tabela 1

b : Genotipos do grupo de aturidade intermediário identificados na Tabela 2

c : Genotipos do grupo de aturidade tardio identificados na rabela 3 
Tabela 48. Proporção das variações genéticas e variâncias esperimentais de sete caracteres em genótipos de três grupos de maturidade, avaliados em dois locais. Soja, semeadura entre $30 / 11$ e $12 / 12 / 84$.

\begin{tabular}{|c|c|c|c|c|c|c|c|c|c|}
\hline GRUPO DE YATURID & $A D E$ & Locais & NDF & $A P F$ & NDN & APY & Ac & AIV & VA \\
\hline \multirow{3}{*}{ Precoce } & \multirow{3}{*}{$\sigma_{e}^{2}$} & $L_{A} L_{E}$ & & & & $1.390 \mathrm{~ns}$ & $0.145 \neq 1$ & $0.921 \mathrm{~ns}$ & $0.865 \mathrm{~ns}$ \\
\hline & & $L_{A} L_{S}$ & & & 0.44047 & $0.717 \mathrm{~ns}$ & $0.010 \$$ & $0.277 \$$ & $0.932 \mathrm{~ns}$ \\
\hline & & $\mathrm{L}_{E} \mathrm{~L}_{S}$ & $2.545 \$$ & $0.507 \$$ & & $0.316 \neq$ & $0.690 \mathrm{~ns}$ & $0.300 \$$ & $1.077 \mathrm{~ns}$ \\
\hline \multirow{3}{*}{ Intermediário } & \multirow{3}{*}{$o_{e}^{2}$} & $\overline{L_{A} L_{E}}$ & & & & $1.386 \mathrm{~ns}$ & 0.6027 & $1.149 \mathrm{~ns}$ & $1.070 \mathrm{~ns}$ \\
\hline & & $L_{A} L_{S}$ & & & $0.974 \mathrm{~ns}$ & $4.567 \$$ & $0.129 \mathrm{~ns}$ & $1.155 n s$ & $0.700 \mathrm{~ns}$ \\
\hline & & $L_{E} L_{S}$ & 0.625 & $1.393 \mathrm{~ns}$ & & $3.300 \$$ & $1.211 \mathrm{~ns}$ & $1.006 \mathrm{~ns}$ & $0.626 \notin$ \\
\hline \multirow{3}{*}{ Tardio } & \multirow{3}{*}{$o_{e}^{2}$} & $L_{A} L_{E}$ & & & 0.15474 & $0.700 \mathrm{~ns}$ & $1.260 \mathrm{~ns}$ & 6.52074 & $3.105 \$$ \\
\hline & & $L_{A}^{L} L_{S}$ & & & $1.06 \operatorname{lns}$ & $0.437 *$ & $1.303 \mathrm{~ns}$ & $1.647 \mathrm{~ns}$ & \\
\hline & & $L_{E} L_{S}$ & 4.2914 & 3.7224 & 6.878 & $0.630 \mathrm{~ns}$ & $1.033 \mathrm{~ns}$ & $0.253 \neq 1$ & \\
\hline
\end{tabular}

$\sigma_{e}^{2}:$ Variância erperimental

$L_{A}$ : Local Anhembi

$L_{E}:$ Local ESALQ

$\mathrm{L}_{S}:$ Local Sertãozinho

* e \#: significativo a $5 \%$ e $1 \%$ de probabilidade pelo teste $F$ respectivamente

ns : nâo significativo

NDF : número de dias para florescimento

APF : altura da planta no florescimento

NDM : número de dias para maturidade

APN : altura da planta na aturidade

Ac : acamamento

AIV : altura de inserção da primeira vagem

VA : Valor Agronômico 
Apêndice 1. Valores e significância dos quadrados médios obtidos da análise da variância de caracteres com modelo matemático não significativo. Soja, semeaduras entre 04/12 e 06/12/84.

\begin{tabular}{|c|c|c|c|c|c|c|c|c|c|c|c|c|}
\hline \multirow{4}{*}{$\begin{array}{c}\text { Fontes } \\
\text { de } \\
\text { Variação }\end{array}$} & \multicolumn{11}{|c|}{ QUADRADOS NEDIOS DOS CARACTERES } & \\
\hline & \multicolumn{7}{|c|}{ GRUPO DE MATURIDADE INTERNEDIARIO } & \multicolumn{5}{|c|}{ GRUPO DE NATURIDADE TARDIO } \\
\hline & \multicolumn{2}{|r|}{ ANABEBI } & \multicolumn{4}{|c|}{ ESALC } & \multicolumn{5}{|c|}{ ESALQ } & SERTHOZINHO \\
\hline & GL & $\begin{array}{c}\mathrm{PG} \\
\mathrm{Kg} / \mathrm{ha}\end{array}$ & GL & $\begin{array}{c}\mathrm{PG} \\
\mathrm{Kg} / \mathrm{hg}\end{array}$ & GL & $\begin{array}{c}\mathrm{PO} \\
\mathrm{Kg} / \mathrm{hB}\end{array}$ & GL & $\begin{array}{c}\text { Non } \\
\text { (dias) }\end{array}$ & GL & $\begin{array}{l}\text { APM } \\
\text { (cI) }\end{array}$ & $\begin{array}{l}\text { GL AIV } \\
\text { (c) })\end{array}$ & $x$ \\
\hline \multicolumn{13}{|c|}{ Genotipos (G) 38 299959.54\$\#30 269473.68as 412} \\
\hline$B \mid 0 \cos (B)$ & 1 & $3369.82 \mathrm{~ns}$ & 1 & $1461.31 \mathrm{~ns}$ & 1 & $2415.68 \mathrm{~ns}$ & 1 & $16.5312 \mathrm{~ns}$ & & 306.0000 & $118.3824 a \mathrm{~s}$ & $116.67361 \mathrm{~ns}$ \\
\hline Residuo & 38 & 52904.64 & 301 & 149776.24 & 41 & 10061.85 & 15 & 34.0646 & 16 & 41.8750 & $16 \quad 5.2574$ & 178.81126 \\
\hline \multirow{2}{*}{ Média $=\bar{I} \pm s \bar{I}$} & & $\begin{array}{c}1849.18 \\
\pm\end{array}$ & & $\begin{array}{c}2663.40 \\
\pm\end{array}$ & & $\begin{array}{c}640.27 \\
\pm\end{array}$ & 1 & $\begin{array}{c}146.16 \\
!\end{array}$ & & $\begin{array}{c}92.12 \\
\pm\end{array}$ & $\begin{array}{c}13.44 \\
\pm\end{array}$ & $\begin{array}{c}20.24 \\
\pm\end{array}$ \\
\hline & & 162.64 & & 273.66 & & 70.93 & & 4.13 & & 4.58 & 1.62 & 3.04 \\
\hline $\begin{array}{l}\text { Média das } \\
\text { testenunas }\end{array}$ & & 2083.17 & & 2857.83 & & 684.82 & & 142.42 & & 86.67 & 16.42 & 21.63 \\
\hline$C V(n)$ & & 12.44 & & 14.53 & & 15.67 & & 3.99 & & 6.73 & 17.06 & 14.66 \\
\hline
\end{tabular}

* e $\$$ : significativo a 5\% e 14 de probabilidade pelo teste $t$, respectivanente.

ns: nảo significativo

HDY : núnero de dias para naturidade

APN : altura da planta na aturidade

AIV : altura de inserçáo da prineira vagen

PG : produtividade de gräos

צOL : porcentager de 6leo

Po : produtividade de 6leo

1 : foraı elininados os genótipos cor valores discordantes (entre repetições). 
Apêndice 2. Comparação dos valores médios de nove caracteres dos grupos de maturidade intermediário e tardio em relação ao grupo de maturidade precoce considerado como $0 \%$. Soja, semeaduras entre $30 / 11$ e $12 / 12 / 84$.

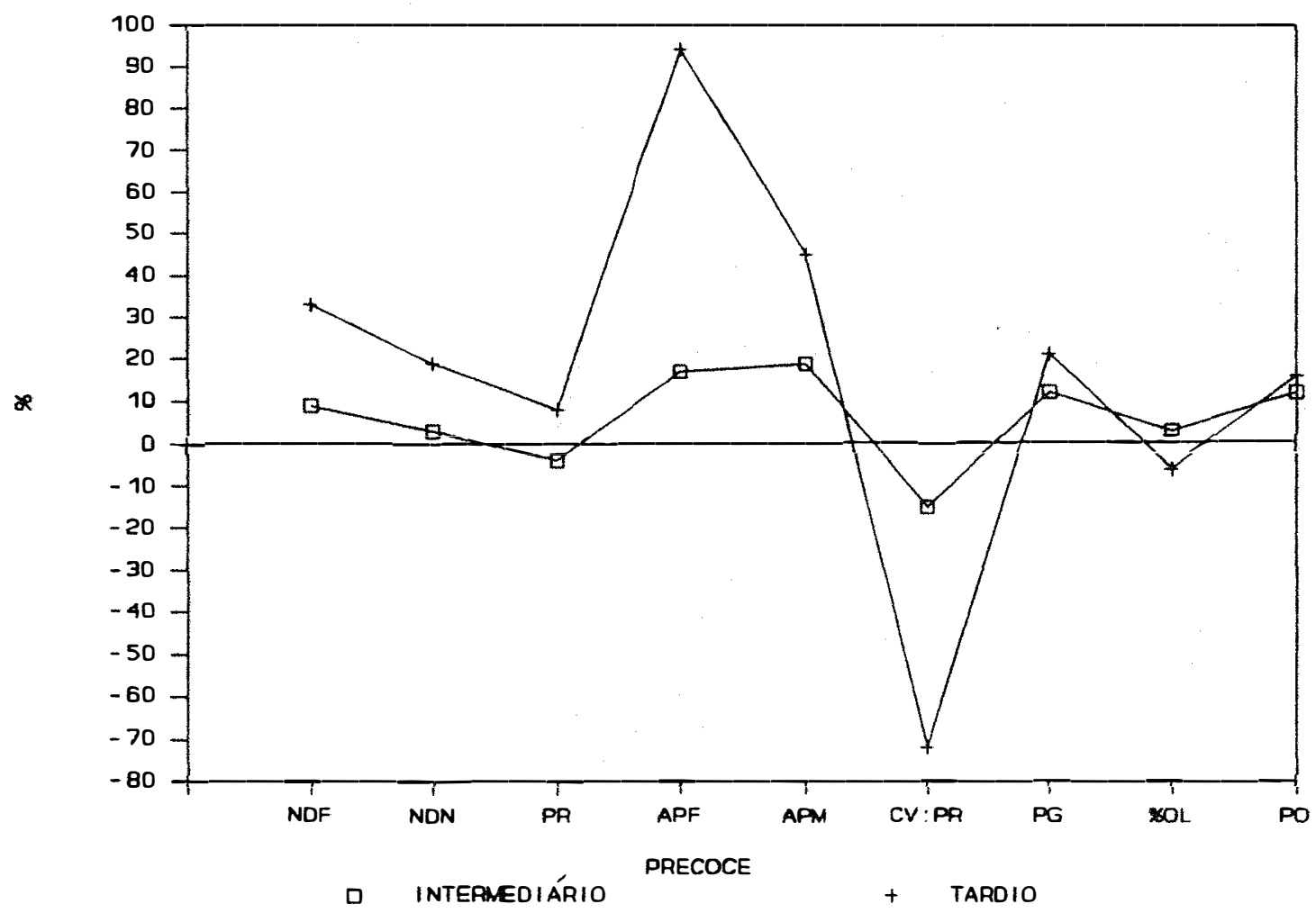

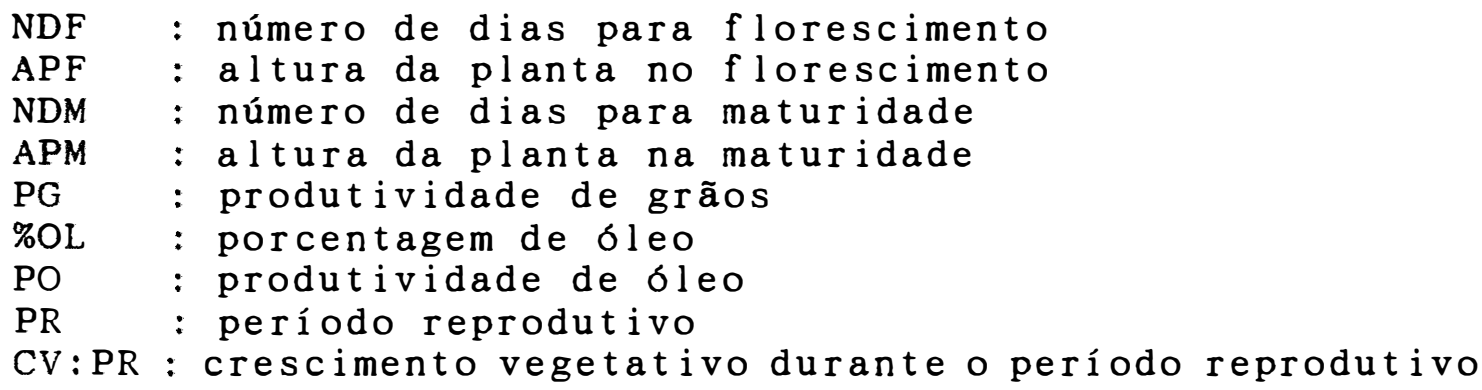


Apêndice 3: Grupo de maturidade precoce: ordem dos genótipos em base ao desempenho médio nos três locais com duas repetições, para quatro caracteres. Soja, semeadura entre $30 / 11$ e $12 / 12 / 84$.

\begin{tabular}{|c|c|c|c|c|c|c|c|c|c|c|c|}
\hline G & $N$ & NDM & G & $\mathrm{N}$ & $P G$ & G & $\mathrm{N}$ & $\% \mathrm{OL}$ & G & $N$ & PO \\
\hline 09 & 4 & 126.000 & 27 & 6 & 2586.3 & 34 & 6 & 24.483 & 04 & 6 & 629.56 \\
\hline 05 & 4 & 125.000 & 04 & 6 & 2575.7 & 04 & 6 & 24.417 & 37 & 6 & 605.92 \\
\hline 04 & 4 & 124.750 & 56 & 6 & 2544.3 & 39 & 6 & 24.133 & 56 & 6 & 591.06 \\
\hline 13 & 4 & 124.500 & 33 & 6 & 2526.3 & 60 & 6 & 23.900 & 22 & 6 & 583.71 \\
\hline 19 & 4 & 124.250 & 32 & 6 & 2460.5 & 54 & 6 & 23.883 & 32 & 6 & 583.20 \\
\hline 02 & 4 & 123.750 & 22 & 6 & 2455.7 & 22 & 6 & 23.783 & 27 & 6 & 575.20 \\
\hline 07 & 4 & 123.500 & 37 & 6 & 2394.5 & 32 & 6 & 23.783 & 63 & 6 & 562.71 \\
\hline 23 & 4 & 123.500 & 23 & 6 & 2387.7 & 37 & 6 & 23.767 & 60 & 6 & 558.10 \\
\hline 60 & 4 & 123.250 & 59 & 6 & 2385.8 & 63 & 6 & 23.750 & 46 & 6 & 557.20 \\
\hline 01 & 4 & 123.250 & 08 & 6 & 2382.8 & 21 & 6 & 23.733 & 45 & 6 & 556.32 \\
\hline 48 & 4 & 123.000 & 18 & 6 & 2381.2 & 03 & 6 & 23.560 & 33 & 6 & 555.44 \\
\hline 08 & 4 & 122.750 & 45 & 6 & 2376.5 & 46 & 6 & 23.617 & 23 & 6 & 547.88 \\
\hline 03 & 4 & 122.250 & 63 & 6 & 2364.7 & 38 & 6 & 23.600 & 08 & 6 & 542.07 \\
\hline 50 & 4 & 122.250 & 46 & 6 & 2362.5 & 52 & 6 & 23.533 & 16 & 6 & 540.84 \\
\hline 29 & 4 & 122.250 & 16 & 6 & 2357.7 & 45 & 6 & 23.533 & 59 & 6 & 540.17 \\
\hline 56 & 4 & 121.750 & 60 & 6 & 2341.2 & 30 & 6 & 23.350 & 28 & 6 & 529.99 \\
\hline 52 & 4 & 121.750 & 10 & 6 & 2323.2 & 13 & 6 & 23.333 & 05 & 6 & 529.21 \\
\hline 18 & 4 & 121.500 & 29 & 6 & 2313.2 & 40 & 6 & 23.300 & 03 & 6 & 526.23 \\
\hline 51 & 4 & 121.500 & 28 & 6 & 2313.2 & 56 & 6 & 23.250 & 54 & 6 & 523.95 \\
\hline 41 & 4 & 121.250 & 05 & 6 & 2291.8 & 19 & 6 & 23.250 & 68 & 6 & 523.91 \\
\hline 64 & 4 & 121.250 & 68 & 6 & 2282.2 & 64 & 6 & 23.183 & 19 & 6 & 523.18 \\
\hline 10 & 4 & 121.000 & 66 & 6 & 2279.2 & 53 & 6 & 23.183 & 18 & 6 & 510.91 \\
\hline 43 & 4 & 121.000 & 51 & 6 & 2257.2 & 43 & 6 & 23.150 & 39 & 6 & 505.66 \\
\hline 31 & 4 & 120.750 & 42 & 6 & 2243.0 & 58 & 6 & 23.050 & 51 & 6 & 503.83 \\
\hline 30 & 4 & 120.750 & 19 & 6 & 2227.5 & 41 & 6 & 23.033 & 34 & 6 & 502.54 \\
\hline 12 & 4 & 120.500 & 57 & 6 & 2205.7 & 35 & 6 & 22.983 & 42 & 6 & 495.46 \\
\hline 27 & 4 & 120.500 & 03 & 6 & 22 & 05 & 6 & 22.967 & 10 & 6 & 494.65 \\
\hline 24 & 4 & 120.500 & 54 & 6 & 2197.2 & 28 & 6 & 22.967 & 24 & 6 & 492.24 \\
\hline 14 & 4 & 120.250 & 47 & 6 & 2188.2 & 68 & 6 & 22.967 & 57 & 6 & 491.31 \\
\hline 63 & 4 & 119.750 & 29 & 6 & 216 & 36 & 6 & 22.967 & 21 & 6 & 488.90 \\
\hline 35 & 4 & 119.750 & 20 & 6 & 2159.8 & 16 & 6 & 22 . & 38 & 6 & 488.79 \\
\hline 42 & 4 & 119.500 & 67 & 6 & 2150.7 & 10 & 6 & 22.900 & 25 & 6 & 488.27 \\
\hline 06 & 4 & 119.250 & 50 & 6 & 2146.7 & 23 & 6 & 22.883 & 67 & 6 & 484.16 \\
\hline 59 & 4 & 119.250 & 31 & 6 & 2132.8 & 44 & 6 & 22.883 & 43 & 6 & 482.25 \\
\hline 28 & 4 & 119.250 & 26 & 6 & 2097.3 & 65 & 6 & 22.867 & 13 & 6 & 478.61 \\
\hline 39 & 4 & 119.000 & 11 & 6 & 2089.7 & 62 & 6 & 22.867 & 58 & 6 & 477.79 \\
\hline 44 & 4 & 119.000 & 38 & 6 & 2089.5 & 59 & 6 & 22.850 & 64 & 6 & 476.24 \\
\hline 20 & 4 & 118.750 & 36 & 6 & 2087.0 & 29 & 6 & 22.800 & 36 & 6 & 475.94 \\
\hline
\end{tabular}




\begin{tabular}{|c|c|c|c|c|c|c|c|c|c|c|c|}
\hline G & $\mathrm{N}$ & NDM & G & $\mathrm{N}$ & $P G$ & G & $\mathrm{N}$ & $\% \mathrm{OL}$ & G & $N$ & PO \\
\hline 46 & 4 & 118.750 & 13 & 6 & 2082.8 & 42 & 6 & 22.800 & 44 & 6 & 474.96 \\
\hline 65 & 4 & 118.500 & 43 & 6 & 2074.8 & 48 & 6 & 22.783 & 47 & 6 & 474.19 \\
\hline 45 & 4 & 118.250 & 44 & 6 & 2073.8 & 66 & 6 & 22.783 & 26 & 6 & 470.16 \\
\hline 16 & 4 & 117.750 & 39 & 6 & 2069.0 & -08 & 6 & 22.767 & 52 & 6 & 467.22 \\
\hline 11 & 4 & 117.500 & 58 & 6 & 2068.8 & 67 & 6 & 22.617 & 50 & 6 & 467.00 \\
\hline 55 & 4 & 117.500 & 65 & 6 & 2062.5 & 61 & 6 & 22.617 & 11 & 6 & 463.36 \\
\hline 15 & 4 & 117.250 & 34 & 6 & 2061.3 & 51 & 6 & 22.583 & 62 & 6 & 461.54 \\
\hline 33 & 4 & 117.000 & 64 & 6 & 2061.3 & 01 & 6 & 22.500 & 53 & 6 & 455.97 \\
\hline 37 & 4 & 116.750 & 21 & 6 & 2042.5 & 26 & 6 & 22.483 & 41 & 6 & 452.37 \\
\hline 21 & 4 & 116.750 & 62 & 6 & 2028.5 & 51 & 6 & 22.383 & 20 & 6 & 444.40 \\
\hline 62 & 4 & 116.750 & 06 & 6 & 2020.8 & 57 & 6 & 22.350 & 66 & 6 & 443.87 \\
\hline 57 & 4 & 116.750 & 14 & 6 & 2018.2 & 27 & 6 & 22.300 & 48 & 6 & 438.83 \\
\hline 68 & 4 & 116.750 & 49 & 6 & 2018.0 & 07 & 6 & 22.250 & 65 & 6 & 438.68 \\
\hline 17 & 4 & 116.500 & 15 & 6 & 1997.8 & 11 & 6 & 22.233 & 35 & 6 & 437.40 \\
\hline 36 & 4 & 116.500 & 53 & 6 & 1993.0 & 02 & 6 & 22.083 & 49 & 6 & 434.21 \\
\hline 34 & 4 & 116.250 & 52 & 6 & 1989.2 & 33 & 6 & 22.017 & 55 & 6 & 432.17 \\
\hline 49 & 4 & 116.000 & 41 & 6 & 1961.3 & 50 & 6 & 21.900 & 30 & 6 & 425.38 \\
\hline 38 & 4 & 115.750 & 55 & 6 & 1924.5 & 47 & 6 & 21.817 & 15 & 6 & 416.38 \\
\hline 46 & 4 & 115.250 & 48 & 6 & 1920.2 & 49 & 6 & 21.600 & 06 & 6 & 415.05 \\
\hline 67 & 4 & 115.250 & 35 & 6 & 1887.5 & 17 & 6 & 21.200 & 14 & 6 & 410.77 \\
\hline 32 & 4 & 115.250 & 30 & 6 & 1825.0 & 18 & 6 & 21.133 & 40 & 6 & 398.99 \\
\hline 58 & 4 & 115.000 & 24 & 6 & 1791.8 & 25 & 6 & 21.083 & 31 & 6 & 385.88 \\
\hline 40 & 4 & 114.250 & 17 & 6 & 1771.5 & 15 & 6 & 20.733 & 61 & 6 & 374.95 \\
\hline 25 & 4 & 114.250 & 40 & 6 & 1726.3 & 06 & 6 & 20.717 & 17 & 6 & 373.08 \\
\hline 61 & 4 & 114.000 & 61 & 6 & 1643.0 & 20 & 6 & 20.450 & 24 & 6 & 361.68 \\
\hline 21 & 4 & 114.000 & 07 & 6 & 1468.7 & 14 & 6 & 20.433 & 07 & 6 & 327.49 \\
\hline 26 & 4 & 113.250 & 12 & 6 & 1382.0 & 09 & 6 & 20.167 & 02 & 6 & 306.93 \\
\hline 66 & 4 & 112.000 & 02 & 6 & 1365.3 & 24 & 6 & 19.967 & 01 & 6 & 295.59 \\
\hline 53 & 4 & 111.750 & 01 & 6 & 1296.0 & 12 & 6 & 19.067 & 12 & 6 & 263.48 \\
\hline 54 & 4 & 111.000 & 09 & 6 & 855.0 & 31 & 6 & 18.267 & 09 & 6 & 176.71 \\
\hline
\end{tabular}

NDM : Número de dias para maturidade

PG : Produtividade de grãos

\%OL : Procentagem de óleo

PO : Produtividade de 6 leo

$\mathrm{N}$ : Número de observações

G : Número do genótipo, identificado na Tabela 1, página 78. 
Apêndice 4: Grupo de maturidade intermediario: ordem dos genótipos em base ao desempenho médio nos três locais com duas repetições, para quatro caracteres. Soja, semeadura entre $30 / 11$ e $12 / 12 / 84$

\begin{tabular}{|c|c|c|c|c|c|c|c|c|c|c|c|}
\hline G & $\mathrm{N}$ & NDM & $G$ & $N$ & $P G$ & G & $\mathrm{N}$ & $\% O L$ & G & $\mathrm{N}$ & $\mathrm{PO}$ \\
\hline 39 & 4 & 135.250 & 36 & 6 & 2877.0 & 49 & 6 & 24.850 & 49 & 6 & 684.95 \\
\hline 51 & 4 & 132.250 & 51 & 6 & 2801.3 & 39 & 6 & 24.350 & 36 & 6 & 683.35 \\
\hline 12 & 4 & 131.750 & 49 & 6 & 2773.0 & 47 & 6 & 24.067 & 39 & 6 & 651.21 \\
\hline 36 & 4 & 129.750 & 39 & 6 & 2679.8 & 21 & 6 & 24.050 & 51 & 6 & 647.78 \\
\hline 38 & 4 & 127.000 & 34 & 6 & 2668.7 & 40 & 6 & 24.000 & 34 & 6 & 637.55 \\
\hline 06 & 4 & 126.750 & 38 & 6 & 2656.3 & 36 & 6 & 23.883 & 38 & 6 & 622.54 \\
\hline 45 & 4 & 125.750 & 45 & 6 & 2627.8 & 20 & 6 & 23.883 & 45 & 6 & 612.11 \\
\hline 02 & 4 & 125.250 & 10 & 6 & 2578.5 & 43 & 6 & 23.817 & 40 & 6 & 608.11 \\
\hline 49 & 4 & 125.000 & 28 & 6 & 2554.8 & 34 & 6 & 23.783 & 46 & 6 & 593.59 \\
\hline 26 & 4 & 124.250 & 41 & 6 & 2545.3 & 14 & 6 & 23.717 & 43 & 6 & 593.27 \\
\hline 27 & 4 & 124.000 & 46 & 6 & 2536.8 & 07 & 6 & 23.700 & 37 & 6 & 581.39 \\
\hline 47 & 4 & 124.000 & 40 & 6 & 2527.3 & 16 & 6 & 23.550 & 42 & 6 & 580.65 \\
\hline 20 & 4 & 123.750 & 43 & 6 & 2494.5 & 38 & 6 & 23.517 & 28 & 6 & 578.43 \\
\hline 40 & 4 & 123.500 & 08 & 6 & 2461.8 & 02 & 6 & 23.517 & 41 & 6 & 574.73 \\
\hline 08 & 4 & 123.500 & 42 & 6 & 2458.5 & 45 & 6 & 23.500 & 10 & 6 & 573.12 \\
\hline 11 & 4 & 123.250 & 06 & 6 & 2427.8 & 42 & 6 & 23.467 & 06 & 6 & 558.47 \\
\hline 04 & 4 & 123.000 & 27 & 6 & 2417.5 & 03 & 6 & 23.467 & 17 & 6 & 555.18 \\
\hline 28 & 4 & 123.000 & 50 & 6 & 2415.5 & 37 & 6 & 23.450 & 08 & 6 & 554.75 \\
\hline 21 & 4 & 122.750 & 12 & 6 & 2406.3 & 17 & 6 & 23.383 & 27 & 6 & 554.30 \\
\hline 33 & 4 & 122.750 & 25 & 6 & 2405.8 & 15 & 6 & 23.167 & 12 & 6 & 550.23 \\
\hline 23 & 4 & 122.750 & 29 & 6 & 2399.3 & 48 & 6 & 23.167 & 25 & 6 & 546.63 \\
\hline 09 & 4 & 122.500 & 17 & 6 & 2375.0 & 51 & 6 & 23.150 & 09 & 6 & 544.71 \\
\hline 50 & 4 & 122.250 & 11 & 6 & 2373.8 & 09 & 6 & 23.133 & 14 & 6 & 541.36 \\
\hline 39 & 4 & 122.000 & 13 & 6 & 2369.7 & 23 & 6 & 23.117 & 11 & 6 & 539.51 \\
\hline 14 & 4 & 121.750 & 04 & 6 & 2368.6 & 46 & 6 & 23.050 & 04 & 6 & 538.79 \\
\hline 03 & 4 & 121.750 & 09 & 6 & 236 & 35 & 6 & 23.000 & 24 & 6 & 538.03 \\
\hline 15 & 4 & 121.500 & 24 & 6 & 235 & 06 & 6 & 67 & 13 & 6 & 537.63 \\
\hline 44 & 4 & 121.500 & 33 & 6 & 233 & 27 & 6 & 22.950 & 50 & 6 & 525.19 \\
\hline 34 & 4 & 121.250 & 37 & 6 & 2303.8 & 04 & 6 & 22.933 & 21 & 6 & 534.75 \\
\hline 46 & 4 & 121.250 & 05 & 6 & 2293.0 & 24 & 6 & 22.933 & 07 & 6 & 530.54 \\
\hline 10 & 4 & 121.000 & 03 & 6 & 2282.7 & 05 & 6 & 22.883 & 05 & 6 & 527.93 \\
\hline 05 & 4 & 121.000 & 14 & 6 & 2279.2 & 12 & 6 & 22.767 & 03 & 6 & 525.82 \\
\hline 13 & 4 & 120.750 & 15 & 6 & 2235.3 & 22 & 6 & 22.750 & 15 & 6 & 519.05 \\
\hline 17 & 4 & 120.750 & 07 & 6 & 2231.5 & 13 & 6 & 22.733 & 29 & 6 & 515.93 \\
\hline 18 & 4 & 120.500 & 44 & 6 & 2227.8 & 32 & 6 & 22.733 & 33 & 6 & 509.06 \\
\hline 19 & 4 & 120.250 & 24 & 6 & 222774 & 25 & 6 & 22.700 & 16 & 6 & 508.68 \\
\hline 30 & 4 & 120.250 & 26 & 6 & 2207.2 & 11 & 6 & 22.650 & 22 & 6 & 506.60 \\
\hline
\end{tabular}


... cont inuação

\begin{tabular}{ccccccccccccc}
\hline$G$ & $N$ & NDM & G & N & PG & G & N & \%OL & G & N & PO \\
\hline 43 & 4 & 120.250 & 20 & 6 & 2210.5 & 18 & 6 & 22.517 & 20 & 6 & 505.92 \\
01 & 4 & 120.000 & 22 & 6 & 2210.3 & 28 & 6 & 22.500 & 48 & 6 & 502.10 \\
07 & 4 & 120.000 & 48 & 6 & 2167.3 & 08 & 6 & 22.433 & 44 & 6 & 496.32 \\
41 & 4 & 119.750 & 16 & 6 & 2150.8 & 41 & 6 & 22.417 & 35 & 6 & 490.54 \\
37 & 4 & 119.750 & 19 & 6 & 2146.0 & 01 & 6 & 22.250 & 47 & 6 & 484.56 \\
42 & 4 & 119.500 & 35 & 6 & 2130.7 & 10 & 6 & 22.233 & 23 & 6 & 473.63 \\
24 & 4 & 119.500 & 23 & 6 & 2063.3 & 30 & 6 & 22.217 & 26 & 6 & 465.51 \\
31 & 4 & 119.250 & 47 & 6 & 2036.8 & 44 & 6 & 22.100 & 18 & 6 & 451.36 \\
22 & 4 & 119.250 & 18 & 6 & 2023.7 & 31 & 6 & 22.083 & 32 & 6 & 446.08 \\
35 & 4 & 117.500 & 01 & 6 & 1993.0 & 50 & 6 & 21.967 & 01 & 6 & 445.07 \\
25 & 4 & 117.500 & 32 & 6 & 1948.0 & 33 & 6 & 21.700 & 19 & 6 & 437.72 \\
48 & 4 & 115.750 & 30 & 6 & 1791.7 & 29 & 6 & 21.650 & 02 & 6 & 396.25 \\
16 & 4 & 115.500 & 02 & 6 & 1685.8 & 26 & 6 & 21.150 & 30 & 6 & 390.14 \\
32 & 4 & 114.000 & 31 & 6 & 1591.3 & 19 & 6 & 20.417 & 31 & 6 & 353.10 \\
\hline
\end{tabular}

NDM : Número de dias para maturidade

$P G$ : Produtividade de grãos

$\% O L$ : Procentagem de óleo

PO : Produtividade de oleo

$N$ : Número de observações

G : Número do genótipo, identificado na Tabela 2, página 79. 
Apêndice 5: Grupo de maturidade tardio: ordem dos genótipos em base ao desempenho médio nos três locais com duas repetições, para quatro caracteres. Soja, semeadura entre $30 / 11$ e $12 / 12 / 84$

\begin{tabular}{cccccccccccc}
\hline G & N & NDM & G & N & PG & G & N & $\%$ OL & $G$ & $N$ & PO \\
\hline 20 & 6 & 160.167 & 17 & 6 & 2949.3 & 12 & 6 & 22.883 & 17 & 6 & 669.60 \\
19 & 6 & 158.000 & 03 & 6 & 2927.0 & 06 & 6 & 22.667 & 03 & 6 & 648.43 \\
22 & 6 & 147.667 & 14 & 6 & 2910.5 & 17 & 6 & 22.667 & 11 & 6 & 635.01 \\
21 & 6 & 147.000 & 10 & 6 & 2903.5 & 08 & 6 & 22.517 & 14 & 6 & 632.15 \\
07 & 6 & 143.167 & 05 & 6 & 2882.7 & 11 & 6 & 22.333 & 08 & 6 & 627.56 \\
18 & 6 & 143.000 & 13 & 6 & 2861.0 & 02 & 6 & 22.200 & 10 & 6 & 603.34 \\
06 & 6 & 143.000 & 11 & 6 & 2825.3 & 03 & 6 & 22.150 & 18 & 6 & 601.71 \\
03 & 6 & 142.833 & 18 & 6 & 2789.7 & 14 & 6 & 21.733 & 02 & 6 & 600.04 \\
09 & 6 & 140.667 & 08 & 6 & 2764.3 & 15 & 6 & 21.667 & 06 & 6 & 600.00 \\
05 & 6 & 140.000 & 02 & 6 & 2694.5 & 09 & 6 & 21.633 & 12 & 6 & 589.53 \\
13 & 6 & 139.833 & 22 & 6 & 2637.7 & 16 & 6 & 21.617 & 05 & 6 & 585.75 \\
08 & 6 & 139.677 & 06 & 6 & 2623.5 & 22 & 6 & 21.433 & 13 & 6 & 585.42 \\
14 & 6 & 139.000 & 19 & 6 & 2588.3 & 18 & 6 & 21.383 & 22 & 6 & 565.52 \\
02 & 6 & 138.167 & 12 & 6 & 2587.7 & 04 & 6 & 21.133 & 15 & 6 & 548.62 \\
04 & 6 & 138.000 & 15 & 6 & 2550.0 & 19 & 6 & 20.917 & 16 & 6 & 544.91 \\
16 & 6 & 137.167 & 16 & 6 & 2522.8 & 01 & 6 & 20.517 & 19 & 6 & 544.09 \\
17 & 6 & 136.667 & 04 & 6 & 2390.8 & 13 & 6 & 20.483 & 09 & 6 & 529.87 \\
01 & 6 & 136.000 & 21 & 6 & 2235.5 & 05 & 6 & 20.450 & 04 & 6 & 505.16 \\
12 & 6 & 135.500 & 07 & 6 & 2218.7 & 21 & 6 & 20.250 & 21 & 6 & 453.06 \\
10 & 6 & 132.000 & 09 & 6 & 2206.2 & 07 & 6 & 20.250 & 07 & 6 & 451.50 \\
11 & 6 & 131.833 & 20 & 6 & 2135.5 & 10 & 6 & 17.850 & 20 & 6 & 372.42 \\
15 & 6 & 130.333 & 01 & 6 & 876.5 & 20 & 6 & 17.300 & 01 & 6 & 181.32 \\
\hline
\end{tabular}

NDM : Número de dias para maturidade

PG : Produtividade de grãos

\%OL : Procentagem de óleo

PO : Produtividade de óleo

$\mathrm{N}$ : Número de observações

G : Número do genótipo, identificado na Tabela 3, página 80 . 